\title{
Performance of compact mobile emissions monitoring system for real-time on-board emissions measurement
}

\author{
Chandima S. Jayasinghe
}

West Virginia University

Follow this and additional works at: https://researchrepository.wvu.edu/etd

\section{Recommended Citation}

Jayasinghe, Chandima S., "Performance of compact mobile emissions monitoring system for real-time on-board emissions measurement" (2007). Graduate Theses, Dissertations, and Problem Reports. 1830. https://researchrepository.wvu.edu/etd/1830

This Thesis is protected by copyright and/or related rights. It has been brought to you by the The Research Repository @ WVU with permission from the rights-holder(s). You are free to use this Thesis in any way that is permitted by the copyright and related rights legislation that applies to your use. For other uses you must obtain permission from the rights-holder(s) directly, unless additional rights are indicated by a Creative Commons license in the record and/ or on the work itself. This Thesis has been accepted for inclusion in WVU Graduate Theses, Dissertations, and Problem Reports collection by an authorized administrator of The Research Repository @ WVU. For more information, please contact researchrepository@mail.wvu.edu. 


\title{
Performance of Compact Mobile Emissions Monitoring System for Real-Time On-Board Emissions Measurement
}

\author{
Chandima S. Jayasinghe \\ Thesis submitted to the \\ College of Engineering and Mineral Resources \\ at West Virginia University \\ in partial fulfillment of the requirements \\ for the degree of \\ Master of Science \\ in \\ Mechanical Engineering \\ Mridul Gautam, Ph.D., Chair \\ W. Scott Wayne, Ph.D. \\ Mohan Krishnamurthy, Ph.D.
}

Department of Mechanical and Aerospace Engineering

Morgantown, West Virginia

2007

Keywords: PEMS, On-road Real-Time Emission Measurement System, $\mathrm{CO}_{2}, \mathrm{NOx}$

Copyright 2007 Chandima S. Jayasinghe 


\section{Abstract \\ Performance of Compact Mobile Emissions Monitoring System for Real-Time On- Board Emissions Measurements \\ By Chandima S. Jayasinghe}

The objective of this study was to evaluate the performance of the Compact Mobile Emissions Monitoring System (CMEMS) in an engine dynamometer test cell equipped with laboratory grade analyzers, and under real-world testing conditions. The CMEMS was evaluated in the test cell with the engine operating under transient (FTP) and steady state conditions and results were compared with laboratory data.

In response to the Consent Decrees, which were entered into by some of the heavy duty engine manufactures and the United States, several in-use portable emissions measurement systems (PEMS) have been developed, and some of them are commercially available. However, most of these systems are based upon an impractical design that requires one or more "boxes" to be placed in the cab of the test vehicle, with heated analyzers and sample handling systems, an exhaust flow rate measurement system installed on the tailpipe, and heated sample lines. Such systems place a taxing power demand on the engine. They are bulky and heavy, and the deskew times contribute to measurement uncertainties.

In response to the "lessons learned" from the use of WVU's Mobile Emissions Measuring System (MEMS), WVU has developed compact MEMS, which addresses the concerns associated with currently available PEMS, including the MEMS.

The unique feature of the CMEMS is that it is a single unit with all components incorporated in the single 34"x 8"x 8" container, which is mounted on the exhaust stack. Compared to the MEMS, the Compact Emissions Monitoring System weighs 60lb, which is 70lb less than the MEMS. CMEMS consists of a $\mathrm{CO}_{2}$ analyzer, NOx sensor and the control unit to measure $\mathrm{CO}_{2}$ and NOx emissions from a vehicle. CMEMS uses solid state nondispersive infrared detector BE-150 for measuring $\mathrm{CO}_{2}$ emissions. CMEMS has a built in Data Acquisition System. On the other hand, even though the Engine Control Module (ECM) uses a CAN (Controller Area Network) to serial adaptor, the ECU was not probed with the current set-up of the CMEMS.

The engine was tested over the steady-state cycles, federal heavy-duty certification cycle and simulated on-road cycle. Mass emissions rates measured by CMEMS differed from laboratory generated results by $6.2 \%$ for $\mathrm{CO}_{2}$ and by $5.7 \%$ for NOx over the steady-state cycle. Over the FTP transient cycle, the differences observed were $-8.3 \%$ for $\mathrm{CO}_{2}$ and $11.1 \%$ for NOx. Significantly lower percentage differences were recorded while testing CMEMS over the on-road cycle: 1.4 and $2.9 \%$ for $\mathrm{CO}_{2}$ and $\mathrm{NOx}$ emissions respectively. Under real-world conditions, the CMEMS had a maximum error percentage of $7.7 \%$ for $\mathrm{CO}_{2}$ and $8 \%$ for NOx, in comparison to the MEMS.

CMEMS in its current configuration was unable to maintain the required temperature for the chiller, under real world testing. Lack of ventilation and heat dissipation problems 
were accountable for temperature problems, hence the erroneous $\mathrm{CO}_{2}$ reading by CMEMS. Further both BE-150 and MEXA-720, the NOx analyzer, were sensitive for vibration. Therefore, rugged road conditions too account for bad $\mathrm{NOx}$ and $\mathrm{CO}_{2}$ readings. Compact layout of CMEMS made trouble shoot time consuming when problems occurred.

It should be noted that, to the best authors' knowledge, this is the first attempt to develop an engine emissions measuring system directly attached on the tail pipe of a heavy-duty truck. Further considerations and work will be needed when redesigning the system in order to get better engine emissions data. 


\section{Acknowledgements}

As my graduate studies come to an end, many people come to my mind that I am grateful for. First and foremost I am very thankful for my supervisor Dr. Mridul Gautam for giving me the opportunity to continue my studies in a field had no previous experience. I sincerely appreciate your guidance throughout my years in WVU. I would like to express my deepest gratitude to Wes Riddle, Dan Carder, Tom Spencer, Brad Ralston, Richard Atkinson and Ryan Barnett for the support you all gave me in and out of the college. Also, I would like to thank the faculty members Dr. Scott Wayne, Dr. Mohan Krishnamurthy, Dr. Ben Shade and Dr. Greg Thompson for helping me in various ways to fulfill my masters project.

I will never forget the awesome staff in Westover and EERL, Chris, Ron, Byron, Jason, Ted, Zach, Curt, Wayne, Gary and John. Thanks a lot for teaching me what you all knew and lending me a helping hand when ever I wanted. Also, my sincere appreciation goes to Mrs. Goonathilake, Dr. Jack Humbles and Mrs. S. Bernasconi for helping me to write my thesis.

I would like to extend my gratitude to my friend Michelangelo for the extraordinary support and advice you gave me through out my years in Morgantown. Also, Aaron I will never forget how much you helped me when I was in trouble and thank you so much for all that. Next, a group that I can never forget, Emry, John, Raffaello, Glen, Josh, Petr, Aseem and Mac. I enjoyed working with you all and appreciate your help very much.

Finally, my deepest appreciation goes to my family. Thaththi and Ammi, the love and support you two gave was the strength for me to stand even in difficult times in my life. You two have shown me the light since the day I was born and have stood beside me like two strong pillars. My brother, if it was not for you I would not have got this brilliant opportunity to study at WVU. You were always there for me whenever I wanted you. My little brother Teddy, thank you so much for making me happy all the time I am with you. You two are awesome. I would like to thank my grandparents, aunt Ruth, sister-in-law Shilpani, little brother Prabash and the extended family for the support you gave me towards ending my graduate studies. 


\section{Table of Contents}

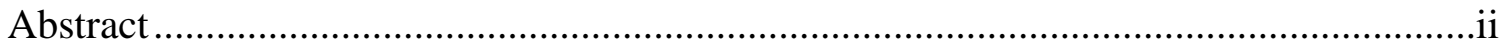

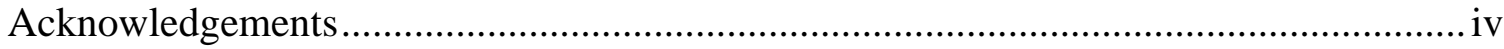

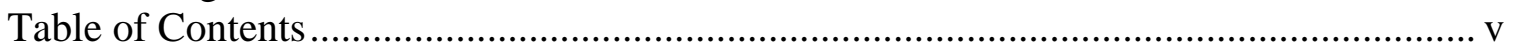

NOMENCLATURE ............................................................................................... vii

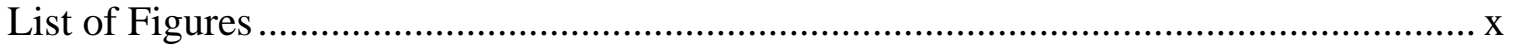

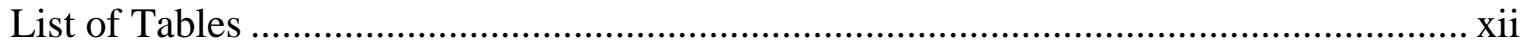

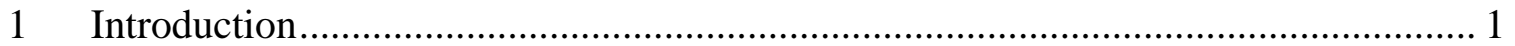

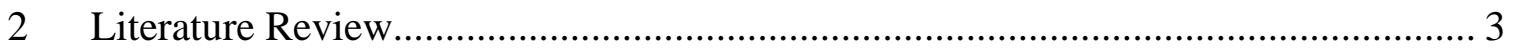

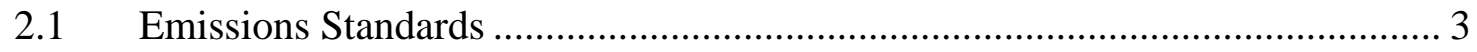

2.1.1 Consent Decrees................................................................................. 3

2.1.2 Model Year 2004 Standards................................................................. 7

2.1.3 Model Year 2007 and Later Standards ........................................................ 7

2.2 History of Mobile Emissions Measuring Systems........................................... 8

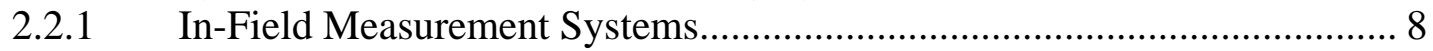

2.2.1.1 Southwest Research Institute, 1983 .................................................. 8

2.2.1.2 Michigan Technological University, 1992 ....................................... 8

2.2.1.3 University of Minnesota, 1997 ....................................................... 9

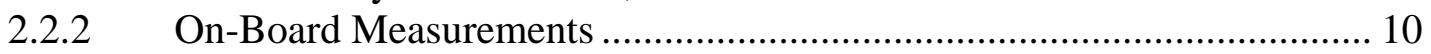

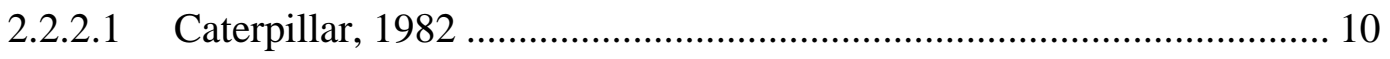

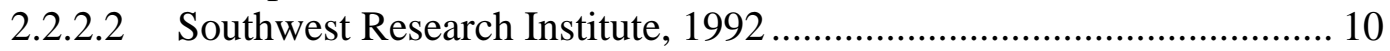

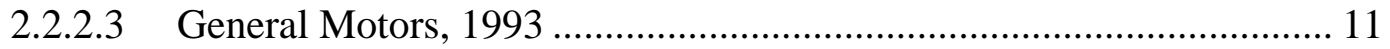

2.2.2.4 Ford Motor Company, 1994 ............................................................. 11

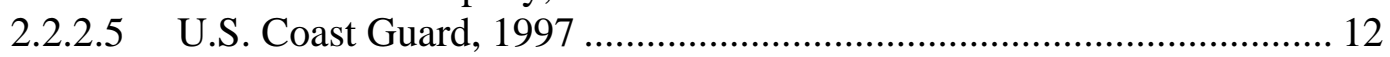

2.2.2.6 University of Pittsburgh, 1997 ...................................................... 13

2.2.2.7 Flemish Institute for Technological Research, 1997 .......................... 13

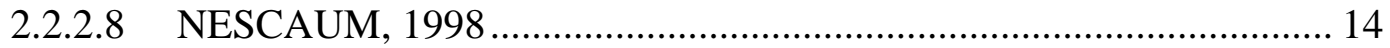

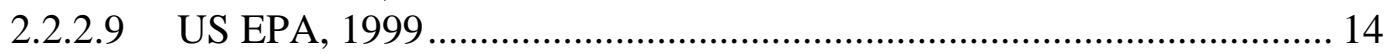

2.2.2.10 Ford Motor Company and WPI-Microprocessor Systems, Inc., 1999 .

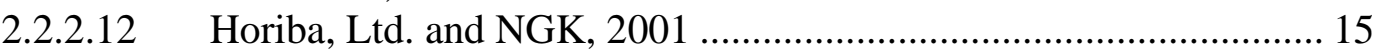

2.2.2.13 Honda R\&D and Nicolet Instrument Corp., 2001 ........................... 16

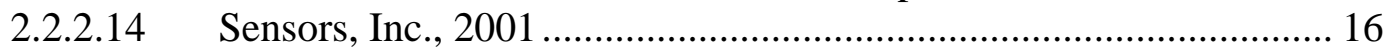

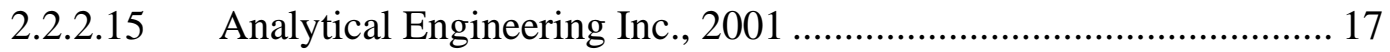

2.2.2.16 Clean Air Technologies International, Inc., 2001 ........................... 17

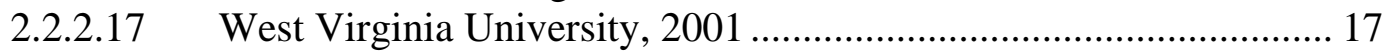

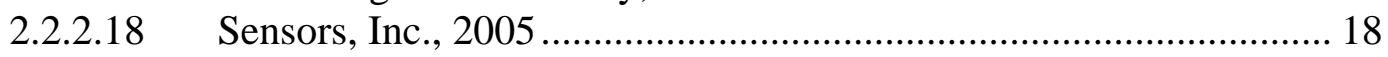

2.2.2.19 The College of Engineering-Center for Environmental Research and. Technology(CECERT)2005........................................................ 19

2.2.2.20 West Virginia University (WVU), 2005 ........................................ 19

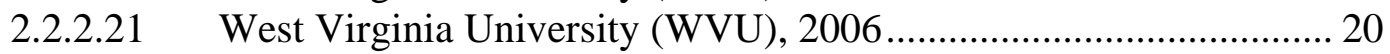

2.2.2.22 West Virginia University (WVU), 2007 ....................................... 20

2.2.2.23 West Virginia University (WVU), 2007 ......................................... 21 
2.2.2.24 U.S. Environmental Protection Agency (EPA) / Sensors, Inc., 200722

2.2.2.25 Horiba Instruments, Inc., 2007 ..................................................... 22

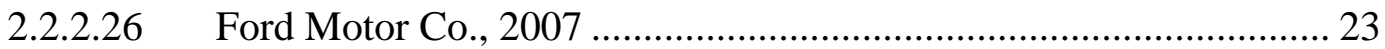

2.2.3 U. S. EPA PEMS Measurement Allowance Program............................... 24

3 Compact Mobile Emission Monitoring System (CMEMS)................................... 26

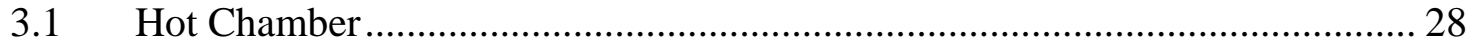

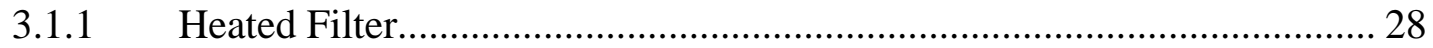

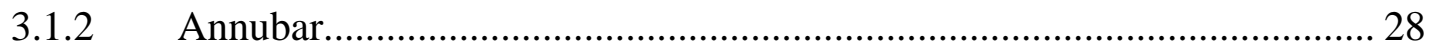

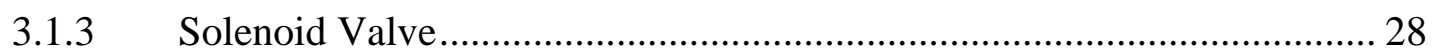

3.1.4 NOx Sensor and MEXA 720 Control Unit ............................................ 29

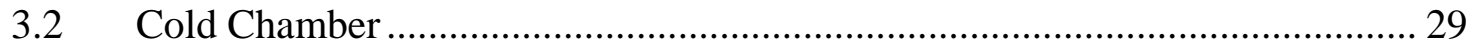

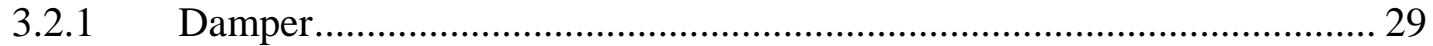

3.2.2 Secondary Filter .................................................................................. 30

3.2.3 Gast Manufacturing Pressuring Pump ................................................... 30

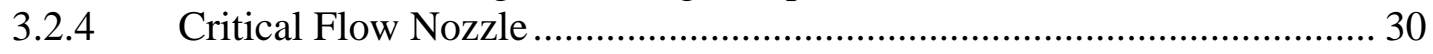

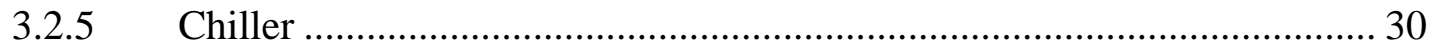

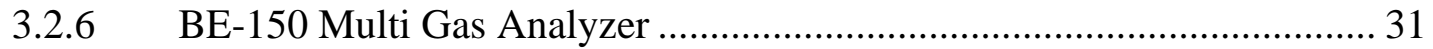

3.2.7 Power Supply ............................................................................ 31

3.2.8 Data Acquisition System - National Instruments Compact Field Point

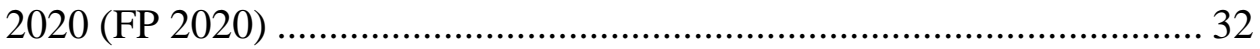

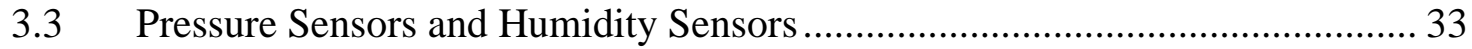

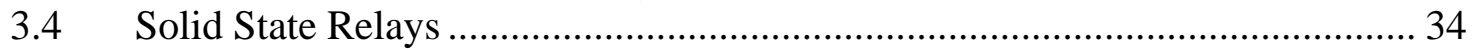

4 Experimental Equipment and Procedure ......................................................... 36

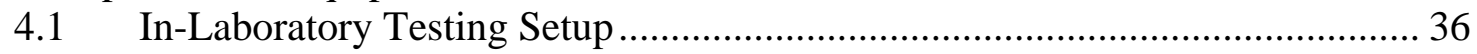

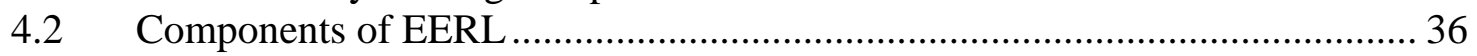

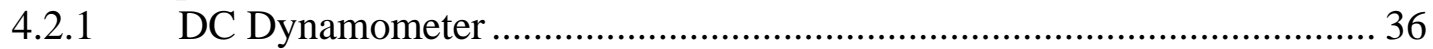

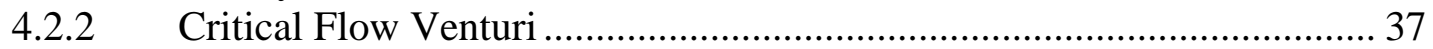

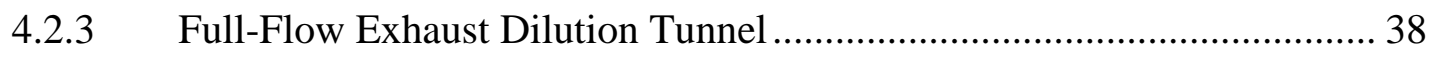

4.2.4 Gaseous Emission Sampling System .................................................. 39

4.2.5 Instrumentation Control and Data Acquisition ..................................... 40

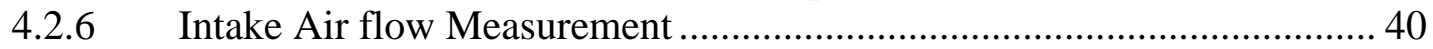

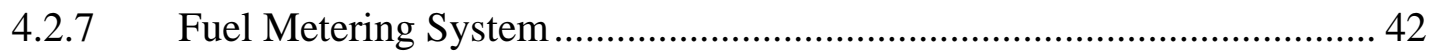

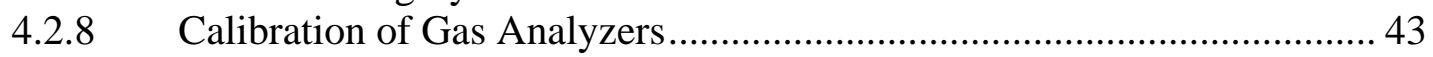

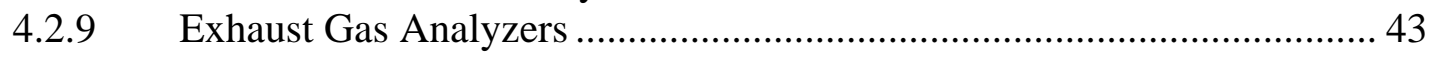

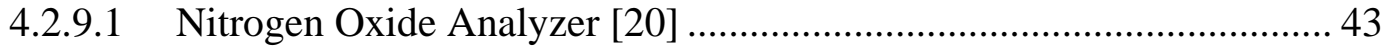

4.2.9.2 Carbon Monoxide/Carbon Dioxide Analyzers .................................... 44

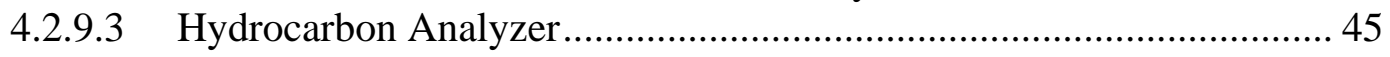

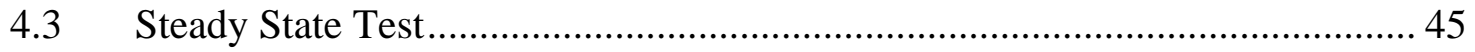

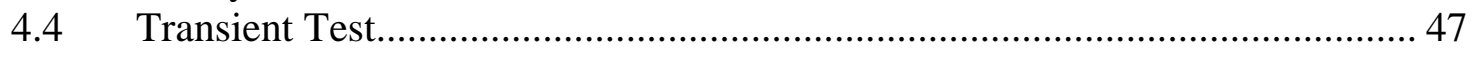

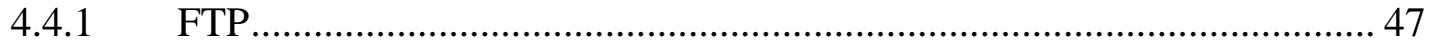

4.4.2 Simulated Transient Cycle ............................................................... 48

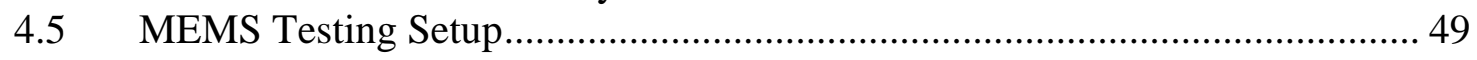

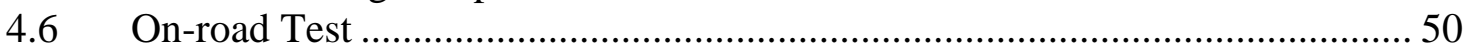

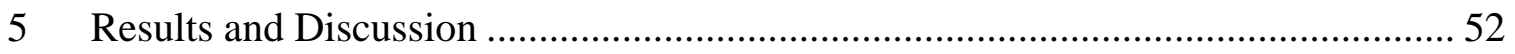

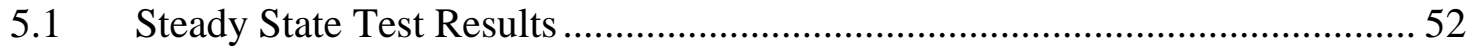

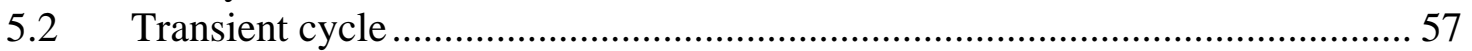




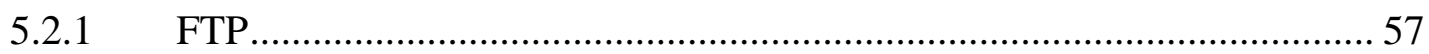

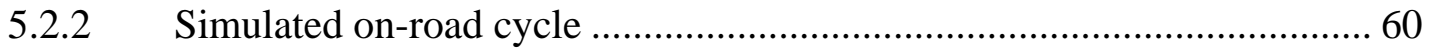

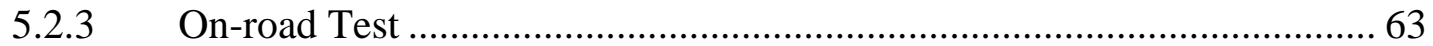

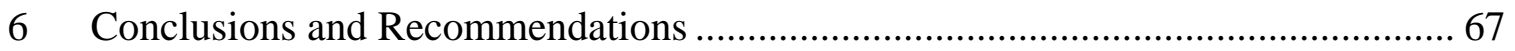

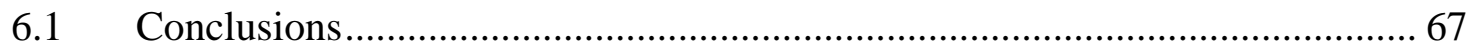

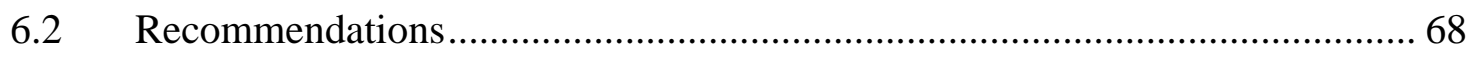

6.2.1 Overheating Chiller..................................................................................... 68

6.2.2 Inadequate Ventilation of the Cold Chamber ............................................. 70

6.2.3 Vibration of the Truck Exhaust Pipe ..................................................... 70

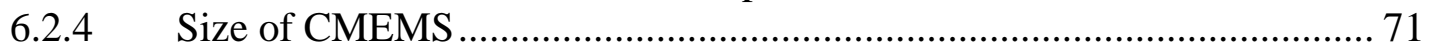

6.2.5 Positioning of Chiller Outlet Probe.......................................................... 72

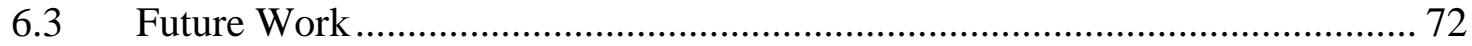

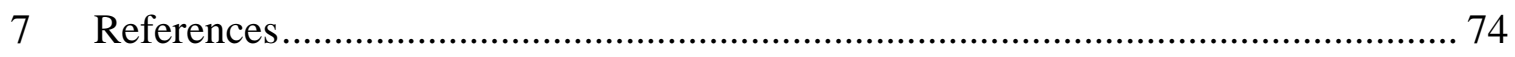

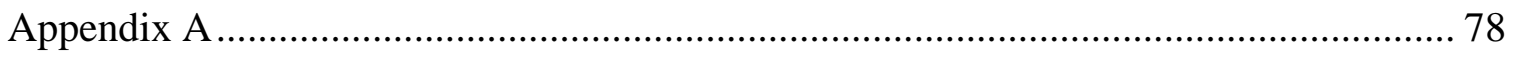

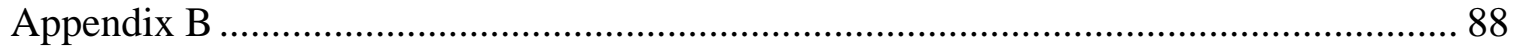




\section{NOMENCLATURE}

\begin{tabular}{|c|c|}
\hline $\mathrm{BSCO}_{2}$ & Brake-specific $\mathrm{CO}_{2}$ \\
\hline BSNOx & Brake-specific NOx \\
\hline CAN & Controller Area Network \\
\hline CATI & Clean Air Technologies International, Inc. \\
\hline CMEMS & Compact Mobile Emissions Monitoring System \\
\hline CARB & California Air Resources Board \\
\hline CFV-CVS & Critical Flow Venturi - Constant Volume Sampler \\
\hline $\mathrm{CO}$ & Carbon Monoxide \\
\hline $\mathrm{CO}_{2}$ & Carbon Dioxide \\
\hline COV & Coefficient of Variation \\
\hline CE-CERT & Center for Environmental Research \& Technology \\
\hline CFR & Code of Federal Regulations \\
\hline CLA & Chemiluminescent Analyzer \\
\hline CVS & Constant Volume Sampling \\
\hline DDC & Detroit Diesel Corporation \\
\hline ECM & Engine Control Module \\
\hline EERL & Engine and Emissions Research Laboratory \\
\hline EPA & Environmental Protection Agency \\
\hline ESC & European Steady-State Cycle \\
\hline EMA & Emissions Measurement Apparatus \\
\hline EAMP & Emissions Assisted Maintenance Procedure \\
\hline EGS & Electrochemical Gas Sensors \\
\hline EFM & Exhaust Flow-Meter \\
\hline FFD & Ford Flow Device \\
\hline FTP & Federal Test Procedure \\
\hline FTIR & Fourier Transform Infrared \\
\hline $\mathrm{ft}-\mathrm{lb}$ & Foot pound \\
\hline g/bhp-hr & Grams per brake-horse power hour \\
\hline $\mathrm{g} / \mathrm{s}$ & Grams per second \\
\hline $\mathrm{HC}$ & Hydrocarbons \\
\hline $\mathrm{H}_{2} \mathrm{O}$ & Water Vapor \\
\hline HFID & Heated Flame Ionization Detector \\
\hline LFE & Laminar Flow Element \\
\hline LPM & Liters per Minute \\
\hline MEMS & Mobile Emissions Measurement System \\
\hline MoA & Memorandum of Agreement \\
\hline MEL & Mobile Emissions Laboratory \\
\hline $\mathrm{N}_{2}$ & Nitrogen \\
\hline NDIR & Non-Dispersive Infrared \\
\hline NDUV & Non-Dispersive Ultraviolet \\
\hline NESCAUM & Northeast States for Coordinated Air Use Management \\
\hline $\mathrm{NH}_{3}$ & Ammonia \\
\hline NMHC & Non-Methane Hydrocarbons \\
\hline $\mathrm{Nm}$ & Newton meter \\
\hline
\end{tabular}




$\begin{array}{ll}\mathrm{NO} & \text { Nitric Oxide } \\ \mathrm{NO}_{2} & \text { Nitrogen Dioxide } \\ \mathrm{NOx} & \text { Oxides of Nitrogen } \\ \mathrm{NTE} & \text { Not-To-Exceed } \\ \mathrm{O}_{2} & \text { Oxygen } \\ \mathrm{O}_{3} & \text { Ozone } \\ \mathrm{OBE} & \text { On-Board Emissions Systems } \\ \mathrm{PID} & \text { Parameter Identification } \\ \mathrm{PEMS} & \text { Portable Emissions Measurement Systems } \\ \text { PM } & \text { Particulate Matter } \\ \text { ppm } & \text { Parts per million } \\ \text { PREVIEW } & \text { Portable Real-Time Emission Vehicular Integrated Engineering } \\ & \text { Workstation } \\ \text { PPMD } & \text { Proportional Particulate Mass Device } \\ \text { QCM } & \text { quartz-crystal microbalance } \\ \text { RAM } & \text { Random Access Memory } \\ \text { rpm } & \text { Revolutions per minute } \\ \text { RTD } & \text { Resistive Temperature Device } \\ \text { sec } & \text { Seconds } \\ \text { SAO } & \text { Smooth Approach Orifice } \\ \text { S-HDDE } & \text { Settling Heavy-Duty Diesel Engine } \\ \text { SET } & \text { Supplemental Emission Test } \\ \text { SO } & \text { Sulfur Dioxide } \\ \text { SwRI } & \text { Southwest Research Institute } \\ \text { THC } & \text { Total Hydro Carbon } \\ \text { VOEM } & \text { Vito’s On-the-road Emission and Energy Measurement System } \\ \text { WVU } & \text { West Virginia University } \\ & \end{array}$




\section{List of Figures}

Figure 1: CMEMS mounted on an exhaust pipe on a truck bed [2] ............................... 27

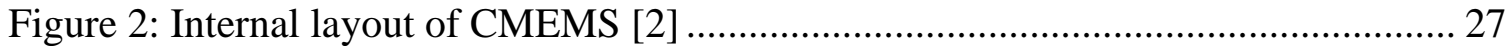

Figure 3: Circuit diagram for the pressure sensors in hot chamber ............................... 34

Figure 4: Schematic diagram for the solid state relays in hot chamber .......................... 34

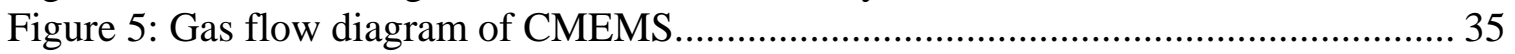

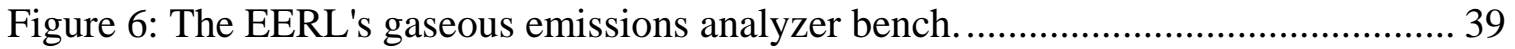

Figure 7:Time vs. speed and torque for steady state test A ........................................ 46

Figure 8: Time vs. speed and torque for steady state test B ...................................... 47

Figure 9: Time vs. speed and torque for steady state test B ...................................... 48

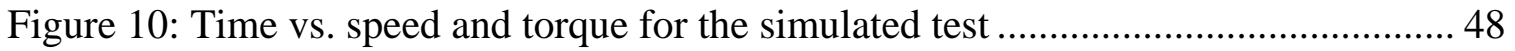

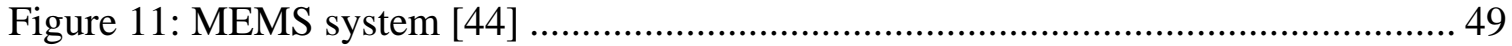

Figure 12: Schematic of the MEMS as tested on a vehicle [16] ................................... 49

Figure 13: Schematic of the CMEMS as tested on a vehicle......................................... 50

Figure 14: CMEMS was mounted on the tail pipe of the truck ..................................... 50

Figure 15: Time vs. speed and torque for on-road test A ............................................. 51

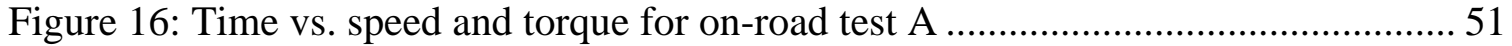

Figure 17: $\mathrm{CO}_{2}$ comparison of CMEMS and EERL results on test $\mathrm{A}$............................. 53

Figure 18: NOx comparison of CMEMS and EERL results on test A ............................ 54

Figure 19: CMEMS vs. EERL NOx mass flow rate linearity comparison for ................. 54

Figure 20: CMEMS vs. EERL $\mathrm{CO}_{2}$ mass flow rate linearity comparison for .................. 55

Figure 21: $\mathrm{CO}_{2}$ comparison of CMEMS and EERL results on test $\mathrm{B}$........................... 55

Figure 22: NOx comparison of CMEMS and EERL results on test B .......................... 56

Figure 23: Average BSNOx emissions for steady state tests. (Error bars represent......... 56

Figure 24: Average $\mathrm{BSCO}_{2}$ emissions for steady state tests. (Error bars represent ......... 57

Figure 25: $\mathrm{CO}_{2}$ comparison of CMEMS and EERL results on FTP1 ........................... 58

Figure 26: NOx comparison of CMEMS and EERL results on FTP1 1.......................... 59

Figure 27: CMEMS vs. EERL NOx mass flow rate linearity comparison for ................ 59

Figure 28: CMEMS $\mathrm{CO}_{2}$ mass flow rate linearity comparison of FTP1 vs. FTP2 .......... 60

Figure 29: CMEMS vs. EERL $\mathrm{CO}_{2}$ mass flow rate linearity comparison for .................. 61

Figure 30: CMEMS NOx mass flow rate linearity comparison for transient ................... 62

Figure 31: $\mathrm{CO}_{2}$ mass flow rate comparison of CMEMS and EERL results on ................ 62

Figure 32: NOx mass flow rate comparison of CMEMS and EERL results on ............... 63

Figure 33: $\mathrm{CO}_{2}$ concentration comparison of CMEMS vs. MEMS on on-road test A..... 64

Figure 34: NOx concentration comparison of CMEMS vs. MEMS on on-road test A.... 65

Figure 35: $\mathrm{CO}_{2}$ mass flow rate comparison of CMEMS vs. MEMS on on-road test A ... 65

Figure 36: NOx mass flow rate comparison of CMEMS vs. MEMS on on-road test A .. 66

Figure 37: An example of cascade Peltier modules [3] ............................................. 69

Figure 38: CMEMS vs. EERL NOx mass flow rate linearity comparison for steady ...... 88

Figure 39: CMEMS vs. EERL $\mathrm{CO}_{2}$ mass flow rate linearity comparison for steady ....... 88

Figure 40: EERL NOx mass flow rate linearity comparison of FTP1 vs. FTP2 ............. 89

Figure 41: CMEMS NOx mass flow rate linearity comparison of FTP1 vs. FTP2 .......... 89

Figure 42: EERL NOx mass flow rate linearity comparison of FTP1 vs. FTP3 .............. 90

Figure 43: CMEMS NOx mass flow rate linearity comparison of FTP1 vs. FTP3.......... 90

Figure 44: EERL NOx mass flow rate linearity comparison of FTP2 vs. FTP3 ............. 91 
Figure 45: CMEMS NOx mass flow rate linearity comparison of FTP2 vs. FTP3......... 91

Figure 46: CMEMS vs. EERL NOx mass flow rate linearity comparison for FTP2 ....... 92

Figure 47: CMEMS vs. EERL NOx mass flow rate linearity comparison for FTP3 ...... 92

Figure 48: EERL $\mathrm{CO}_{2}$ mass flow rate linearity comparison of FTP1 vs. FTP2 .............. 93

Figure 49: EERL $\mathrm{CO}_{2}$ mass flow rate linearity comparison of FTP1 vs. FTP3 .............. 93

Figure 50: CMEMS $\mathrm{CO}_{2}$ mass flow rate linearity comparison of FTP1 vs. FTP3........... 94

Figure 51: EERL $\mathrm{CO}_{2}$ mass flow rate linearity comparison of FTP2 vs. FTP3 …........... 94

Figure 52: CMEMS $\mathrm{CO}_{2}$ mass flow rate linearity comparison of FTP2 vs. FTP3.......... 95

Figure 53: CMEMS vs. EERL $\mathrm{CO}_{2}$ rate linearity comparison for FTP1....................... 95

Figure 54: CMEMS vs. EERL $\mathrm{CO}_{2}$ mass flow rate linearity comparison for FTP2 ........ 96

Figure 55: CMEMS vs. EERL $\mathrm{CO}_{2}$ mass flow rate linearity comparison for FTP3 ....... 96

Figure 56: Average BSNOx emissions for FTP tests. (Error bars represent the .............. 97

Figure 57: Average $\mathrm{BSCO}_{2}$ emissions for FTP tests. (Error bars represent the ............... 97

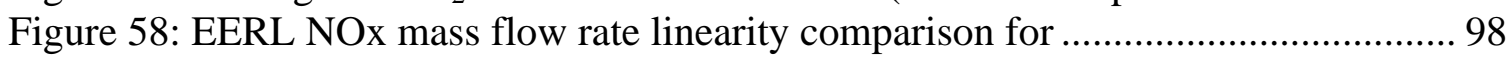

Figure 59: EERL $\mathrm{CO}_{2}$ mass flow rate linearity comparison for .................................... 98

Figure 60: CMEMS $\mathrm{CO}_{2}$ mass flow rate linearity comparison for................................ 99

Figure 61: CMEMS vs. EERL NOx mass flow rate linearity comparison for ................. 99

Figure 62: CMEMS vs. EERL NOx mass flow rate linearity comparison for ............... 100

Figure 63: CMEMS vs. EERL $\mathrm{CO}_{2}$ mass flow rate linearity comparison for ................ 100

Figure 64: Average BSNOx emissions for simulated tests. (Error bars represent the.... 101

Figure 65: Average $\mathrm{BSCO}_{2}$ emissions for simulated tests. (Error bars represent the..... 101

Figure 66: CMEMS vs. MEMS NOx concentration linearity comparison for ............... 102

Figure 67: CMEMS vs. MEMS NOx mass flow rate linearity comparison for ............. 102

Figure 68: CMEMS vs. MEMS $\mathrm{CO}_{2}$ concentration linearity comparison for on-road .. 103

Figure 69: CMEMS vs. MEMS $\mathrm{CO}_{2}$ mass flow rate linearity comparison for .............. 103

Figure 70: $\mathrm{CO}_{2}$ mass flow rate comparison of CMEMS and EERL results on FTP2 .... 104

Figure 71: NOx mass flow rate comparison of CMEMS and EERL results on FTP2 ... 104

Figure 72: $\mathrm{CO}_{2}$ mass flow rate comparison of CMEMS and EERL results on FTP3 .... 105

Figure 73: NOx mass flow rate comparison of CMEMS and EERL results on FTP3 ... 105

Figure 74: NOx mass flow rate comparison of CMEMS and EERL results on ............. 106

Figure 75: CO2 mass flow rate comparison of CMEMS and EERL results on ............. 106

Figure 76: $\mathrm{CO}_{2}$ concentration comparison of CMEMS vs. MEMS on on-road test B ... 107

Figure 77: NOx concentration comparison of CMEMS vs. MEMS on on-road test B.. 107

Figure 78: $\mathrm{CO}_{2}$ mass flow rate comparison of CMEMS vs. MEMS on on-road test B . 108

Figure 79: NOx mass flow rate comparison of CMEMS vs. MEMS on on-road test B 108 


\section{List of Tables}

Table 1: EPA emissions standards for the heavy-duty truck engines over FTP in............. 6

Table 2: California emissions standards for the heavy-duty truck engines over FTP ........ 6

Table 3: EPA specified lifetime for heavy-duty truck engines.............................................. 6

Table 4: Steady state test A....................................................................................... 46

Table 5: Steady state test $\mathrm{B}$......................................................................................... 46

Table 6: Brake-specific NOx and $\mathrm{CO}_{2}$ results for CMEMS vs. EERL on steady state.... 52

Table 7: Mass flow rate difference of $\mathrm{NOx}$ and $\mathrm{CO}_{2}$ for CMEMS vs. EERL on .............. 53

Table 8: Brake-specific NOx and $\mathrm{CO}_{2}$ results for CMEMS vs. EERL on FTP test......... 57

Table 9: Brake-specific NOx and $\mathrm{CO}_{2}$ results for CMEMS vs. EERL on simulated....... 60

Table 10: Mass flow rate difference for NOx and $\mathrm{CO}_{2}$ for CMEMS vs. EERL on............61

Table 11: Gas comparison of CMEMS vs. MEMS on on-road test .................................. 63 


\section{Introduction}

With the ever increasing need for lower greenhouse gasses and lesser air pollutants, pollution control regulators such as US EPA (Environment Protection Agency) has mandated stringent emissions requirements on all the engine manufacturers. Particularly, this legislation has driven the diesel engine manufacturers to their limits. These vigorous standards were assessed by performing EPA certified test cycles such as Federal Transient Procedure and 13-Mode Steady State Test in a test cell environment. These tests lack the accuracy of real-world engine operations and do not comply with some of the regulations set upon by consent decrees of engine manufacturers, such as smoke or alternative opacity limits and transient load response limits. EPA and other regulation bodies then required engine manufactures to use on-board Portable Emission Measuring Systems (PEMS), other than FTP certification, for 2007 and future engine models. Hence, engine manufacturers explored the possibilities of real-time emissions monitoring methods during vehicle operation.

This led to the development of the WVU MEMS (Mobile Emissions Measurement System), which evaluates emissions to satisfy real-time emissions regulations mandated by Consent Decrees. MEMS demonstrated a good agreement (3\% for $\mathrm{CO}_{2}$ error and $4 \%$ for NOx) with laboratory graded analyzers. As the $3^{\text {rd }}$ generation of MEMS, WVU developed CMEMS (Compact-MEMS) to improve characteristics of MEMS as well as to improve the accuracy of engine emission measurements [45].

PEMS needed capability of measuring exhaust flow rate and collecting ECU data while measuring real-time exhaust emissions. This was a difficult task to accomplish while maintaining the accuracy and the reliability of the emissions data. Measuring exhaust 
flow rate was a big challenge in designing a PEMS. There are many ways of measuring exhaust flow rates, and each of them has its own advantages and disadvantages. MEMS and CMEMS, for instance, installed a probe in the exhaust stream to measure exhaust flow rate by using the annubar device. High temperature and PM were the obstacles which had to be overcome using this method of measuring exhaust flow rate.

The other major challenge in designing a PEMS was to overcome harsh road conditions. The measurement devices used cannot be sensitive to vibration, high temperature and orientation. CMEMS used less sensitive zirconia based analyzers to measure NOx but onroad testing data showed they are not very accurate.

Another major requirement for PEMS was compactness. CMEMS is smaller in size and weight compared to MEMS and any other commercially available PEMS

Another major accomplishment of CMEMS was that it could be mounted on the exhaust stack. This was accomplished by incorporating sampling and data acquisition systems of MEMS into one unit by using compact solid state gas analyzers, a smaller sampling system and a small stand alone data acquisition system. "That leads to maintain low power consumption, portability and ease of installation and on the other hand opened a path way which leads to reduction of residence time, deskew times, sample dispersion in sampling lines and operation intrusiveness"[45]. 


\section{Literature Review}

There are different agencies around the world engaged in regulating vehicle emissions. In the United States, the Environmental Protection Agency (EPA) is the main body regulating emissions standards as well as some state governments. California is one of the states that has the strictest emissions regulations, which are enforced by California Air Resources Board (CARB), following the California AB 1493 [6].

\subsection{Emissions Standards}

Emissions standards are a set of regulations issued by a government body to limit the pollutants in a vehicle's exhaust released into the environment. "Standards generally regulate the emissions of NOx, particulate matter (PM) or soot, carbon moNOxide (CO), or volatile hydrocarbons. The main components of automobile exhaust, carbon dioxide $\left(\mathrm{CO}_{2}\right)$ and water vapor $\left(\mathrm{H}_{2} \mathrm{O}\right)$, have not so far been regulated by emission standards, but the European Union is moving towards mandatory $\mathrm{CO}_{2}$ standards and USA has reflected them in Greenhouse Gas Score” [6].

\subsubsection{Consent Decrees}

Consent Decrees were issued in the early 1990's, because most of the heavy duty diesel engines produced before did not meet the NOx emission standards [6]. Engine manufacturers were programming the ECU to get a high performance out of the engine in a steady-state condition, which could not be achieved without increasing the tail pipe emissions. This led to the signing of Consent Decrees where S-HDDE (Settling HeavyDuty Diesel Engine) manufactures were required to provide funding for emission reduction in the future and were required to meet emissions standards for engines by 
2004 [7]. Consent Decrees are a set of rules which came from the court settlement between engine manufactures (Caterpillar Inc., Cummins Engine Company, Volvo Truck Corp., Detroit Diesel Corporation, International Truck Co., Mack Trucks Inc.) and EPA, Department of Justice and California ARB. In addition to FTP new tests, Supplemental Emission Test (SET) and Not-to-Exceed (NTE) limits were implemented.

The SET was introduced to control emissions of a heavy-duty engine during a steadystate type driving. That is a 13-mode steady-state test based on the EU 13-mode ESC schedule (Euro III cycle) [8].

Not-to-Exceed (NTE) limits test was used to control heavy-duty engine emissions over a full range of speed and load combinations. This test was conducted for the area (NTE zone) under the torque curve of an engine where emissions were not to exceed a specified value for any of the regulated pollutants [8]. "The NTE test procedure involves driving of any type that could occur within the bounds of the NTE control area, including operation under steady-state or transient conditions and under varying ambient conditions. Emissions are averaged over a minimum time of thirty seconds and then compared to the applicable NTE emission limits” [8].

Some manufactures had to modify the engine according to the new emissions standards during the production. Engine manufacturers were also required to fund independent researchers to research on-board emissions measurement devices. As a result, West Virginia University (WVU) got a contract to implement a Mobile Emissions Measurement System (MEMS). As the MEMS became successful in on-board emissions measuring, WVU came up with the idea of making more compact MEMS and built a Compact Mobile Emissions Measurement System (CMEMS). 
The vehicles sold in the United States had to meet "Tier II" standards, which came into effect in 2004. "Tier II" standards should be completed by 2009. "BIN 1-10" is a sub rank of "Tier II", 1 being the zero emissions vehicle and 10 being the high emissions vehicle [6]. Former regulations, from 1994 to 2003, were different for light weight trucks (pickup trucks, mini vans and SUV's) and automobiles. But “Tier II” standards are the same for both vehicle types. California state regulations are much stricter in emissions standards, allowing only $0.01 \mathrm{~g} /$ mile particulate matter (PM) in tail pipe emissions [6].

Light heavy-duty vehicles $-8500 \mathrm{lb}$. to $19,500 \mathrm{lb}$.

Medium heavy-duty vehicles - 19,500lb. to 33,000lb.

Heavy heavy-duty vehicles - greater than 33,000lb.

Besides, California considered light heavy-duty vehicles to be from 14,000lb to $19,500 \mathrm{lb}$ after 1995.

According to current federal requirements heavy-duty engines do not have to be chassis certified. Instead, engines have to be certified. For the certification, an engine has to be tested over a Transient FTP dynamometer cycle and emissions should be expressed in g/bhp-hr [8]. Table 1shows EPA emissions standards for heavy-duty truck engines and Table 2 shows California emissions standards for heavy-duty truck engines. Vehicles must meet these standards for a specified lifetime of a vehicle as shown in table 3. 
Table 1: EPA emissions standards for the heavy-duty truck engines over FTP in g/bhp-hr [6]

\begin{tabular}{|c|c|c|c|c|}
\hline MODEL YEAR & NOx & HC & CO & PM \\
\hline 1990 & 6.0 & 1.3 & 15.5 & 0.60 \\
\hline $1991-1993$ & 5.0 & 1.3 & 15.5 & 0.25 \\
\hline $1994-1997$ & 5.0 & 1.3 & 15.5 & 0.10 \\
\hline $1998-2003$ & 4.0 & 1.3 & 15.5 & 0.10 \\
\hline
\end{tabular}

Table 2: California emissions standards for the heavy-duty truck engines over FTP in g/bhp-hr [6]

\begin{tabular}{|c|c|c|c|c|c|}
\hline MODEL & NOx & Total & Non-Methane & CO & PM \\
\hline YEAR & HC & HC & & \\
\hline $1987-1990$ & 6.0 & 1.3 & - & 15.5 & 0.60 \\
\hline $1991-1993$ & 5.0 & 1.3 & 1.2 & 15.5 & 0.25 \\
\hline $1994-2003$ & 5.0 & 1.3 & 1.2 & 15.5 & 0.10 \\
\hline
\end{tabular}

Table 3: EPA specified lifetime for heavy-duty truck engines

\begin{tabular}{|c|c|}
\hline Heavy-Duty Sub Class & EPA Specified Lifetime \\
\hline Light & 8 years or 110,000 miles, whichever occurs first \\
\hline Medium & 8 years or 185,000 miles, whichever occurs first \\
\hline Heavy & 8 years or 290,000 miles, whichever occurs first \\
\hline
\end{tabular}




\subsubsection{Model Year 2004 Standards}

From model year 2004 and later, EPA had new regulations for heavy-duty truck engine emissions [8]. EPA wanted engine manufactures to maintain the level of NOx emissions at 2.0g/bhp-hr. Manufacturers had two options for the engine certification. Option one was to maintain NMHC (Non Methane Hydrocarbon) and NOx at a level of 2.4g/bhp-hr. The second option was to maintain NMHC at $0.5 \mathrm{~g} / \mathrm{bhp}-\mathrm{hr}$ while both NOx and NMHC could be at a level of $2.5 \mathrm{~g} / \mathrm{bhp}-\mathrm{hr}$. All the other emissions standards would continue according to the 1998 agreement. The California standards were harmonized with the 2004 Federal standards except that engines had to go through Supplemental Emission Test and NTE limits of 1.25 times the FTP standards for California standards.

\subsubsection{Model Year 2007 and Later Standards}

EPA signed new emissions standards for model year 2007 engines and later, in December 2000 [8]. "Emission certification requirements also include the SET test, with limits equal to the FTP standards, and NTE limits of $1.5 \times$ FTP standards” [8]. In the 2007 the emissions standards, crankcase emissions have to be considered as other exhaust emissions. Therefore, engine manufactures were required to route crankcase emissions back to the engine intake or to the engine exhaust stream. According to the new regulations, the emissions standards are as below:

$\begin{array}{ll}\text { Constituents } & \text { Brake specific Values } \\ \text { NOx } & 0.2 \text { g/bhp-hr } \\ \text { NMHC } & 0.14 \text { g/bhp-hr } \\ \text { HC } & 1.3 \text { g/bhp-hr } \\ \text { CO } & 15.5 \text { g/bhp-hr } \\ \text { PM } & 0.01 \text { g/bhp-hr } \\ \mathrm{CO}_{2} & \text { Not Regulated }\end{array}$




\subsection{History of Mobile Emissions Measuring Systems}

Different mobile emission measuring systems have been tested by different institutions for various research studies in order to evaluate their performances. The following literature review is extracted from the paper, "Assessment of Mobile Monitoring Technologies for Heavy -Duty Vehicle Emissions” [4], published by WVU. This paper discusses mobile emissions measuring systems from 1983 through 2001.

\subsubsection{In-Field Measurement Systems}

\subsubsection{Southwest Research Institute, 1983}

From 1978 to 1983 Southwest Research Institute launched a project to develop a transportable system for I/M testing of diesel engines [24]. The transportable system had a portable dynamometer, a volumetric fuel flow meter, a laminar air flow meter and laboratory-grade emissions analyzers and emissions instruments. "The emissions measuring system consisted of a heated flame ionization detector (HFID) for HC, nondispersive infrared (NDIR) analyzers for $\mathrm{CO}$ and $\mathrm{CO}_{2}$, a heated chemiluminescent analyzer (CLA) for NOx, and a polar graphic analyzer for $\mathrm{O}_{2}$. Calibration gases for these analyzers were carried along with the unit”[4]. A mini dilution tunnel was included to measure PM. This system, which was to measure on-board vehicle emissions, was an unsuccessful project due to lack of portability.

\subsubsection{Michigan Technological University, 1992}

An emissions Measurement Apparatus (EMA) system was developed by Michigan Technology University to measure PM and gaseous emissions [26]. The system was 
tested in an underground mining site. "It consisted of a dilution bag sampling system, a mini-dilution tunnel for gravimetric analysis of PM, battery powered portable emissions analyzers (for off-line bag analysis), and heated sample lines (to avoid thermophoresis and condensation related problems)" [4]. When results were compared with laboratorygrade analyzers on steady-state engine dynamometer tests, the accuracy for $\mathrm{CO}_{2}$ was within 5\%, CO within 10\%, NO within 5\% and PM within 7\%[4]. However, the EMA system was too bulky to use for on-board applications.

\subsubsection{University of Minnesota, 1997}

University of Minnesota developed an emissions-assisted maintenance procedure (EAMP) for diesel-powered mining equipment [27]. EAMP showed engine faults even though it was more portable compared to systems developed by the South West Research Institute in 1983 and Michigan Technology University in 1997. Assessments of portability were made for various instruments including NDIR, Fourier transform infrared (FTIR) spectrophotometer, and electrochemical gas sensors (EGS). Ecom-AC and Ecom-E analyzers by ECOM America Ltd and EGS sensors were accurate, rugged and portable. The accuracy of measuring $\mathrm{NO}, \mathrm{NO}_{2}, \mathrm{CO}, \mathrm{CO}_{2}$, and $\mathrm{O}_{2}$ was within $5 \%$. Ecom-E was less accurate compared to the laboratory-grade instruments. The EAMP was designed to measure on-site emissions concentrations changing vehicle loads by stalling either their torque converters or hydrostatic transmissions. 


\subsubsection{On-Board Measurements}

\subsubsection{Caterpillar, 1982}

Caterpillar Inc. developed a portable bag collection system to measure NOx emissions in specific fuels [28]. It was a two-bag collection system, and water vapor was removed before entering the bags. The collection system could fit in a "small suitcase" and the driver could control it remotely. It was powered by an on-board supply. NOx emissions measurements using this system had an accuracy of $10 \%$, concentration on parts per million, compared to laboratory based equipment.

\subsubsection{Southwest Research Institute, 1992}

Southwest Research Institute developed a portable system to measure tailpipe emissions of diesel engine busses [29]. The results were compared with EPA transient test cycles. The system was used to collect information on engine emissions without using the chassis dynamometer. Several test cycles, ranging from idle, no-load testing to loading the engine against the transmission through prescribed accelerator pedal positions, were developed to test the engine while the vehicle was parked. All these test cycles were performed on automatic transmission engines. Enerac 2000E was used to measure undiluted $\mathrm{CO}, \mathrm{NOx}, \mathrm{O}_{2}$, and $\mathrm{CO}_{2}$ from a bag sample. A small dilution tunnel was used to

measure PM. Enerac 2000E measurements were within 5\% of laboratory grade measurements. However, this system could not be used for continuous on-board emissions measurements. 


\subsubsection{General Motors, 1993}

A $400 \mathrm{lb}$ data acquisition system was housed in the trunk of a 1989 gasoline fueled passenger vehicle to measure engine emissions. This system was made up of five 12 volt batteries, inverters, computers, and five different emissions analyzers [30]. The vehicle was driven along highways and through cities to measure real world emissions. "The analyzers included a Horiba MEXA 311GE for $\mathrm{CO}_{2}$ and hydrocarbon (HC), a Horiba MEXA 324GE for $\mathrm{HC}$ and CO, a Siemens Ultramat 22P for HC and CO, a Siemens analyzer for NO, and a Draeger analyzer for ambient CO. Redundant measurements of $\mathrm{CO}$ and HC were made in order to accommodate 9 different emissions levels. Ambient CO measurement was made to monitor the passenger compartment concentration levels” [4]. Intake flow rate was correlated with the exhaust flow rate. A Kurz flowmeter was used to measure the exhaust flow rate, and the intake flow rate was derived from the stock mass flow meter signals. The relationship between intake and exhaust flow rates was used to infer the exhaust flow. Some data had to be discarded due to the time alignment problems. Low data rate, one sample per second, caused problems capturing transient events. However, the system was useful to collect some data on spark ignited passenger vehicles.

\subsubsection{Ford Motor Company, 1994}

Several reports showed results of three different passenger vehicles equipped with emissions measuring systems [31, 32, 33, 34]. The purpose of the study was to compare the results of On-Board Emissions Systems (OBE) to remote measurement techniques. The OBE system consisted of a FTIR and a dilution tunnel and was placed on an Aerostar 
van. "The OBE was compared against Horiba laboratory-grade equipment for the vehicle on a chassis dynamometer. The comparison showed that the OBE system was within (on average) $2 \%$ for $\mathrm{CO}_{2}, 3 \%$ for $\mathrm{CO}, 10 \%$ for $\mathrm{NOx}$, and $7 \%$ for $\mathrm{HC}$. The on-road test showed that the OBE system was within (on average) $10 \%$ for $\mathrm{CO}, 1 \%$ for $\mathrm{CO}_{2}, 6.6 \%$ for NOx, and $1 \%$ for HC when compared against laboratory-grade equipment.” Since the FTIR-based system was very slow, it was not fast enough to record real-time transient data.

A Ford Taurus was equipped with infrared-based analyzers to measure $\mathrm{CO}, \mathrm{HC}, \mathrm{O}_{2}$, and $\mathrm{CO}_{2}$, and an unspecified fast response (1.1 seconds) non-dispersive ultraviolet (NDUV) system to measure NO. NO measurements were compared between the on-board NDIR analyzers and laboratory-grade equipment. Results showed a correlation of 0.97 , with a slope of 0.8 , between the fast response NDUV analyzer and chemiluminescent lab equipment. The above mentioned equipment was built to test gasoline engine emissions.

\subsubsection{U.S. Coast Guard, 1997}

As part of the 1990 Clean Air Act for non-road air pollution the US Coast Guard developed an on-board emissions measuring system [35, 36]. Even though the system lacked portability it could be housed in a ship. "The emissions of $\mathrm{CO}, \mathrm{NO}, \mathrm{NO}_{2}$, sulfur dioxide $\left(\mathrm{SO}_{2}\right), \mathrm{O}_{2}$, and $\mathrm{HC}$ were monitored with an Energy Efficiency Systems, Inc., Enerac 2000E” [4]. $\mathrm{CO}_{2}$ was computed from measured emissions. Shaft torque and speed were measured using radio frequency transmitters via Wireless Data Corporation power metering equipment. 


\subsubsection{University of Pittsburgh, 1997}

University of Pittsburg developed a portable, inexpensive on-board emissions measurement system for I/M. The system was used to measure natural gas powered passenger vehicles [37]. It measured undiluted gas concentrations of $\mathrm{HC}, \mathrm{CO}, \mathrm{CO}_{2}$, $\mathrm{NO}$, and $\mathrm{O}_{2}$ by using a RG240 five-gas analyzer. "Engine data were collected via the OBD-II plug with third-party diagnostic equipment”[4]. Because the measurement equipment was made for gasoline engines, the HC measurements were not accurate. This system had issues on determination of mass emission rates, time alignment of signals and analyzer and the system response times.

\subsubsection{Flemish Institute for Technological Research, 1997}

VOEM (Vito’s On-the-road Emission and Energy Measurement system), an on-board emissions measurement system, was developed by VITO, the Flemish Institute for Technological Research. VOEM was powered by a $12 \mathrm{~V}$ battery for one hour operation and weighed 500 lbs. "The system used NDIR analyzers to measure $\mathrm{CO}_{2}$ and $\mathrm{CO}$, a FID to determine HC concentrations, and a chemiluminescent analyzer to measure NOx" [4]. The exhaust sample was drawn from the tail pipe and diluted in order to prevent water condensation from the sample. A nitrogen driven ejector was used to draw the exhaust sample. To prevent the loss of heavy hydrocarbons, a high temperature $\left(190^{\circ} \mathrm{C}\right)$ sampling line was used. "Partial dilute exhaust measurements were combined with fuel consumption, engine speed, and lambda value determination in order to present gaseous emissions on a $\mathrm{g} / \mathrm{km}$ and $\mathrm{g} / \mathrm{s}$ basis” [4]. The data generated by VOEM for gasoline cars and diesel busses were compared with a fixed chassis dynamometer. Accuracy of the 
results was within $10 \%$ except for $20 \%$ for $\mathrm{CO}$ and $25 \%$ for $\mathrm{HC}$ for diesel fueled vehicles.

\subsubsection{NESCAUM, 1998}

Northeast States for Coordinated Air Use Management (NESCAUM) introduced a computer controlled sampling system with a small dilution tunnel [38]. The system had a heated line to transport a portion of raw exhaust to the dilution tunnel. A MPSI five-gas portable gas analyzer and bag sample were used to monitor continuous emissions. To collect PM, a 70-mm filter was used at the end of the dilution tunnel. The analyzer and bag sample readings were not accurate enough when compared with the engine dynamometer testing. It was found that there was a $27 \%$ difference for $\mathrm{CO}, 12 \%$ for NOx, 22\% difference for HC and a 9\% difference for the fuel consumption calculation.

\subsubsection{US EPA, 1999}

The Office of Mobile Sources at the EPA developed a system called ROVER to measure light duty gasoline vehicle emissions. It used an Annubar with a differential pressure sensor for exhaust flow rate measurement and a Snap-On MT3505 multi-gas analyzer for gas analysis. The system measured the vehicle distance and the speed either by using a Global Positioning System (GPS) or a microwave speed and distance sensor or by sampling an engine control module. ROVER measured exhaust emissions of $\mathrm{CO}, \mathrm{CO}_{2}$, $\mathrm{HC}, \mathrm{O}_{2}$ and $\mathrm{NO}$ in grams per distance traveled. In addition, the system recorded engine speed, A/F ratio, and exhaust mass flow rate. 


\subsubsection{Ford Motor Company and WPI-Microprocessor Systems, Inc., 1999}

"Ford Motor Company and WPI-Microprocessor Systems, Inc. developed a Portable Real-Time Emission Vehicular Integrated Engineering Workstation (PREVIEW) that will sample water-laden exhaust”[39]. This system has a capability of measuring exhaust mass emissions of $\mathrm{CO}, \mathrm{CO}_{2}, \mathrm{NO}$ and $\mathrm{HC}$ and up to forty engine parameters simultaneously with the use of an engine control module. Results of the system were compared against the dynamometer laboratory test for FTP and HWFET: $\mathrm{CO}_{2}$ was within $1.5 \%$, CO was within $3.4 \%$, NOx was within $0.4 \%$ and for hydrocarbons it was $12.3 \%$ [4]. The system used a NDIR analyzer while the lab used a FID analyzer to measure hydrocarbons [9].

\subsubsection{U. S. EPA, 2000}

EPA developed a Portable Emissions Measurement System (PEMS) to measure emissions from on-road and non-road vehicles [12]. The system included a $\mathrm{ZrO}_{2}$ sensor for NOx measurement, a pressure drop device for flow measurement, and a data acquisition system that is used to record various kinds of information such as vehicle speed, engine speed, etc [6]. PEMS had most of the features that MEMS had and could be installed on the vehicle within an hour.

\subsubsection{Horiba, Ltd. and NGK, 2001}

Horiba, Ltd. and NGK developed a NOx measurement system using a solid state zirconium oxide sensor [10]. The sensor was capable of reading a NOx range of 0 5000ppm. The intake air flow rate, vehicle speed, engine speed, ambient pressure, intake 
air temperature, ambient temperature, intake manifold air pressure, excess-air ratio, intake air relative humidity, and engine coolant temperature were the other parameters measured by the system. Compared to laboratory tests, the accuracy for NOx emissions was within $4 \%$, within $3 \%$ for fuel consumption and within $1 \%$ for distance.

\subsubsection{Honda R\&D and Nicolet Instrument Corp., 2001}

Honda R\&D Americas, Ltd., Honda R\&D Co., Ltd., and Nicolet Instrument Corp. developed a system to measure NMHC, NOx and CO [11]. It was an FTIR based onboard system to measure light duty gasoline vehicles. The system had some problems with vibrations.

\subsubsection{Sensors, Inc., 2001}

SEMTECH-D was developed by Sensors Inc. to measure diesel emissions, $\mathrm{HC}, \mathrm{CO}, \mathrm{CO}_{2}$, $\mathrm{NO}, \mathrm{NO}_{2}$ and PM [13]. A heated line was used to draw an emissions sample into the system. "A unique feature of this system is the hydrocarbon measurement with an infrared optical bench operating at $200^{\circ} \mathrm{C}$. Downstream of the heated HC analyzer is a nonheated NDIR analyzer used to measure $\mathrm{CO}, \mathrm{CO}_{2}$ and $\mathrm{HC}$. $\mathrm{HC}$ results are optional. NO and $\mathrm{NO}_{2}$ are measured separately with two NO electrochemical cells in parallel, one of which has a NOx converter upstream. PM is measured with a laser light scattering principle from a separate diluted sample” [6]. The system used a NDUV analyzer for NO, $\mathrm{NO}_{2}$ and $\mathrm{SO}_{2}$. The data could be transmitted through wireless, and the system was also equipped with a GPS system. 


\subsubsection{Analytical Engineering Inc., 2001}

Analytical Engineering Inc. developed an on-board emissions measurement system for EPA [14]. The system was mainly used to calculate break-specific NOx in terms of grams per bhp-hr and fuel-specific. Among other measured parameters were $\mathrm{O}_{2}$ concentration, engine speed, exhaust mass flow rate, exhaust temperature, ambient temperature, barometric pressure, altitude, and vehicle velocity and position.

\subsubsection{Clean Air Technologies International, Inc., 2001}

Clean Air Technologies International, Inc. (CATI) has developed a system, OEM 2100, to measure emissions on both gasoline and diesel fueled vehicles [4]. This system also could be used for light or heavy-duty vehicles. OEM 2100 is a five-gas system which measures $\mathrm{CO}, \mathrm{CO}_{2}, \mathrm{NOx}, \mathrm{HC}$ and $\mathrm{O}_{2}$ in grams per second and grams per mile. The exhaust mass flow rate is calculated from ECM data. According to the manufactures, it takes only 10 to 15 minutes and a screwdriver to install the system on-board. It can also be calibrated in intervals.

\subsubsection{West Virginia University, 2001}

Mobile Emissions Measurement System (MEMS) was developed by West Virginia University to measure on-board emissions of diesel fueled trucks [6]. Developers built the system with the awareness of the ruggedness and the accuracy needed by an on-board emissions measuring system. After some time, none of the other systems met those requirements. Different types of sensors and detectors were tested to select the most suitable application for the system. MEMS was capable of measuring $\mathrm{NOx}$ and $\mathrm{CO}_{2}$. 
After the implementation, MEMS was tested and the results were compared against the laboratory-grade analyzers. The accuracy of $\mathrm{CO}_{2}$ was within $3 \%$ and NOx was within $8 \%$ (ppm) of raw emissions and within $4 \%$ for mass emission rate $(\mathrm{g} / \mathrm{s})$ measurements [16]. After testing against the EERL, on-road routes were assigned to collect on-road emissions data.

After the successful and extreme use of MEMS for on-road measurement of exhaust emissions, WVU designed and developed the Compact Mobile Emissions Measuring System (CMEMS) to measure exhaust emissions from heavy duty trucks. The main idea behind developing this system was to make it lighter and have compact so that it could be installed on the tailpipe of the truck. To achieve the desired requirements designers used commercially available compact solid-state gas analyzers and developed the sampling system smaller than the MEMS sampling system [2]. CMEMS was designed with an inbuilt data acquisition system unlike in MEMS. Installation time and power requirements of CMEMS were lower compared to MEMS. On the other hand CMEMS did not perform as well as in terms of vibration, motion and rugged road conditions were concerned.

\subsubsection{Sensors, Inc., 2005}

SemtechD was designed to measure emissions from light-duty, oxidation catalyst equipped, diesel cars [46]. SemtechD was evaluated against test cell analyzers. The system was capable of measuring THC, $\mathrm{NOx}, \mathrm{CO}_{2}$ and $\mathrm{CO}$. The $\mathrm{NOx}$ and the $\mathrm{CO} 2$ measurements were within $3 \%$ and $2.6 \%$ respectively. CO agreed within $9 \%$ of the two measurement systems. The SemtechD is capable of measuring THC concentration as low 
as $2 \mathrm{ppmC}$ and with in an accuracy of $4.5 \%$ compared to the test cell instrumentation. The system was tested for eleven vehicles and included more than 6000 data points.

\subsubsection{The College of Engineering-Center for Environmental Research and Technology (CECERT), 2005}

CECERT has developed an emissions laboratory using a 53-foot on-road trailer to measure real-time on-board emissions of heavy-duty trucks [47]. The laboratory was attached to a class 8 tractor to captures the tractor's exhaust, through a flexible connector, when the truck is operating. The laboratory weighs around $44,000 \mathrm{lb}$ and serve as a load to the engine same time. The data collected from the laboratory is useful, to improve the heavy-duty truck emissions inventory, to develop new technology for heavy-duty truck emission controls and to measure any on-road class 8 tractors.

It was found that, the motion, vibration and noise introduced under real-world testing conditions has an effect on the performance of emissions measurement system, but the measurements were in acceptable standards.

\subsubsection{West Virginia University (WVU), 2005}

WVU developed a method to assure quality of test data for emissions measured by any Portable Emissions Measurement System (PEMS) [48]. The method consisted of three stages. The first stage was to make sure correct operation of different sensors and transducers during data collection and the second stage was data synchronization and preprocessing. The third stage was to check transducer and sensor errors. "It should be noted that the methodology discussed focused on one set of sampling conditioning system and 
certain measurement technologies, the general discussion on the need for quality assurance and the appropriate methodology to achieve quality assurance remained unchanged" [48].

\subsubsection{West Virginia University (WVU), 2006}

Compact Mobile Emissions Measurement System (CMEMS) was developed by WVU to measure real-time on-road emissions from heavy-duty diesel vehicles [2]. It was designed and developed to miniaturize and improve the performance of Mobile Emissions Measurement System (MEMS), so that the entire system can mounted on the tailpipe of a

truck. CMEMS is the $3^{\text {rd }}$ generation of MEMS. Main differences of the two systems were the size, weight, deskew time, power requirement, mounting time and the position of the system.

“The CMEMS generated maximum percentage difference of $5.18 \%$ for NOx and 3.10\% for CO2 against the MEMS in two on-road tests. In addition, the CMEMS also reported a difference of $2.36 \%$ for NOx and $2.69 \%$ for CO2 against laboratory grade analyzers on seven FTP runs. Differences of $1.87 \%$ for NOx and $1.51 \%$ for CO2 were reported against the laboratory grade analyzers on a simulated on-road cycle” [2].

\subsubsection{West Virginia University (WVU), 2007}

WVU has conducted a study to determine the measurement accuracy of Portable Emissions Measurement System (PEMS) [49]. Two PEMS, PEMS-1 and PEMS-2, were investigated for the transient behavior, repeatability, and for the agreement with a certified engine test cell. PEMS-1 was a commercially available unit with $\mathrm{CO}, \mathrm{CO}_{2}$, 
NOx, THC, and $\mathrm{O}_{2}$ analyzers. Exhaust flow rate was measured by a differential pressure device with multiple transducers. A heated sample line, a AC power supply and a battery backup unit was included in PEMS-1.

PEMS-2 was under research and it included NOx, CO, $\mathrm{CO}_{2}, \mathrm{O}_{2}$ and THC analyzers. Annubar was used to measure exhaust flow rate in PEMS-1. A heated sample line, Dearborn protocol adapter, to read data from the ECM, and an AC power supply unit was included in the system.

Some of the in-use challenges were finding non-interfering locations for instrumentation, analyzer drift over long testing periods, ECM communication lapses during tests, leaks in sample lines, wireless communication problems, ambient conditions probes' location and accuracy, blockage (due to soot) of differential pressure lines and inertial effect on pressure measurement devices.

\subsubsection{West Virginia University (WVU), 2007}

WVU conducted a study to evaluate methods to determine in-use emissions of a heavyduty diesel engine in a heavy-duty vehicle at varying test weights [50]. The objectives of the study were to determine the effect of test vehicle weight on occurrence of NTE events and in-use emissions, to determine the influence of test route on occurrence of NTE events and in-use emissions and to compare the methodologies of determining in-use brake-specific emissions of oxides of nitrogen (NOx) and carbon dioxide $\left(\mathrm{CO}_{2}\right)$.

WVU's Mobile Emissions Measurement System (MEMS), which is capable of measuring brake-specific mass emissions of Oxides of Nitrogen and Carbon Dioxide, was used for the on-road testing. "The results showed that the in-use bsNOx emissions 
were more sensitive to the test route than the vehicle test weight and the urban routes had lower in-use bsNOx emissions. An in-use bsCO2 emission was independent of both test route and the test vehicle weight” [50].

\subsubsection{U.S. Environmental Protection Agency (EPA) / Sensors, Inc., 2007}

USEPA and Sensors, Inc. developed a Proportional Particulate Mass Device (PPMD) with an exhaust flow-meter (EFM), a micro-proportional sampling system (MPS) and a quartz-crystal microbalance (QCM) to measure particulate mass. Performance of MPS has been evaluated using USEPA's heavy-duty engine dynamometers and by a on-road testing trip from Ann Arbor, MI to San Diego, CA, regarding its sampling proportionality and PM loss, with the reference constant volume sampling (CVS) system [51]. Both MPS and QCM were evaluated in on-road testing series in spring 2007 [51].

\subsubsection{Horiba Instruments, Inc., 2007}

Horiba Instruments, Inc. has been developed a prototype of partial flow sampler for OnBoard Diesel Particulate Measurement (OBS-PM) [52]. It takes raw engine exhaust and dilute partially. "Particulate matters emitted by a diesel are collected on a $47 \mathrm{~mm}$ filter while diluted exhaust flows through the filter media. Finally, the gravimetric approach or Horiba 1370PM is applied to determine the PM emission” [52]. The system consisted of a fast proportional control system, a raw exhaust flow meter and four 12-volt batteries. The performance of the system was evaluated on a DDC Series 60 heavy-duty diesel engine at Southwest Research Institute (SwRI) and the results were compared with a 
SwRI heavy-duty CVS tunnel which has a secondary dilution under different drive cycles.

The results showed that the CVS tunnel reads much higher background PM emission than the OBS-PM. The OBS-PM was more reliable measuring extremely low PM emission [52].

\subsubsection{Ford Motor Co., 2007}

Ford Flow Device (FFD) was developed by Ford Motor Co. to measure exhaust gas flow from a vehicle under real-world conditions [53]. It is a compact, inexpensive, portable system consisted of a tube that has a circular flow restricting element that can be coupled to the exhaust pipe of a vehicle. "The restricting element induces a pressure drop based on the exhaust gas flow. Pressure ports upstream and downstream of the restricting element are connected to differential pressure transducers and a thermocouple extends through a temperature port that is also positioned downstream” [53]. The exhaust gas flow was calculated using the differential pressure and the temperature, which are the parameters read by a processor.

The FED was tested against Smooth Approach Orifice (SAO) device and the Parameter Identification (PID) technique and had a good agreement of at least $85 \%$ and 95\% consecutively. 


\subsubsection{U. S. EPA PEMS Measurement Allowance Program}

Starting in year 2007, heavy-duty engine manufacturers were required to run an in-use compliance program. The in-use compliance program addressed problems encountered in using Portable Emissions Measurement Systems (PEMS). The problems that were discussed in the program were a result of Memorandum of Agreement (MoA), which was signed by the ARB, US EPA, and the heavy-duty engine companies. "The MoA specified a "measurement allowance program" to determine what the accuracy margin should be relative to the laboratory certification test methods as specified in the Code of Federal Regulations (CFR)” [54]. The CE-CERT validated the PEMS during on-road testing by comparing the test data collected with CE-CERT’s Mobile Emissions Laboratory (MEL) and the PEMS. A Statistical Monte Carlo model was used to evaluate the data from PEMS. The results of this project were used to implement the compliance program for heavy-duty engines.

Southwest Research Institute (SwRI) conducted a study on PEMS measurement allowance program. The Sensors Inc.'s SEMTECH-DS was used in the study. The error surface data experiments were conducted for 600 steady-state points and 1800 transient NTE events in 3 different engines. In addition, many more steady state points were tested for various different conditions and about 200 hours of environmental chamber tests were conducted. SwRI has simulated more than 10,000 statistical models per NTE event and together with CE-CERT it has been generated 450 NTE events over 9 days of in-field operation and three additional week of dynamometer testing.

The results determined 95th percentile for all 10,000 data points for each NTE event and 
95th percentile deltas were collected for all 195 reference NTE events and examined versus level. The "Validation window" of 5th and 95th percentile deltas were also generated for later use in model validation. At respective NTE threshold the measurement error percentage of validated method for BSNOx and BSNMHC was $22.30 \%$ and $10.08 \%$ respectively. 


\section{Compact Mobile Emission Monitoring System (CMEMS)}

CMEMS was designed with two chambers, a heated chamber and a cold chamber. Of the two, the heated chamber is the smaller and it is located at the bottom of CMEMS. The heated chamber contains the heated filter, the Annubar mass flow rate measurement unit, the solenoid valve, the four relays to control the heated filter, NOx sensor, solenoid valve and chiller, the pressure sensor board for Annubar and the heated filter pressure measurements. Because the heated filter and the NOx sensor need to be at a high temperature, the heated chamber has to maintain a relatively high temperature compared to the cold chamber. The cold chamber lies right on top of the heated chamber as shown in the diagram. The cold chamber contains a secondary filter to remove any remaining PM of the exhaust gas, a pump, a three terminal $12 \mathrm{~V}$ DC power supply unit, a $\mathrm{CO}_{2}$ analyzer (BE-150), a National Instruments data acquisition system (FP 2020), a critical flow nozzle to maintain the gas flow, a damper to dampen the signal, a chiller to lower the temperature of the exhaust gas, and a pressure and a humidity sensor board to measure ambient, chiller and critical flow nozzle pressure and humidity values. 


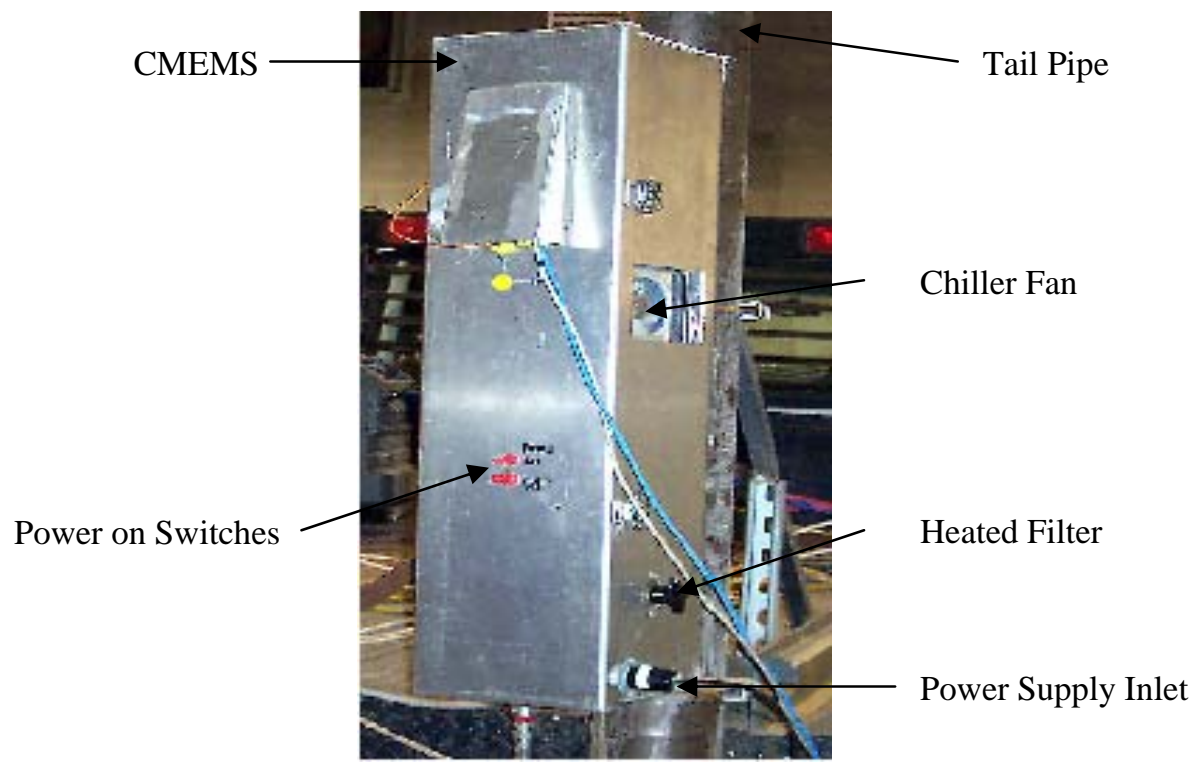

Figure 1: CMEMS mounted on an exhaust pipe on a truck bed [2]

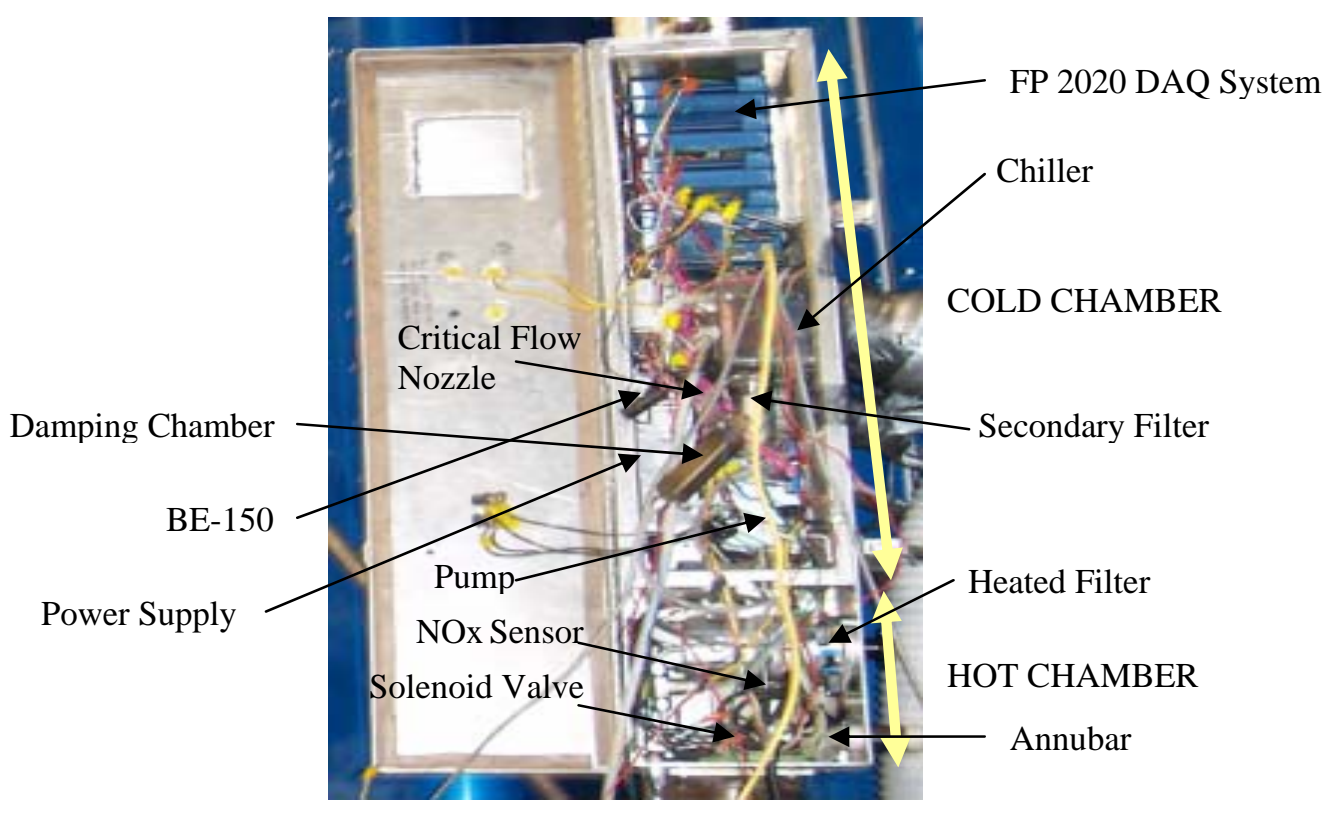

Figure 2: Internal layout of CMEMS [2] 


\subsection{Hot Chamber}

\subsubsection{Heated Filter}

Raw sample exhaust gas comes through a stainless steel probe, which has been designed according to CFR Title 40, Part 1065.145 [19], and flows into the heated filter. The heated filter has small 1.5x2.25 sq. inches filter to remove Particulate Matter (PM) out of the raw exhaust gas. The filter has to be replaced frequently in order to maintain a PM free raw exhaust gas flow throughout the system. The filter is covered by a stainless steel filter holder, which can be heated to around $235^{\circ} \mathrm{F} \pm 15^{\circ} \mathrm{F}$. This will keep the water vapor of the raw exhaust gas from being condensed. This is important for an accurate NOx measurement because $\mathrm{NO}_{2}$ dissolves in water. The pressure drop across the filter varies from 1.5 psi to 0.361 psi depending on the PM deposition.

\subsubsection{Annubar}

An Annubar is a device used to measure exhaust mass flow rate. It records Annubar absolute pressure and Annubar differential pressure. These values can be used to calculate the exhaust mass flow rate, and then can be converted to asses the value of emission gas concentration. Concentration then used to calculate mass measurement per time and to get the ultimate result in mass measurement per distance.

\subsubsection{Solenoid Valve}

CMEMS uses a three-way normally open solenoid valve to switch between exhaust gas and calibration gas. The solenoid valve is a high temperature valve, which is capable of handling the high temperature of exhaust gas flow. Out of the three ports valves, one inlet 
port is connected to the exhaust gas, which comes out of the heated filter. Another inlet port is connected to the output of the gas divider, and the other outlet port is connected to the NOx sensor.

\subsubsection{NOx Sensor and MEXA 720 Control Unit}

After raw exhaust gas flows through the solenoid valve, it enters the NOx sensor, which is capable of measuring Nitric Oxide (NO). To measure Nitrogen Dioxide $\left(\mathrm{NO}_{2}\right)$, there is a NOx converter, which converts $\mathrm{NO}_{2}$ to NO. The sensor is made out of a zirconium oxide material which reaches a temperature of around $900^{\circ} \mathrm{F}$ within a short response time. The sensor is connected to the portable MEXA 720 control unit. The control unit can measure oxygen percentage, $\mathrm{A} / \mathrm{F}$ ratio and excess air ratio in addition to NO. The MEXA 720 is connected to the computer via a null modem to calibrate the NOx sensor. The NOx sensor used in CMEMS is calibrated on 3 points, zero, mid and span. Nitric oxide of around 2000 ppm is used for span gas and nitrogen is used for zero gas concentration. The gas bottles used are regulated to pressure levels of 22 psi for nitric oxide and 19 psi for nitrogen.

\subsection{Cold Chamber}

\subsubsection{Damper}

Once raw exhaust gas flows through the hot chamber, it reaches the cold chamber and flows through a dampening chamber after the NOx sensor. The dampening chamber is used to remove unwanted oscilation of the exhaust gas flow. The damper is made out of aluminum. 


\subsubsection{Secondary Filter}

The exhaust gas reaches the secondary filter after the damper to remove any Particulate Mater remaining. This is a precaution taken to remove the PM and so the prevent BE-150 from getting an exhaust gas sample with Particulate Matter. The secondary filter uses the same size filter as the heated filter and it does not need to be replaced often.

\subsubsection{Gast Manufacturing Pressuring Pump}

The Gast Manufacturing Pressuring pump is located in the cold chamber. After the exhaust gas passes through the damper, it reaches the pump. The pump pressurizes the exhaust gas sample up to 40 psia, which is sufficient to maintain the upstream flow rate. The pump next passes the exhaust gas sample to the critical flow nozzle.

\subsubsection{Critical Flow Nozzle}

The critical flow nozzle is used to maintain a constant flow rate of 3 LPM for the BE150 $\mathrm{CO}_{2}$ analyzer. Maintaining a constant flow rate of $3 \mathrm{LPM}$ for the BE-150 is important for an accurate $\mathrm{CO}_{2}$ reading. The exhaust gas sample enters the chiller after going through the critical flow nozzle.

\subsubsection{Chiller}

A chiller removes the moisture from the raw exhaust gas as it is important for the BE $150 \mathrm{CO}_{2}$ analyzer to have a dry exhaust gas sample flowing through to get an accurate $\mathrm{CO}_{2}$ reading. The chiller is made of an aluminum chamber, a Peltier element, a copper heat sink and a fan. The cold side of the Peltier element is glued to the aluminum 
chamber, which carries exhaust gas through it, so that the temperature of the exhaust gas will go down to around $50^{\circ} \mathrm{F}$. Since it is below the dew point, $122^{\circ} \mathrm{F}$, any water vapor contained in the raw exhaust gas will be condensed. The hot side of the Peltier element is glued to the copper heat sink. A medium capacity fan is attached to the heat sink to dissipate the heat. The open surface of the aluminum chamber is covered by Neoprene rubber foam to avoid heat transfer from the cold side thus maintaining an effective cooling system. It is important to drain the chiller after every CMEMS emissions.

\subsubsection{BE-150 Multi Gas Analyzer}

The cold dry exhaust gas coming out of the chiller enters the BE-150. The BE-150 is a multi gas NDIR analyzer that can measure carbon dioxide, carbon moNOxide and hydrocarbons of an exhaust gas simultaneously. The BE-150 is capable of connecting to oxygen and nitric oxide sensors via analog ports. In that way it can give $\mathrm{O}_{2}$ and $\mathrm{NO}$ readings along with $\mathrm{CO}_{2}$ readings. The $\mathrm{BE}-150$ provides data to the National Instruments Field Point 2020 Data Acquisition System via a RS 232C serial port.

\subsubsection{Power Supply}

CMEMS uses a 12V-19A DC power supply to power most of the devices in it other than the pump and the heated filter. The pump and the heated filter need a 120V power supply to operate. 


\subsubsection{Data Acquisition System - National Instruments Compact Field Point 2020}

(FP 2020)

CMEMS uses a FP 2020 to communicate in real-time between the CMEMS devices and the computer. The software tool used for data logging is the National Instruments LabView 7.1 Real-time. It communicates with the computer via a crossover Ethernet cable in real time with a data acquisition rate of $5 \mathrm{~Hz}$. The Compact Field Point 2020 is a stand alone system with extended 32 MB RAM and 512 MB of removable compact flash storage. The control unit of the FP 2020 consists of three additional serial ports to communicate with other devices other than the RJ 45 Ethernet port. Other than its own processor, there are four data modules connected to its backplane. Each module has 8 data channels. The first module is used for thermocouple data logging; the second and third modules are used for analog input, reading voltages from sensors, and the fourth one is for digital output, sending voltages to switch four relays: heated filter, solenoid valve, and chiller and NOx sensor. The data channels used in Compact Field Point 2020 are as follows:

\section{Thermocouple Module}

Channel 0 - Ambient temperature

Channel 1 - Temperature of the chiller

Channel 2 - Temperature of the heated filter

Channel 3 - Temperature before chiller

Channel 4 - Temperature after chiller

Channel 5 - Temperature of the NOx sensor

Channel 6 - Flow temperature1 of exhaust pipe

Channel 7 - Flow temperature2 of exhaust pipe
Thermocouple Type

- J Type

- K Type

- J Type

- J Type

- J Type

- J Type

- K Type

- K Type 

Analog Input Module -1
Channel 1 - NOx sensor
Channel 2 - Pressure drop at the filter
Channel 3 - Critical flow DP
Channel 4 - Ambient pressure
Channel 5 - Ambient relative humidity
Channel 6 - Relative humidity before chiller
Channel 7 - Relative humidity after chiller

\section{Analog Input Module - 2}

Channel 0 - Annubar absolute pressure

Channel 1 - Annubar differential pressure

\section{Digital Output Module}

Channel 0 - Chiller relay

Channel 1 - Heated filter relay

Channel 2 - NOx analyzer relay

Channel 3 - Solenoid valve relay

\subsection{Pressure Sensors and Humidity Sensors}

There are two circuit boards of pressure and humidity sensors in CMEMS. One circuit board comprises three pressure sensors for the Annubar absolute pressure, Annubar differential pressure and heated filter differential pressure, which are located in the hot chamber. The other circuit board includes the pressure sensors to read the critical flow nozzle differential pressure and ambient pressure, and humidity sensors to get readings of relative humidity before the chiller, relative humidity after the chiller and ambient relative humidity. The type of sensors used for reading pressure and humidity are as follows:

Pressure/Humidity Reading

Annubar absolute pressure Annubar differential pressure Heated filter differential pressure Ambient pressure

Critical flow nozzle differential pressure

Relative humidity before chiller

Relative humidity after chiller Ambient relative humidity

\section{Type of Sensor}

- Motorola SPX 4162 AP

- Motorola MPX 5010 DP

- Motorola MPX 5050 DP

- Motorola MPX 4162 AP

- Motorola MPX 4250 DP

- Honeywell HIH 3610

- Honeywell HIH 3610

- Honeywell 147 
All these sensors have an analog output signal but different operating ranges.

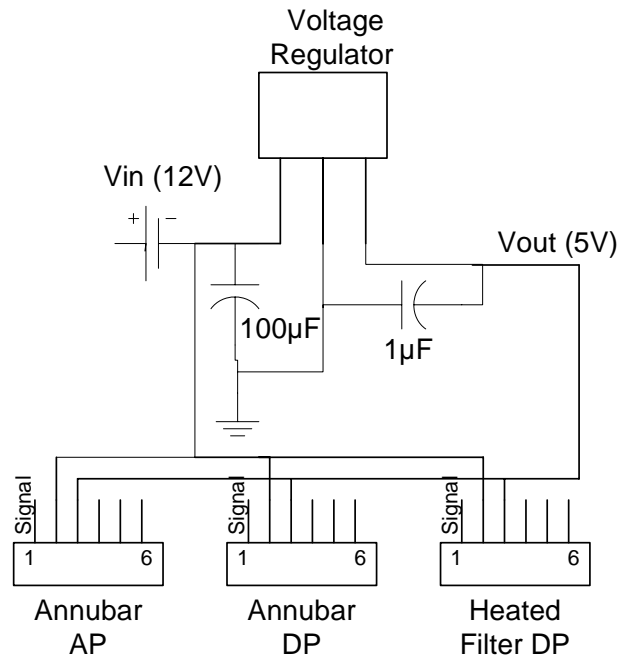

Figure 3: Circuit diagram for the pressure sensors in hot chamber

\subsection{Solid State Relays}

CMEMS uses four Crouzet type relays to control the heated filter, the NOx sensor, the chiller and the solenoid valve. All four relays get a 120V AC input and a 12V DC control input from the FP 2020. The schematic diagram for the four relays is shown below.

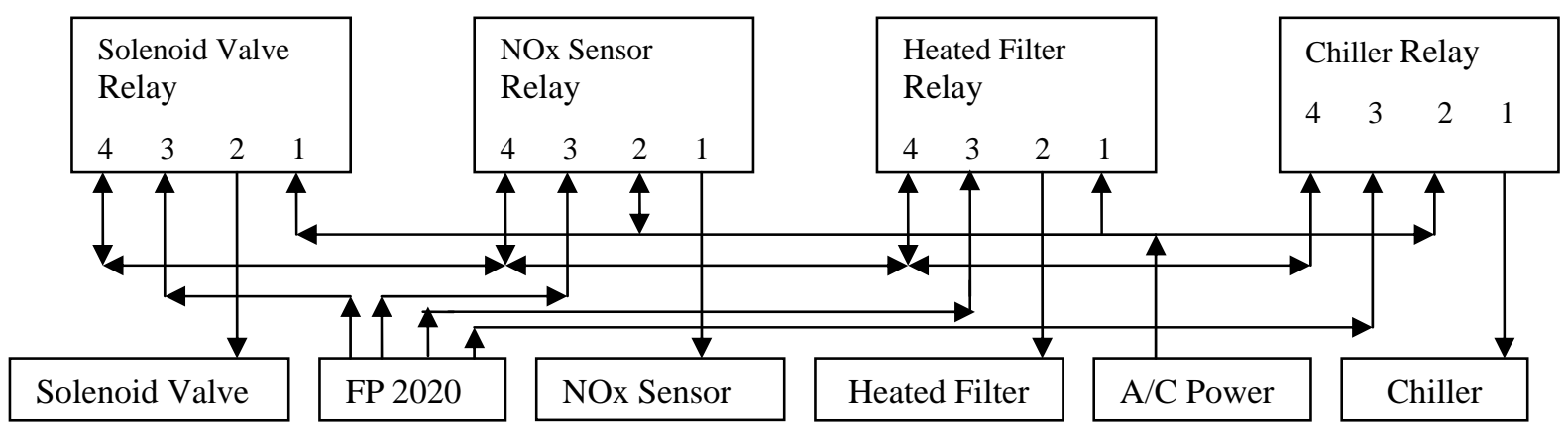

Figure 4: Schematic diagram for the solid state relays in hot chamber 


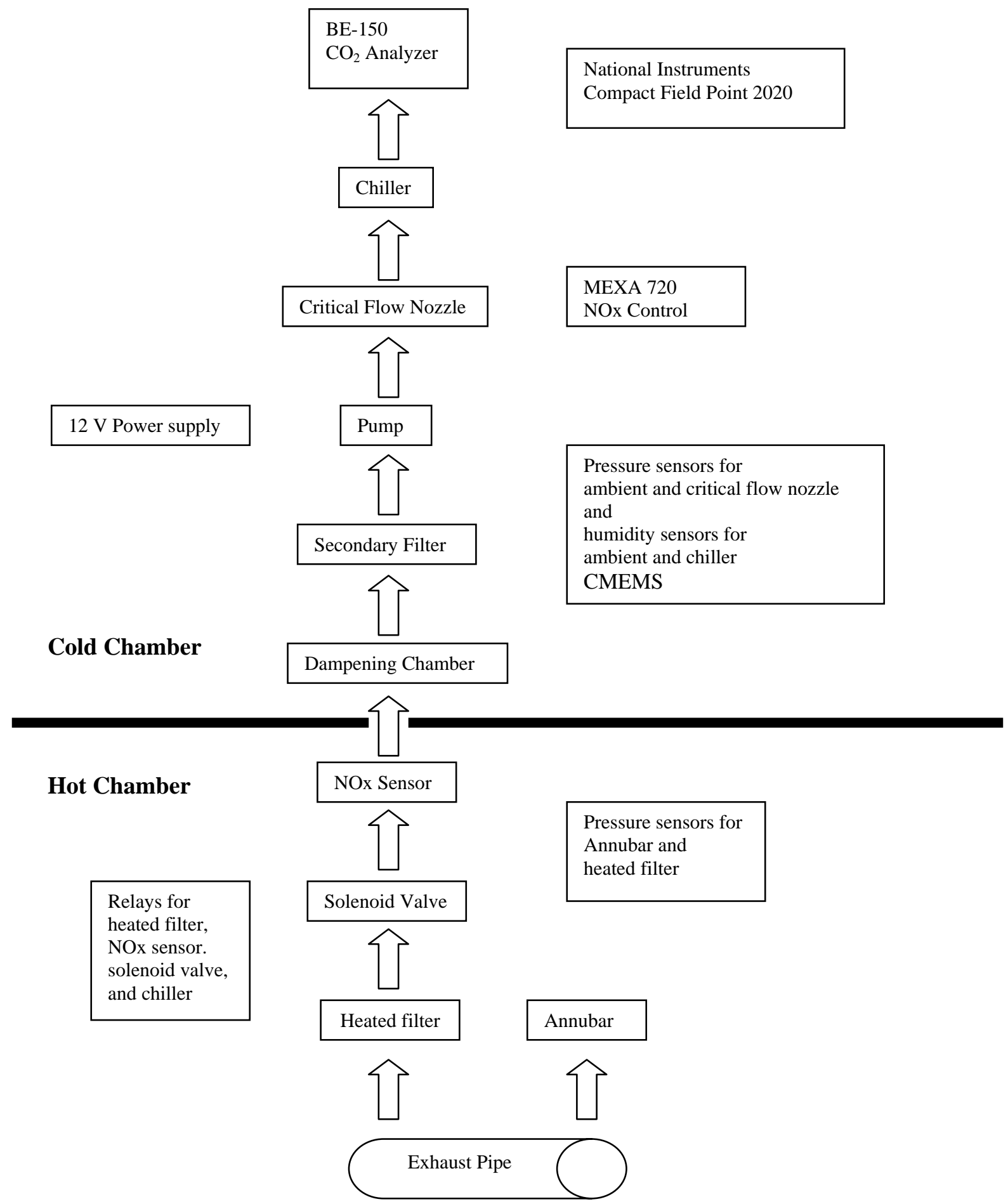

Figure 5: Gas flow diagram of CMEMS 


\section{Experimental Equipment and Procedure}

\subsection{In-Laboratory Testing Setup}

The laboratory testing for CMEMS was conducted in West Virginia University Engine and Emissions Research Laboratory (EERL) located on the WVU Evansdale campus in Morgantown, West Virginia. The EERL is equipped with a full-scale CFV-CVS (critical flow venturi-constant volume sampler) system with all other laboratory apparatus. The laboratory has been constructed according to the specifications delineated in the CFR 40, Part 86, Subpart N [18]. The components of West Virginia University's EERL are discussed in the next section.

\subsection{Components of EERL}

\subsubsection{Dynamometer}

A dynamometer was used in EERL for engine testing to simulate the load that is applied to the engine in a real truck. The EERL was equipped with a GE Model DYC-243 fan cooled, direct current dynamometer. This dynamometer was capable of absorbing $550 \mathrm{hp}$ and providing up to 500 hp during motoring of the engine and has a power rating of 200 hp; current rating of 300 amps at 3000 rpm. “An electric dynamometer closely resembles the electric motors in operation. The DC dynamometer consists of an armature and stator assembly, which generate the torque. The engine output was measured by a load-cell mounted on the dynamometer frame. Altering the load on the dynamometer also varies the load applied. The load cell was calibrated by suspending known weights from an arm of known length, mounted opposite to the load cell. This technique provided tension 
equal to the maximum value of force reachable by the dynamometer at any given time. Engine speed was recorded with a digital speed encoder within the dynamometer"[40].

\subsubsection{Critical Flow Venturi}

According to CFR 40 specifications the EERL used a Critical Flow Venturi System to regulate the flow of diluted exhaust gases passing through the dilution tunnel [16]. A constant mass flow rate was maintained in the dilution tunnel by making the critical flow venturi reach sonic conditions (choked flow). The flow rate was calculated during the sonic operation. The flow through the venturi was a function of the diameter of the throat and the pressure and temperature of the gas upstream. Absolute temperature was recorded using a resistive temperature device (RTD), and absolute pressure was recorded with a Viatran model 1042 AC3AAA20 pressure transducer. Therefore mass flow rate can be calculated as follows:

$$
Q=\frac{K_{V} P}{\sqrt{T}}
$$

Where,

$\mathrm{Q}=\quad$ the flow rate in scfm at standard conditions $\left(20^{\circ} \mathrm{C}\right.$ and $\left.101.3 \mathrm{Kpa}\right)$

$\mathrm{K}_{v}=$ the calibration coefficient of the venturi

$\mathrm{P} \quad=\quad$ the absolute pressure at the inlet of the venturi (Kpa)

$\mathrm{T}=$ the absolute temperature at the inlet of the venturi $\left({ }^{\circ} \mathrm{K}\right)$

The EERL was equipped with four venturis. Three of them were designed to measure 1000scfm nominally and one was used to measure nominal 400scfm. Minimum and maximum flow rates of dilute exhaust used during this study were $1000 \mathrm{scfm}$ and 2400scfm sequentially. 


\subsubsection{Full-Flow Exhaust Dilution Tunnel}

Laboratory conditions should be similar to the environment as possible in order to collect accurate emissions data from an engine. In the real world, exhaust is mixed with the ambient air. To approach real-world standards, a laboratory uses a dilution tunnel to mix exhaust with ambient air. A dilution tunnel serves several purposes other than simulating the real-world conditions in the laboratory. To avoid the condensation of the sampling lines, a dilution tunnel reduces the dew-point temperature of the exhaust. Removing water vapor from the exhaust was important as it harms the analyzers and dissolves $\mathrm{NO}_{2}$ and some of the PM constituents in water. "The dilution air also freezes post-cylinder combustion reactions”[17].

The dilution tunnel at WVU EERL was built according to the specifications outlined in CFR 40, Part 86, Subpart N [23]. It was based on the CFV-CVS (critical flow venturi constant volume sampler) system. The primary tunnel was approximately $40 \mathrm{ft}$ (12.2 m) in length and $18 \mathrm{in} .(0.45 \mathrm{~m})$ in diameter, and it was made of stainless steel to prevent oxidization and degradation. Exhaust gas was mixed with ambient air in the tunnel. This system consisted of a large centrifugal blower which draws the exhaust gas from the tunnel through the critical flow venturi. The blower was driven by a $75 \mathrm{Hp}(56.2 \mathrm{~kW}) \mathrm{GE}$

electric motor. There are four venturies altogether and three of them were $1000 \mathrm{scfm}$ and the other one was a $400 \mathrm{scfm}$. These four venturies were capable of constant volume sampling from $400 \mathrm{scfm}$ to $3400 \mathrm{scfm}$. The exhaust pipe of the engine is connected to the center of the tunnel and the gases pass through a mixing orifice plate located three feet downstream from the beginning of the mixing region [16]. Heated sampling probes are 
used to collect dilute gaseous samples from a distance of $15 \mathrm{ft}$. (4.6 m) downstream from the plate. Afterwards, samples are transferred to the analyzers via electrically heated Teflon and stainless steel lines. The primary tunnel has a probe to draw a sample for the secondary dilution tunnel, which uses the particulate matter (PM) sampling system. It is a 4 in. $(0.10 \mathrm{~m})$ stainless steel tunnel located at the end of the sampling region. The secondary dilution tunnel adds more ambient air to make sure that the soot collection filter faces temperatures of less than $125^{\circ} \mathrm{F}\left(51.7^{\circ} \mathrm{C}\right)$.

\subsubsection{Gaseous Emission Sampling System}

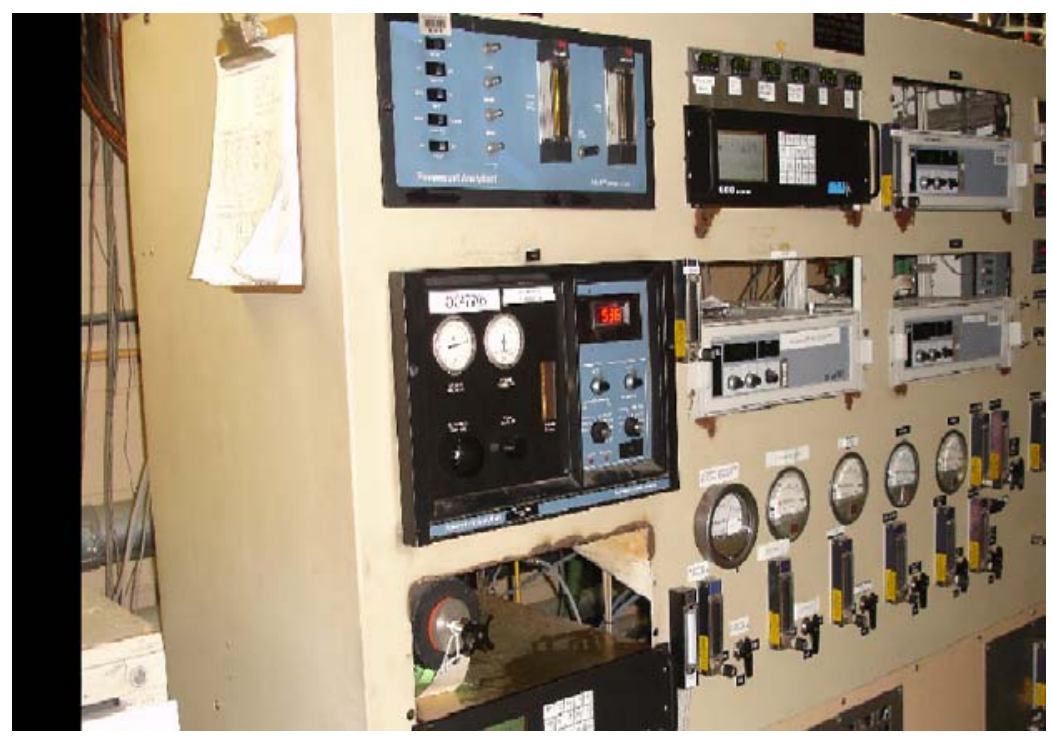

Figure 6: The EERL's gaseous emissions analyzer bench.

As shown in Figure 6, EERL gaseous sampling system consists of gas analyzers, heated filters, heated sampling probes, heated pumps, heated sampling lines and a waterremoving device. Three heated sampling probes were located in ten tunnel diameters, approximately $4.57 \mathrm{~m}$, or $180 \mathrm{in}$. in diameter, downstream from the mixing zone, to make 
sure that total turbulent mixing of the exhaust gases with the dillution air occurred [17]. Electrically heated sampling lines are used to connect sampling probes to the analyzer bench. A Fuji model No. 223-1806 temperature controller is used to control the temperature $\left(375^{\circ} \mathrm{F} \pm 10^{\circ} \mathrm{F}\right)$ of the hydrocarbon sampling line. A high temperature is used in these sampling lines to prevent condensation of hydrocarbons that have a high molecular weight. The sample lines for the $\mathrm{NOx}$ and $\mathrm{CO} / \mathrm{CO}_{2}$ are maintained at a low temperature $\left(235^{\circ} \mathrm{F} \pm 10^{\circ} \mathrm{F}\right)$. Still it maintains a high enough temperature to prevent water condensation in the line.

\subsubsection{Instrumentation Control and Data Acquisition}

WVU EERL software and hardware was used to obtain data from the laboratory. The data acquisition system uses a RTI-815F data acquisition board and Analog Devices Model 3B signal conditioning units to collect data. All the EERL data were recorded in ADC codes and then converted to engineering units with a Visual Basic based reduction program developed in WVU EERL.

\subsubsection{Intake Air flow Measurement}

To determine the intake airflow rates in the EERL, a Meriam Instruments Laminar Flow Element (LFE) was used. The LFE is made up of a series of small capillary tubes placed parallel to the direction of the airflow to make a laminar flow of air from the turbulent air flow [17]. The parameters used to calculate intake volume flow were pressure drop at the LFE and temperature and pressure of both upstream and downstream from the capillaries. The friction of the air passing through the tiny capillaries is used to create the pressure 
drop at the LFE. A MKS 223 B differential pressure transducer was used to measure the pressure drop through the LFE and a Setra Model C280E pressure transducer was used to measure absolute upstream pressure. The temperature of the inlet air upstream from the LFE was recorded with a Resistive Temperature Device (RTD). The LFE has been calibrated using the equation supplied by Meriam Instruments [23].

$$
\dot{V}_{\text {Actual }}=\left(B \times(\Delta P)+C \times(\Delta P)^{2}\right) \times\left(\frac{\mu_{\text {std }}}{\mu_{\text {flow }}}\right)
$$

Where,

$$
\begin{array}{lll}
\dot{V}_{\text {Actual }} & = & \text { volume flow rate of air through LFE } \\
\mathrm{B} & = & \text { coefficient supplied by Meriam Instruments } \\
\Delta P & = & \text { differential pressure across LFE } \\
\mathrm{C} & = & \text { coefficient supplied by Meriam Instruments } \\
\mu_{\text {std }} & = & \text { standard kinematic viscosity } \\
\mu_{\text {flow }} & = & \text { actual flow kinematic viscosity }
\end{array}
$$

A correction factor was used to account for viscosity variations and was as follows [17]:

$$
\begin{aligned}
& \text { Correction Factor }=\left(\frac{529.67}{459.67+T\left({ }^{\circ} F\right)}\right) \times\left(\frac{181.87}{\mu g}\right) \\
& \mu g=\frac{14.58+\left(\frac{459.67+T\left({ }^{\circ} F\right)}{1.8}\right)^{1.5}}{110.4+\left(\frac{459.67+T\left({ }^{\circ} F\right)}{1.8}\right)}
\end{aligned}
$$


The LFE used for laboratory testing at EERL was a Meriam Model 50MC2-4 LFE with inside diameter 4 in. and maximum flow rate of $400 \mathrm{cfm}$ [18].

\subsubsection{Fuel Metering System}

The fuel metering system was important to create accurate exhaust dilution ratios. "The total tunnel flow rates were determined with the CFV-CVS system, but the predicament lies in the understanding of raw exhaust mass flow rates" [17]. Exhaust flow rate cannot be determined directly because of high particulate matter concentrations, elevated temperatures and engine backpressure limits. Therefore, airflow rate and engine fuel consumption rate were used to calculate exhaust mass flow rate.

Max Flow Media 710 Series Fuel Measurement System was used to measure the fuel flow rate [18]. To maintain a constant pressure of $30 \mathrm{psi}$ (206.8 kPa), fuel was drawn from a storage tank to the vapor removal device in the lab through a filter. Then the fuel went through a bypass system. The excess fuel was sent through a pressure regulator to a heat exchanger and back to the storage tank. The heat exchanger used the excess fuel to cool down the fuel from the engine. The fuel that does not go back to the tank is directed to a Model 214 positive displacement flow meter and to a level-controlled tank. The level-controlled tank mixes the metered fuel with the unused engine return fuel, which was already cooled by the heat exchanger. It also maintains a constant volume to calculate the fuel used by the engine. A secondary fuel pump was used to get a high pressure in diesel injection systems, which need a high pressure, such as a common rail system. A bubble detector was used to control a solenoid valve and the engine fuel lines 
to extirpate any vapor in the system. The fuel flows from a solenoid valve to an external heat exchanger to maintain a constant fuel temperature.

\subsubsection{Calibration of Gas Analyzers}

Before each test, each gas analyzer was calibrated for zero and span values with $1 \%$ accuracy traceable to NIST standards. A ten-point calibration curve was plotted afterwards. A SGD-710C gas divider was used to perform the calibration process. It has two inlet ports for span gas and for zero gas and an outlet port to send the blended gas to the required analyzer. The gas was supplied at increments of $10 \%$ of span concentration. Mass flow rate of a capillary of the gas divider was proportional to the pressure drop across the particular capillary. There were ten similar capillaries in the gas divider SGD710C. The EERC emissions bench uses Fuji Model 223-1806 temperature controllers to control the temperatures.

\subsubsection{Exhaust Gas Analyzers}

WVU EERL analysis bench is equipped with laboratory grade gas analyzers to measure NOx, $\mathrm{CO}_{2}$, THC and CO. A brief description of each analyzer is given below.

\subsubsection{Nitrogen Oxide Analyzer [20]}

The NO/NOx analyzer used was a Rosemount Model 955 Chemiluminescent analyzer. This analyzer was capable of detecting concentrations of $\mathrm{NO}$ or $\mathrm{NO}$ and $\mathrm{NO}_{2}$ together, which is also known as NOx. In the NO mode, the analyzer quantitatively converts the $\mathrm{NO}$ in the sample into $\mathrm{NO}_{2}$ by gas-phase oxidation with molecular ozone $\left(\mathrm{O}_{3}\right)$. Ozone for 
this reaction was produced by passing air or oxygen over an ultra violet source. During the oxidation process, approximately $10 \%$ of the $\mathrm{NO}_{2}$ molecules were electrically excited, followed by an immediate return to the non-excited state. This conversion process generates a photon emission. Then a photomultiplier tube was used to identify the photon emission quantity, which was proportional to the NO amount present in the sample. The internal NOx converter was maintained between $660^{\circ} \mathrm{F}\left(350^{\circ} \mathrm{C}\right)$ and $750^{\circ} \mathrm{F}$ $\left(399^{\circ} \mathrm{C}\right)$ en route for maximum $\mathrm{NO}_{2}$ conversion efficiency. If only the determination of NO concentration was desired, the sample could bypass the converter and be measured directly by selecting the NO mode of the analyzer. In the case of NOx detection, the total analyzer response would determine the amount of NO present in the original sample, as well as the $\mathrm{NO}$ created through the dissociation of $\mathrm{NO}_{2}$ in the converter.

\subsubsection{Carbon Monoxide/Carbon Dioxide Analyzers}

The gaseous constituents of $\mathrm{CO}$ and $\mathrm{CO}_{2}$ were determined with Horiba Model AIA210LE and Horiba Model AIA-210 Non-Dispersive Infrared (NDIR) analyzers. An NDIR analyzer operates utilizing the principle of infrared light absorption. NDIR analyzers use the exhaust gas species being measured to detect itself by the principle of selective absorption, in which the infrared energy of a particular wavelength, specific to a certain gas, will be absorbed by that gas. Infrared energy of other wavelengths will be transmitted by that gas, just as the absorbed wavelength will be transmitted by other gases. This sort of NDIR analyzer does not create a linear output, so calibration curves were generated for the analyzers before each testing session began [22]. 


\subsubsection{Hydrocarbon Analyzer}

A Rosemount Model 402 Heated Flame Ionization Detector (HFID) analyzer was utilized to measure the Total Hydrocarbon (THC) in the diesel exhaust. By counting the elemental carbon atoms in the exhaust sample, the analyzer determined the amount of hydrocarbon in the exhaust stream. The sample gas flow was synchronized and flowed through a hydrogen/helium-fueled flame that caused the production of ions. Ions are produced when a regulated flow of sample gas flows through the flame and are collected on the polarized electrodes causing current to flow through the associated electronic measuring circuitry. This assimilation of ions by the electrodes produces a small current flow, which is then quantified and related to the number of carbon atoms contained in the exhaust sample. Hydrocarbons are measured wet, which means that the water vapor was not evaporated out from the sample going into the HC analyzer. The multiplier switch, which is located on the front of the Model 402, allows selection of measurement ranges which best suits the resolution for the particular gas concentration being sampled. The largest scale of the measurement range of the HC analyzer goes up to 250,000 ppm [21].

\subsection{Steady State Test}

The MY1992, DDC Series 60 heavy duty diesel engine was tested on an engine dynamometer over a sequence of steady-state modes. Each run was 30 minutes. The CMEMS was tested on two different steady states, test A and test B. Test A had four modes and test B had five modes as shown in the following tables. 
Table 4: Steady state test A

\begin{tabular}{|c|c|c|c|}
\hline Mode & $\begin{array}{c}\text { Set speed } \\
(\mathrm{rpm})\end{array}$ & $\begin{array}{c}\text { Set torque } \\
(\mathrm{Nm})\end{array}$ & $\begin{array}{c}\text { Mode duration } \\
(\mathrm{sec})\end{array}$ \\
\hline 1 & 600 & 0 & 20 \\
\hline 2 & 1850 & 1500 & 600 \\
\hline 3 & 1250 & 675 & 600 \\
\hline 4 & 600 & 10 & 600 \\
\hline
\end{tabular}

Time vs. speed and torque for steady state test A

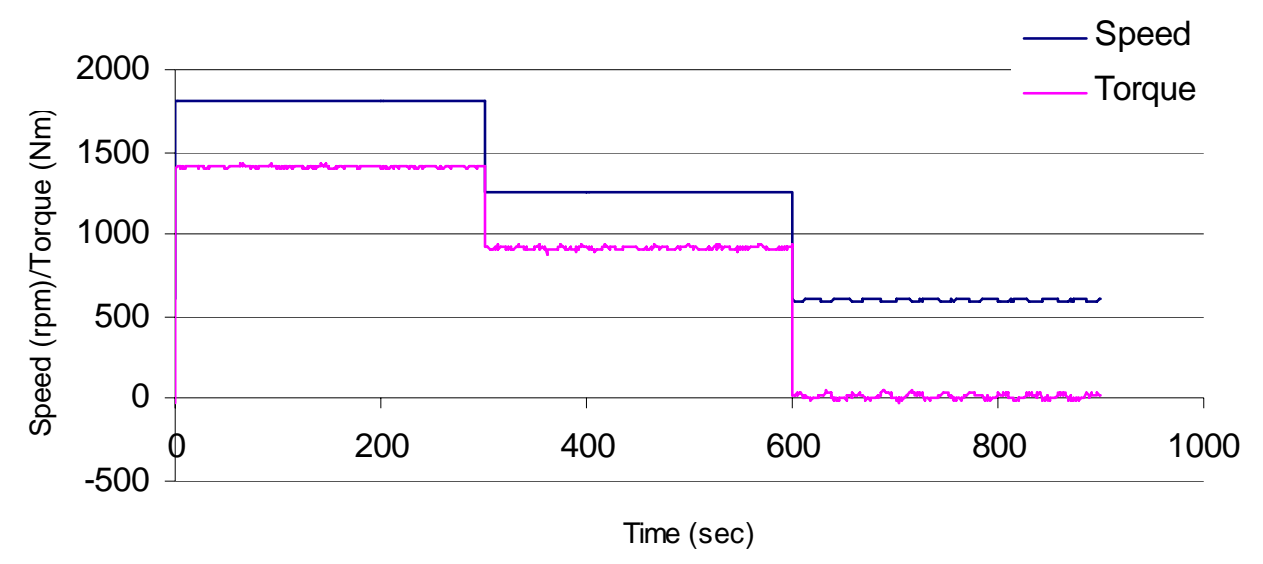

Figure 7:Time vs. speed and torque for steady state test A

Table 5: Steady state test B

\begin{tabular}{|c|c|c|c|}
\hline Mode & $\begin{array}{c}\text { Set speed } \\
(\mathrm{rpm})\end{array}$ & $\begin{array}{c}\text { Set torque } \\
(\mathrm{Nm})\end{array}$ & $\begin{array}{c}\text { Mode duration } \\
(\mathrm{sec})\end{array}$ \\
\hline 1 & 600 & 10 & 20 \\
\hline 2 & 1500 & 1500 & 600 \\
\hline 3 & 1500 & 650 & 600 \\
\hline 4 & 1500 & 10 & 600 \\
\hline 5 & 1500 & -200 & 600 \\
\hline
\end{tabular}


Time vs. speed and torque for steady state test B

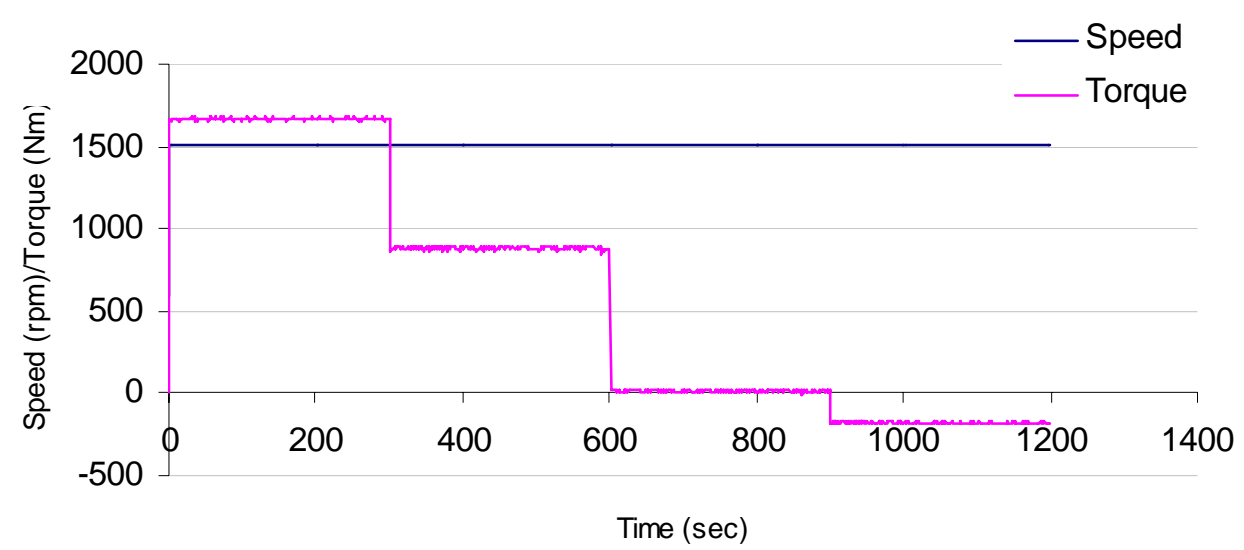

Figure 8: Time vs. speed and torque for steady state test B

\subsection{Transient Test}

\subsubsection{FTP}

The FTP (Federal Test Procedure) transient heavy-duty cycle used for on-road heavy-duty engine emissions measurement in USA [CFR Title 40, Part 86.1333]. The transient test simulates various heavy-duty vehicles and routes in USA and since the cycle includes "motoring" the AC or DC electric dynamometer should be capable of absorbing and supplying power [42]. CMEMS was tested according to Federal Transient Procedure (FTP) on a 1992 Detroit Diesel Corporation (DDC) Series 60 heavy duty diesel engine, in a controlled laboratory environment with laboratory grade analyzers. Both cold start and hot start FTP tests were conducted. A FTP test run for $1200 \mathrm{sec}$ having a pause between each cycle for $1200 \mathrm{sec}$. An average speed of a run is $30 \mathrm{~km} / \mathrm{hr}$ and equivalent to a distance travel for $10.3 \mathrm{~km}$ [42]. 
Time vs. speed and torque for FTP test

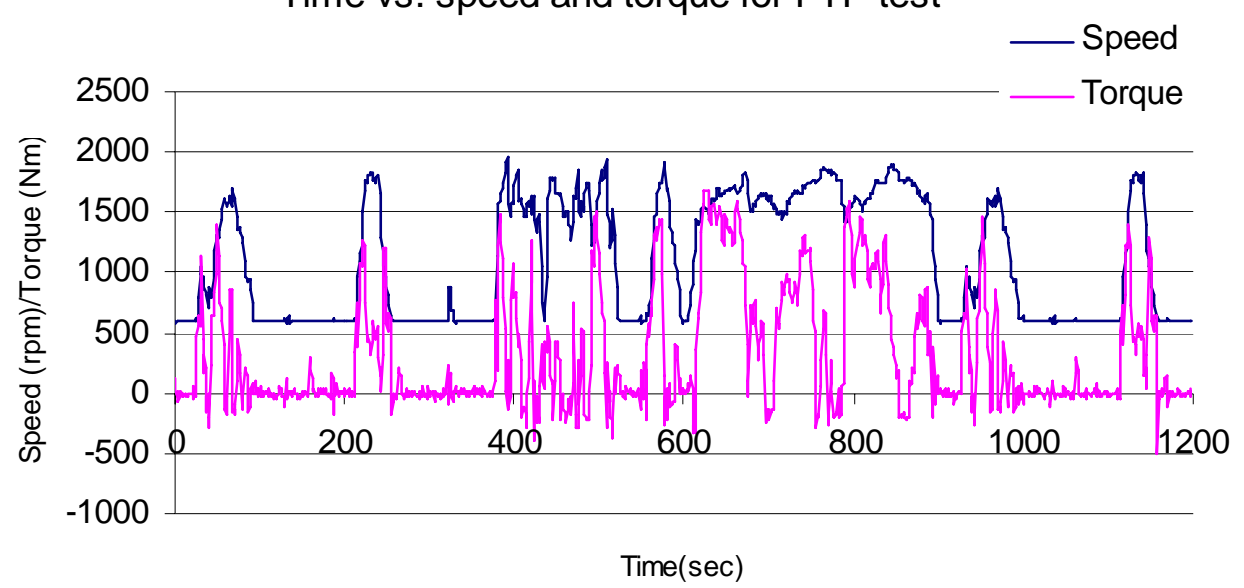

Figure 9: Time vs. speed and torque for steady state test B

\subsubsection{Simulated Transient Cycle}

CMEMS was tested on a simulated transient test in the laboratory on a 1992 Detroit Diesel Corporation (DDC) Series 60 heavy duty diesel engine. The transient test performed in the laboratory was a simulated on-road Sabraton-Bruceton Mills test. The test was a 40 minute run. The speed varied from around $600 \mathrm{rpm}$ up to $1900 \mathrm{rpm}$ and torque was in the range of $-200 \mathrm{ft}-\mathrm{lb}$ to $1300 \mathrm{ft}-\mathrm{lb}$.

Time vs. speed and torque for simulated run

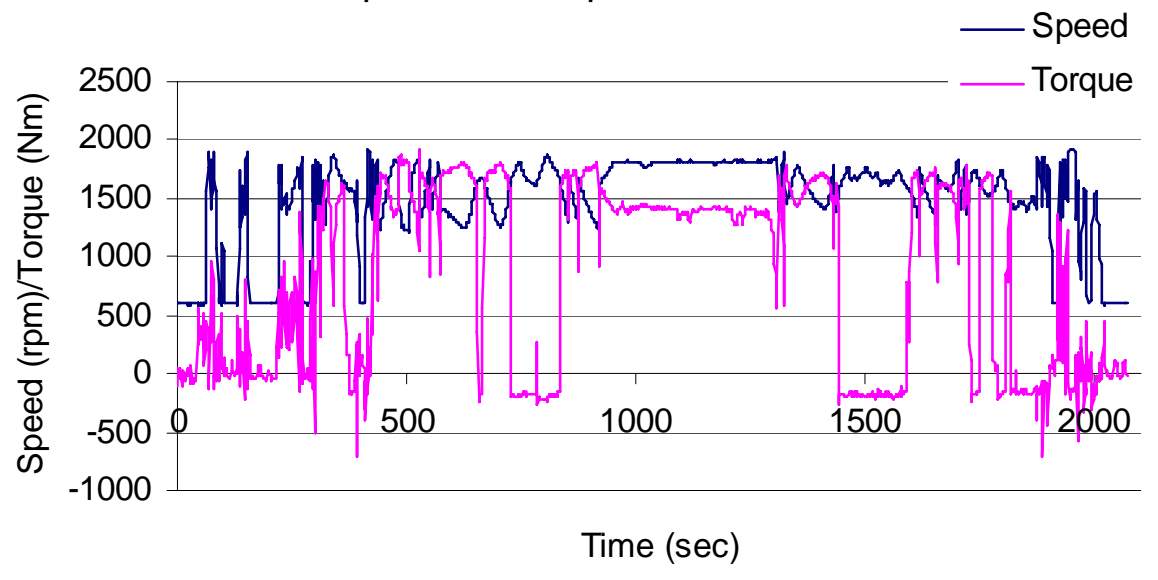

Figure 10: Time vs. speed and torque for the simulated test 


\subsection{MEMS Testing Setup}

Figure 12 shows a schematic diagram of MEMS as tested on the vehicle.

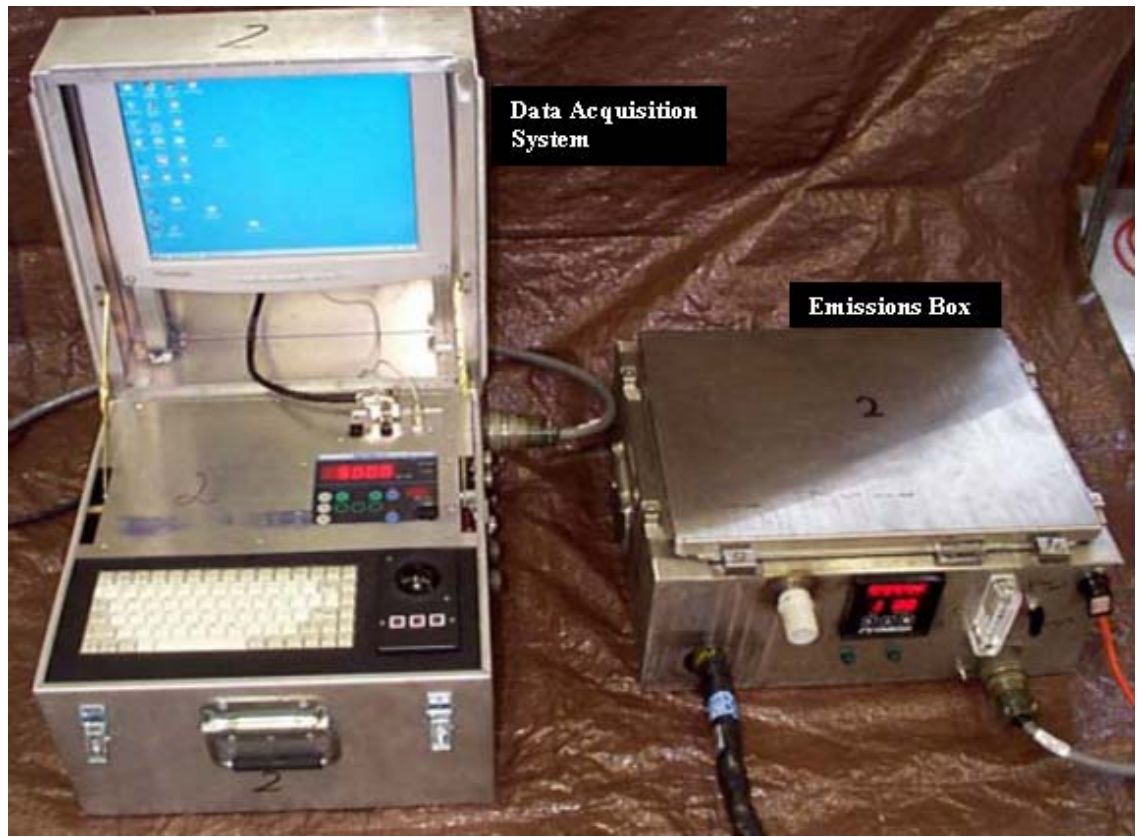

Figure 11: MEMS system [44]

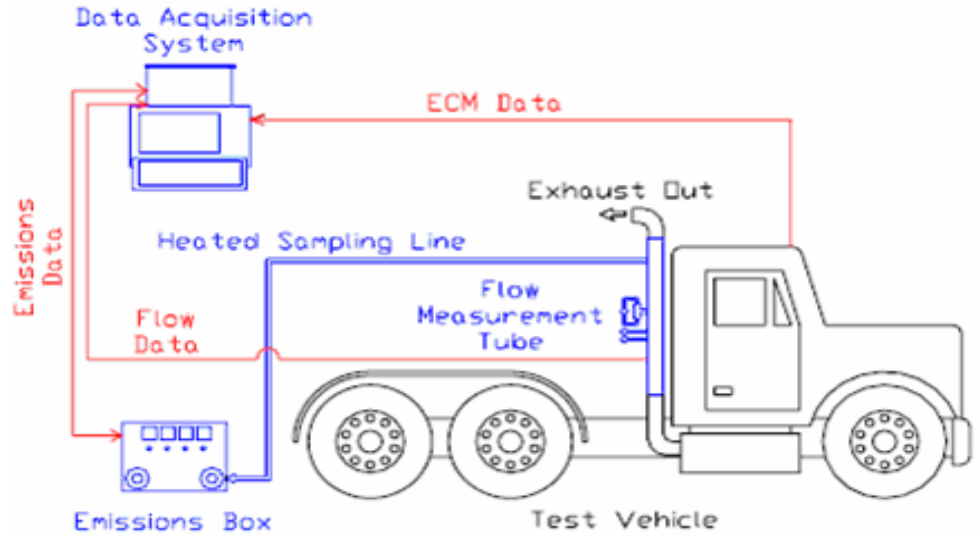

Figure 12: Schematic of the MEMS as tested on a vehicle [16] 


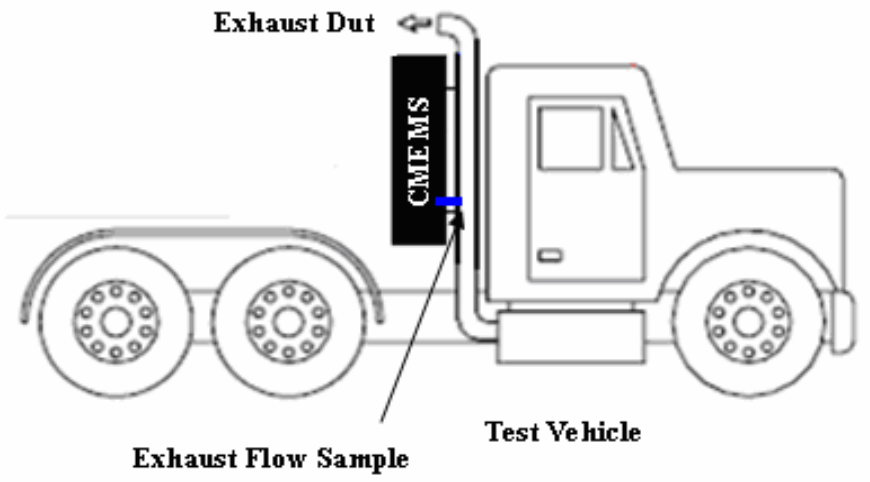

Figure 13: Schematic of the CMEMS as tested on a vehicle

\subsection{On-road Test}

CMEMS was mounted on the tailpipe of a diesel truck, as shown in Figure 14, to test the performance of the system under real-world driving conditions. Results were compared with MEMS which was also mounted on the truck. Two routes were used for the testing which consisted of highway and urban roads. The Morgantown Route and the Bruceton Mills Route were the routes used to test CMEMS.

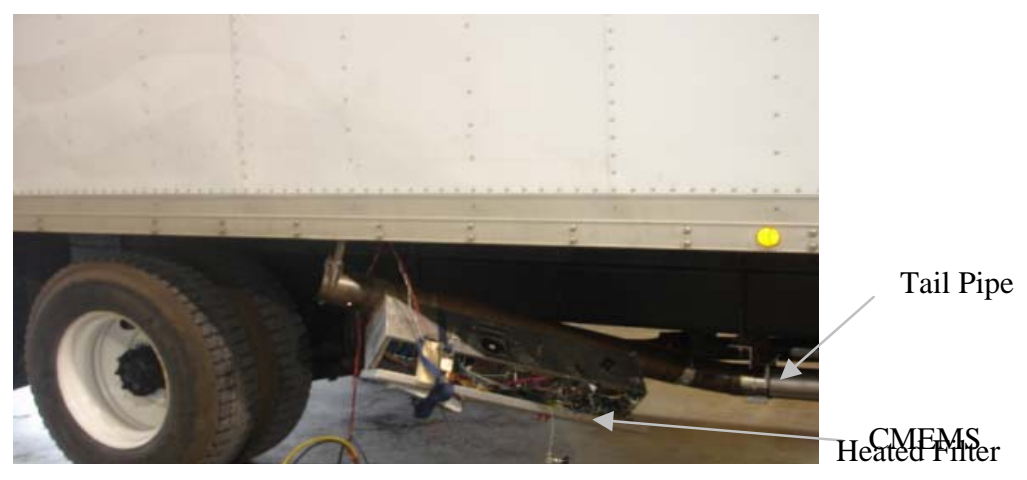

Figure 14: CMEMS was mounted on the tail pipe of the truck 
Time vs. speed and torque for on-road test $A$

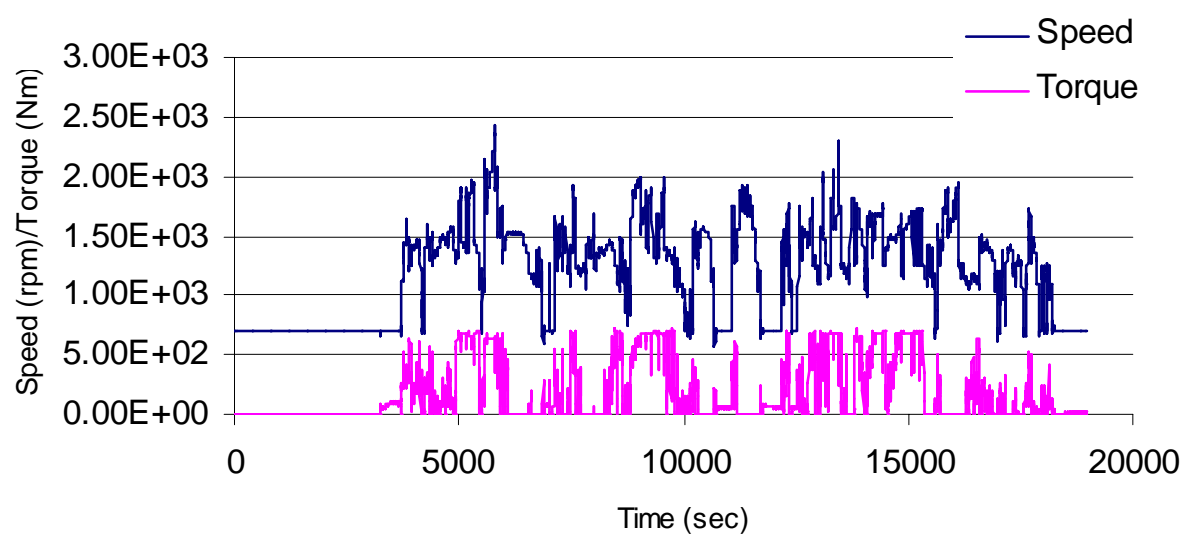

Figure 15: Time vs. speed and torque for on-road test A

Time vs. speed and torque for on-road test B

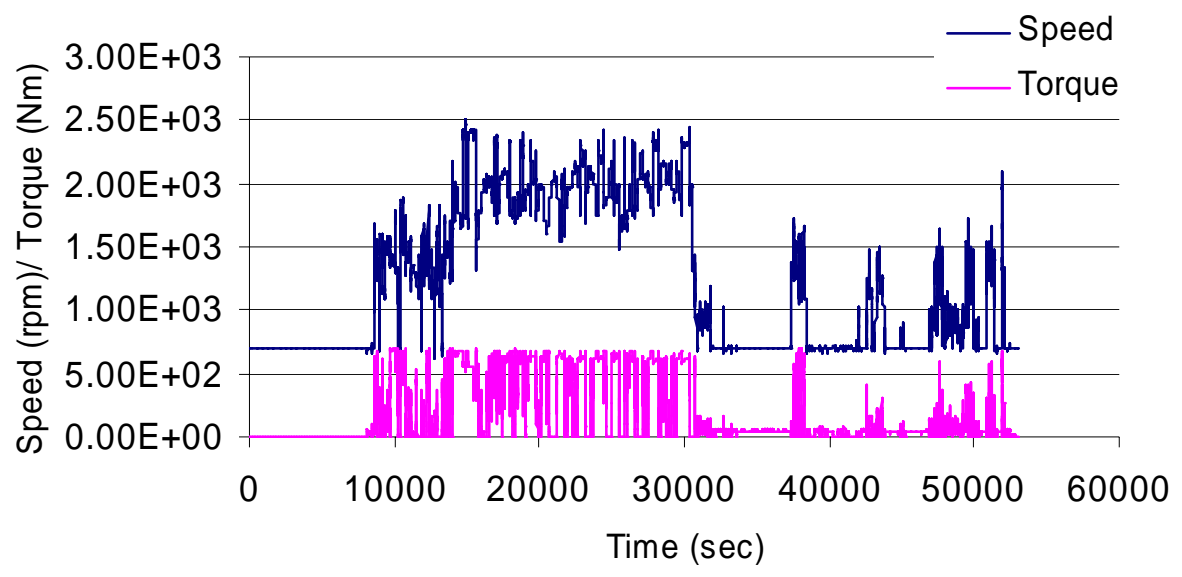

Figure 16: Time vs. speed and torque for on-road test A 


\section{Results and Discussion}

The performance of the CMEMS was evaluated in the WVU Engine Emissions Research Laboratory under a range of engine dynamometer tests, namely, EPA regulated laboratory conditions for Federal Test Procedure (FTP) test, steady state tests and a simulated on-road transient test. CMEMS was also tested on an on-road truck alongside MEMS to evaluate its performance under real-world conditions. Test results are presented in this section. Data for CMEMS was post-processed using MATLAB programs (see Appendix A). An Infinite Impulse Response (IIR) Filter was used in the MATLAB program to filter out the noise in the Annubar absolute pressure and Annubar differential pressure signals.

\subsection{Steady State Test Results}

Table 6 compares the brake specific $\mathrm{CO}_{2}$ and NOx emissions for test A and test $\mathrm{B}$.

Table 6: Brake-specific NOx and $\mathrm{CO}_{2}$ results for CMEMS vs. EERL on steady state test

\begin{tabular}{|c|c|c|c|c|}
\hline $\begin{array}{r}\text { Test } \\
\text { Type }\end{array}$ & $\begin{array}{c}\text { Gas } \\
\text { Type }\end{array}$ & $\begin{array}{c}\text { CMEMS } \\
\text { (g/bhp-hr) }\end{array}$ & $\begin{array}{c}\text { EERL } \\
\text { (g/hhp-hr) }\end{array}$ & $\begin{array}{c}\text { Error } \\
\%\end{array}$ \\
\hline Test A & $\mathrm{CO}_{2}$ & 451.6 & 455.1 & 0.7 \\
\cline { 2 - 5 } & NOx & 7.3 & 7.7 & 5.1 \\
\hline \multirow{2}{*}{ Test B } & $\mathrm{CO}_{2}$ & 487.5 & 465.8 & -4.6 \\
\cline { 2 - 5 } & $\mathrm{NOx}$ & 7.6 & 7.7 & 1.2 \\
\hline
\end{tabular}

Differences in mass emissions rates as obtained by CMEMS and the EERL are shown in Table 7. 
Table 7: Mass flow rate difference of $\mathrm{NOx}$ and $\mathrm{CO}_{2}$ for $\mathrm{CMEMS}$ vs. EERL on steady state tests

\begin{tabular}{|c|c|c|c|c|}
\hline Test & Gas Type & Integrated & Integrated & Error \\
Type & & CMEMS (g/s) & EERL (g/s) & $\%$ \\
\hline Test A & $\mathrm{CO}_{2}$ & $1.9 \times 10^{4}$ & $2.0 \times 10^{4}$ & 5.0 \\
\cline { 2 - 5 } & $\mathrm{NOx}$ & 307.9 & 333.6 & 7.7 \\
\hline Test B & $\mathrm{CO}_{2}$ & $1.9 \times 10^{4}$ & $2.1 \times 10^{4}$ & 9.5 \\
& $\mathrm{NOx}$ & 296.9 & 340.3 & 12.7 \\
\hline
\end{tabular}

CMEMS was in agreement with the EERL continuous trend for both gases during test A (Figure 17, Figure 18). The error difference for g/s measurements was lower than 3.4\%, and good linearity was observed (Figure 19, Figure 20).

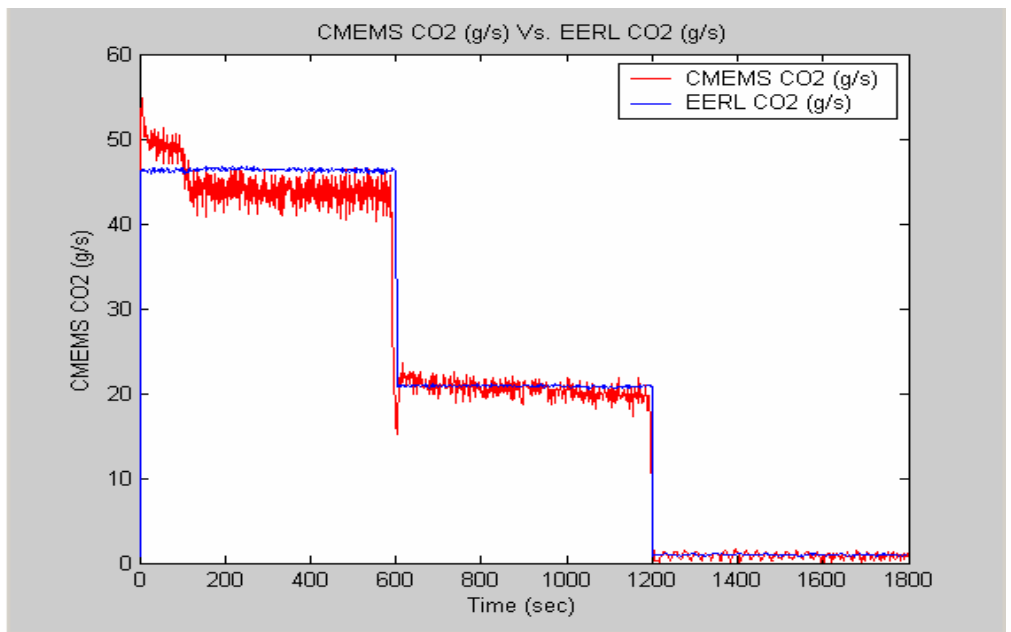

Figure 17: $\mathrm{CO}_{2}$ comparison of CMEMS and EERL results on test $\mathrm{A}$ 


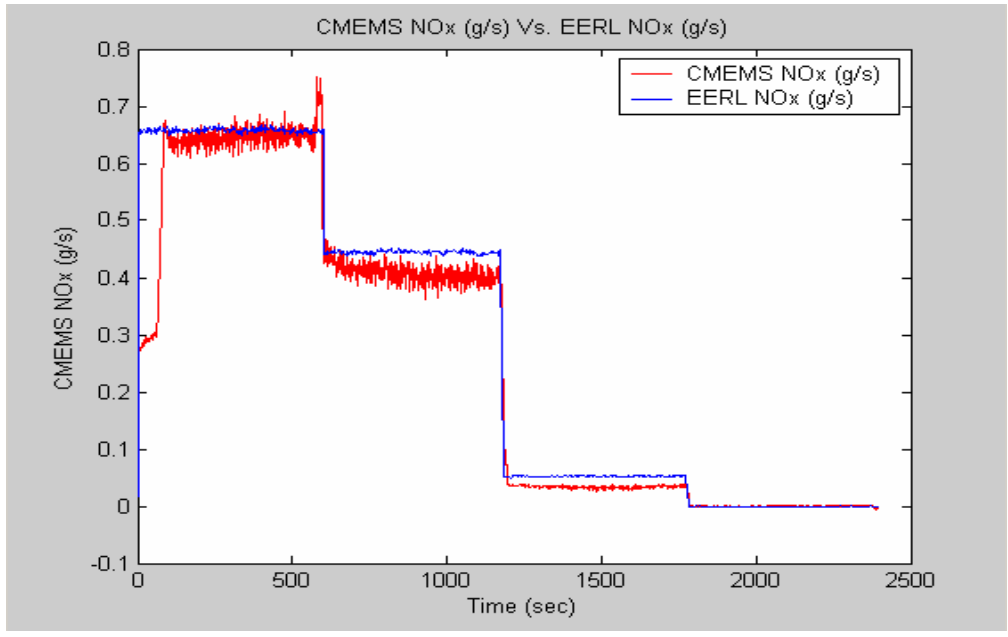

Figure 18: NOx comparison of CMEMS and EERL results on test A

As in the graphs initially, CMEMS over predicts $\mathrm{CO}_{2}$ and under predicts $\mathrm{NOx}$ mass flow rates and concentrations. This can be seen in test $\mathrm{B}$ as well. Therefore, it can be concluded that the $\mathrm{CO}_{2}$ and NOx sensors take some time to read the correct value.

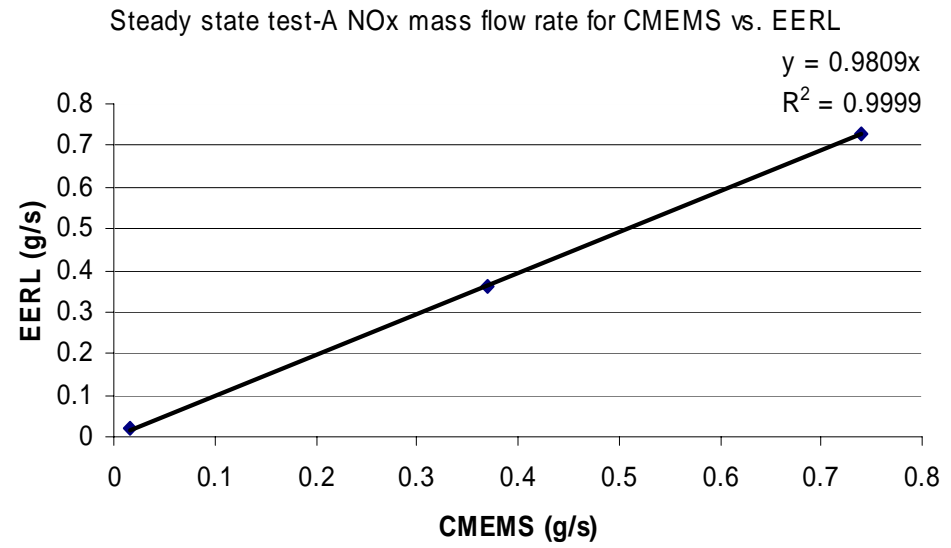

Figure 19: CMEMS vs. EERL NOx mass flow rate linearity comparison for steady state test $\mathrm{A}$ 


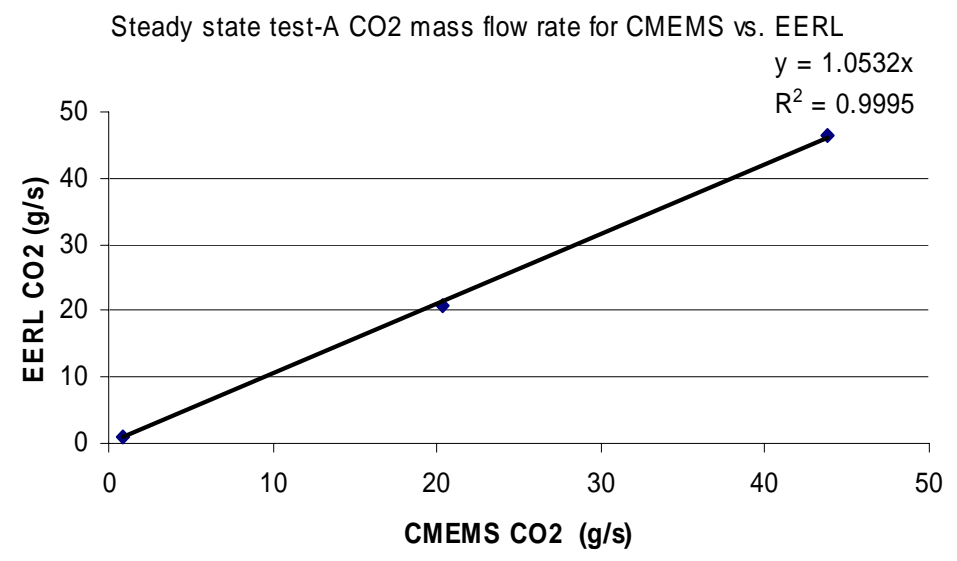

Figure 20: $\mathrm{CMEMS}$ vs. EERL $\mathrm{CO}_{2}$ mass flow rate linearity comparison for transient test A

Differences between CMEMS and the EERL were less than 6.2\% during test B. CMEMS yielded a lower mass emissions rate for both gases at the intermediate loads (Figure 21, Figure 22).

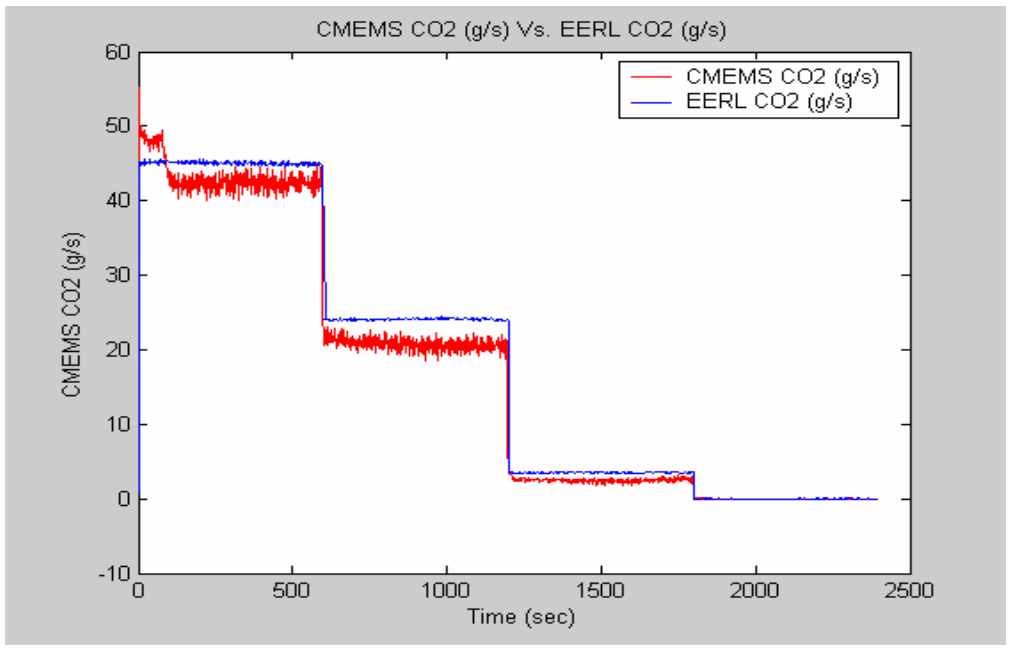

Figure 21: $\mathrm{CO}_{2}$ comparison of CMEMS and EERL results on test $\mathrm{B}$ 


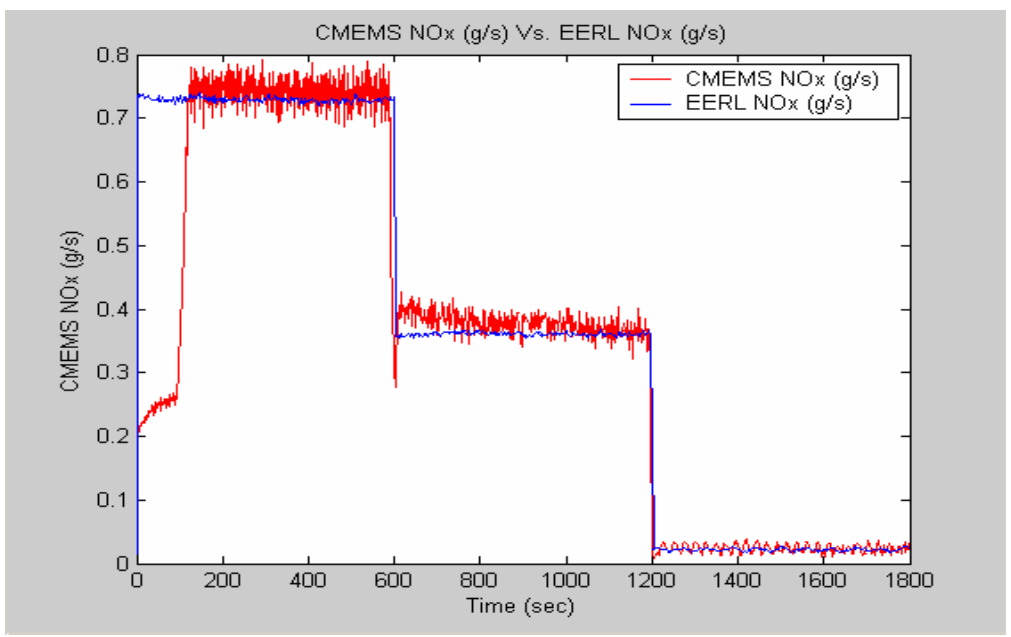

Figure 22: NOx comparison of CMEMS and EERL results on test B

Average BSNOx values for steady state tests

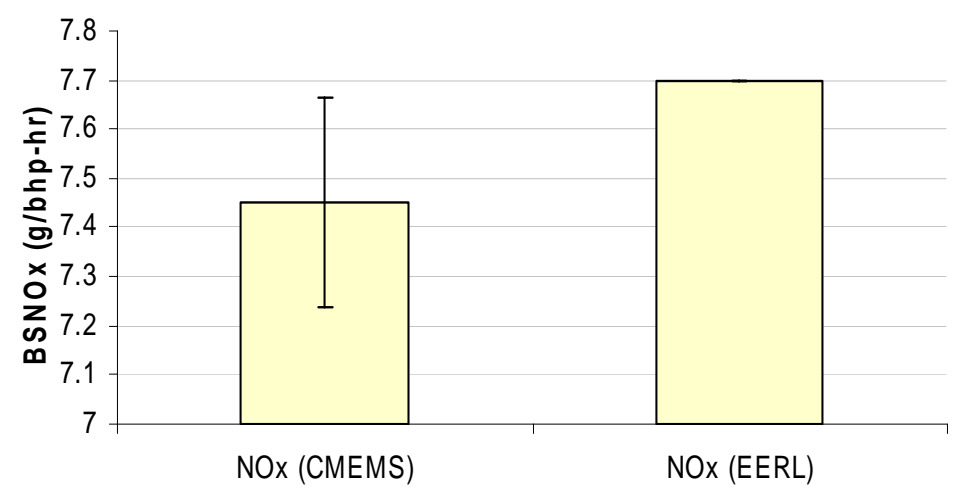

Figure 23: Average BSNOx emissions for steady state tests. (Error bars represent one standard deviation) 
Average $\mathrm{BSCO} 2$ values for steady state tests

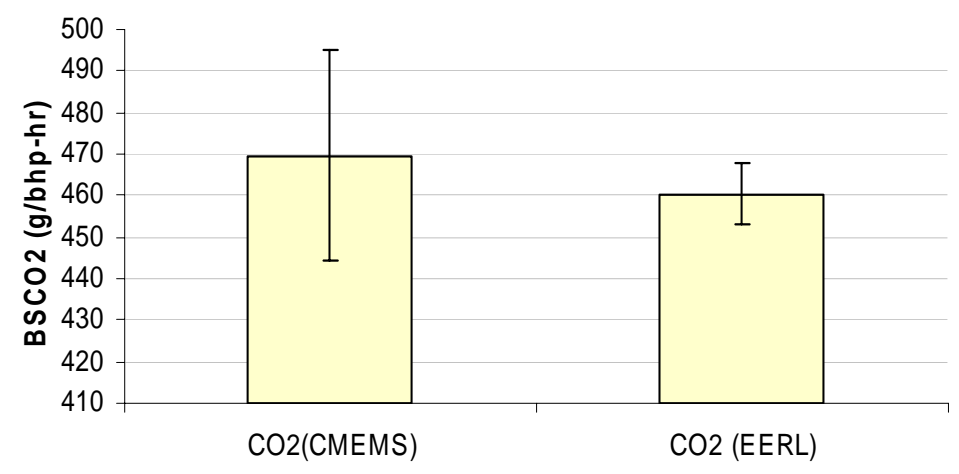

Figure 24: Average $\mathrm{BSCO}_{2}$ emissions for steady state tests. (Error bars represent one standard deviation)

\subsection{Transient cycle}

\subsubsection{FTP}

Table 8 shows the integrated results obtained for brake specific $\mathrm{NOx}$ and $\mathrm{CO}_{2}$ emissions during FTP tests. Brake specific emissions of $\mathrm{CO}_{2}$ with CMEMS showed differences ranging from $1.3 \%$ to $-8.8 \%$ in comparison to EERL. Brake specific emissions of NOx ranges from $4.4 \%$ to $11.1 \%$.

Table 8: Brake-specific NOx and $\mathrm{CO}_{2}$ results for CMEMS vs. EERL on FTP test

\begin{tabular}{|c|c|c|c|c|}
\hline Test & Gas Type & CMEMS & EERL & Error \\
Type & & (g/Bhp-hr) & (g/Bhp-hr) & $\%$ \\
\hline \multirow{2}{*}{ FTP 01 } & $\mathrm{CO}_{2}$ & 516.4 & 523.1 & 1.2 \\
\cline { 2 - 5 } & $\mathrm{NOx}$ & 4.3 & 4.5 & 4.4 \\
\hline FTP 02 & $\mathrm{CO}_{2}$ & 545.6 & 522.3 & -4.4 \\
\hline & $\mathrm{NOx}^{2}$ & 4.0 & 4.5 & 11.1 \\
\hline FTP 03 & $\mathrm{CO}_{2}$ & 563.8 & 520.4 & -8.3 \\
\hline & $\mathrm{NOx}^{2}$ & 4.1 & 4.5 & 8.8 \\
\hline
\end{tabular}


Figure 25 and Figure 26 show plots of mass emissions rates $(\mathrm{g} / \mathrm{s})$ of $\mathrm{NOx}$ and $\mathrm{CO}_{2}$ as measured by the CMEMS and EERL. It was observed that the continuous traces from CMEMS exhibited higher peaks than the EERL during the transient tests. This may be attributed to the fact that CMEMS was sampling raw exhaust in the exhaust transfer tube and the EERL sampling system was drawing a dilute exhaust from the primary dilution tunnel. The dispersion in the dilution tunnel may explain the lower peaks on the EERL traces. Other differences in the trend can be observed in the zones where the engine was operating at high loads for several seconds. During these periods, EERL measured higher NOx levels than CMEMS. This observation, which was also evidenced during the steady state tests, might be due to the quench effect in the EERL chemiluminescence analyzer, due to water vapor.

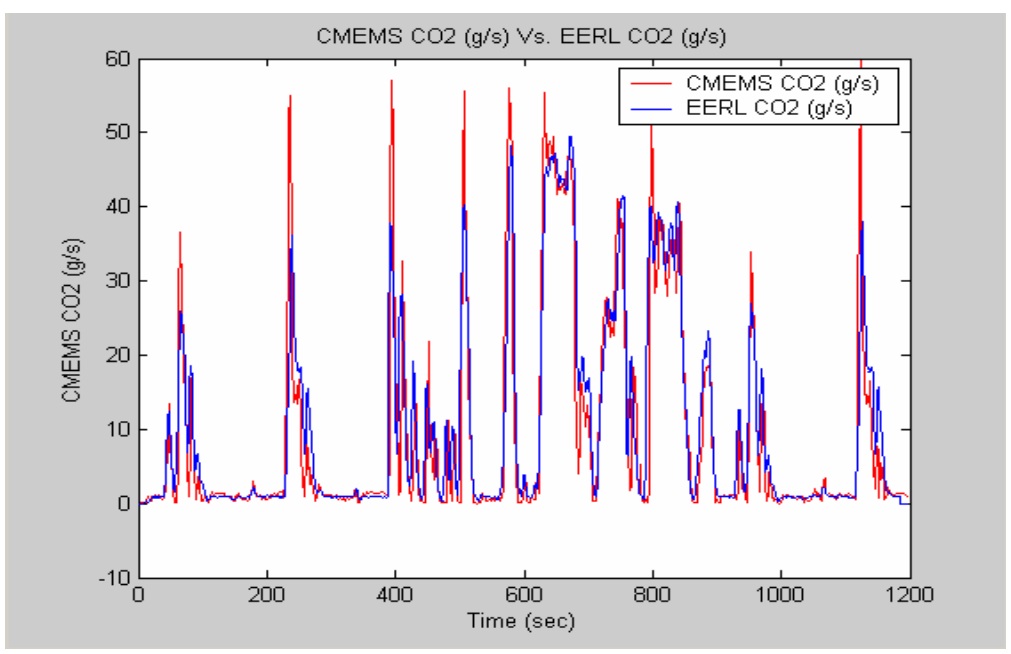

Figure 25: $\mathrm{CO}_{2}$ comparison of CMEMS and EERL results on FTP1 


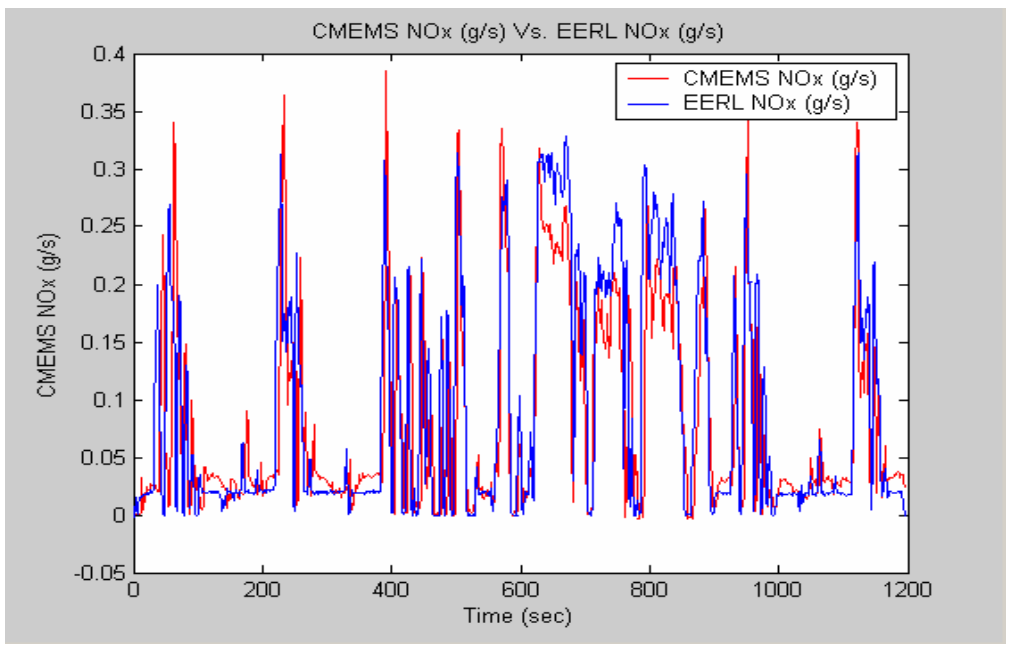

Figure 26: NOx comparison of CMEMS and EERL results on FTP1

Standard deviation of 0.15 and 3.69 of COV were calculated for NOx and 23.91 of standard deviation and 4.41 of COV were observed over the three FTPs of $\mathrm{CO}_{2}$ (Figure 27, Figure 28)

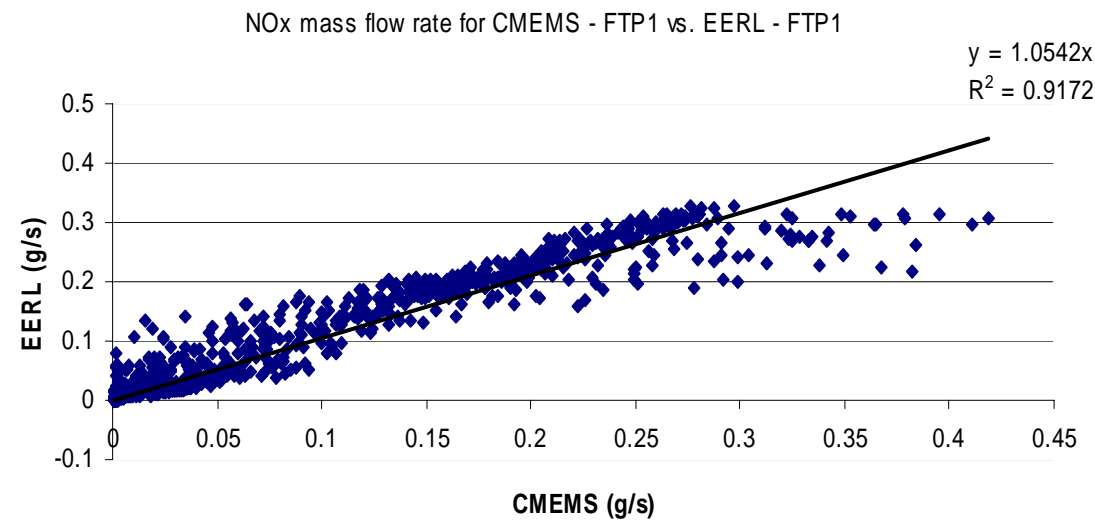

Figure 27: CMEMS vs. EERL NOx mass flow rate linearity comparison for FTP1 


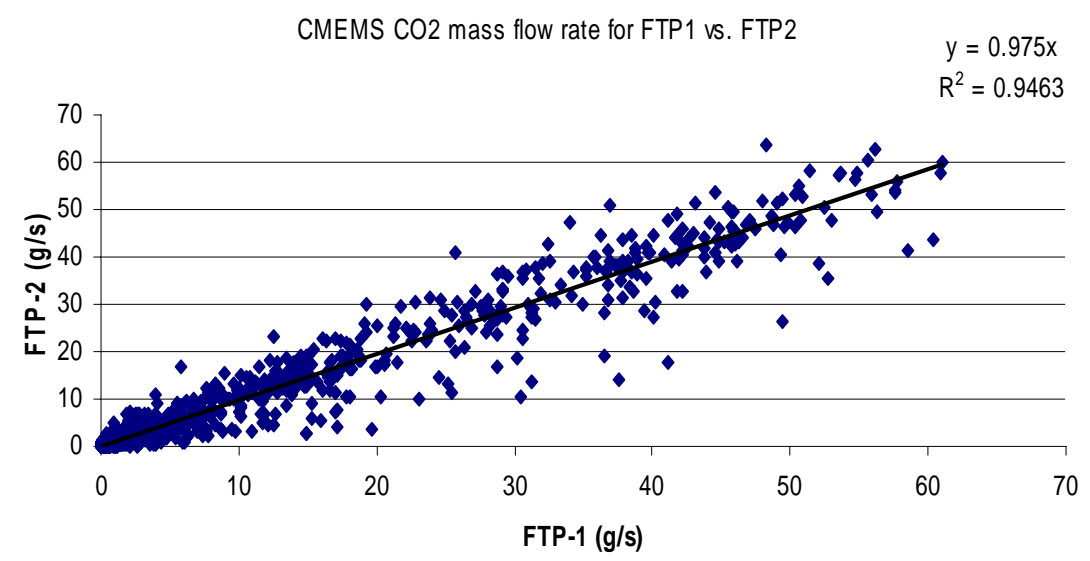

Figure 28: CMEMS $\mathrm{CO}_{2}$ mass flow rate linearity comparison of FTP1 vs. FTP2

\subsubsection{Simulated on-road cycle}

Good agreement was found between CMEMS and the EERL over the simulated cycle. As shown below, Table 9 compares the CMEMS and EERL brake specific $\mathrm{NOx}$ and $\mathrm{CO}_{2}$ emissions over the simulated on-road cycle against the EERL results. Table 10 shows the mass flow rate difference between CMEMS and laboratory results.

Table 9: Brake-specific NOx and $\mathrm{CO}_{2}$ results for CMEMS vs. EERL on simulated run

\begin{tabular}{|c|c|c|c|c|}
\hline Test Type & Gas Type & $\begin{array}{l}\text { CMEMS } \\
\text { (bhp-hr) }\end{array}$ & $\begin{array}{c}\text { EERL } \\
\text { (bhp-hr) }\end{array}$ & $\begin{array}{c}\text { Error } \\
\%\end{array}$ \\
\hline Simulated & $\mathrm{CO}_{2}$ & 464.1 & 464.2 & 0.02 \\
\hline Test 1 & $\mathrm{NOx}$ & 5.4 & 5.6 & 3.5 \\
\hline Simulated & $\mathrm{CO}_{2}$ & 466.9 & 463.9 & -0.6 \\
\hline Test 2 & NOx & 5.4 & 5.5 & 1.8 \\
\hline
\end{tabular}


Table 10: Mass flow rate difference for $\mathrm{NOx}$ and $\mathrm{CO}_{2}$ for $\mathrm{CMEMS} \mathrm{vs.} \mathrm{EERL} \mathrm{on}$ simulated test

\begin{tabular}{|c|c|c|c|c|}
\hline Test & Gas Type & Integrated & Integrated & Error \\
Type & & CMEMS(g/s) & EERL(g/s) & $\%$ \\
\hline Transient & $\mathrm{CO}_{2}$ & $5.0 \times 10^{4}$ & $5.1 \times 10^{4}$ & 1.4 \\
\hline Test 1 & $\mathrm{NOx}$ & 565.9 & 604.4 & 6.3 \\
\hline Transient & $\mathrm{CO}_{2}$ & $5.1 \times 10^{4}$ & $5.0 \times 10^{4}$ & 0.6 \\
\hline \multirow{2}{*}{ Test 2 } & $\mathrm{NOx}$ & 572.6 & 604.1 & -1.8 \\
\hline
\end{tabular}

CMEMS mass emissions rate $(\mathrm{g} / \mathrm{s})$ compares well with the one measured by the EERL and the tests are repeatable (Figure 29, Figure 30). A good agreement was observed between the EERL and CMEMS for both gases (Figure 31, Figure 32).

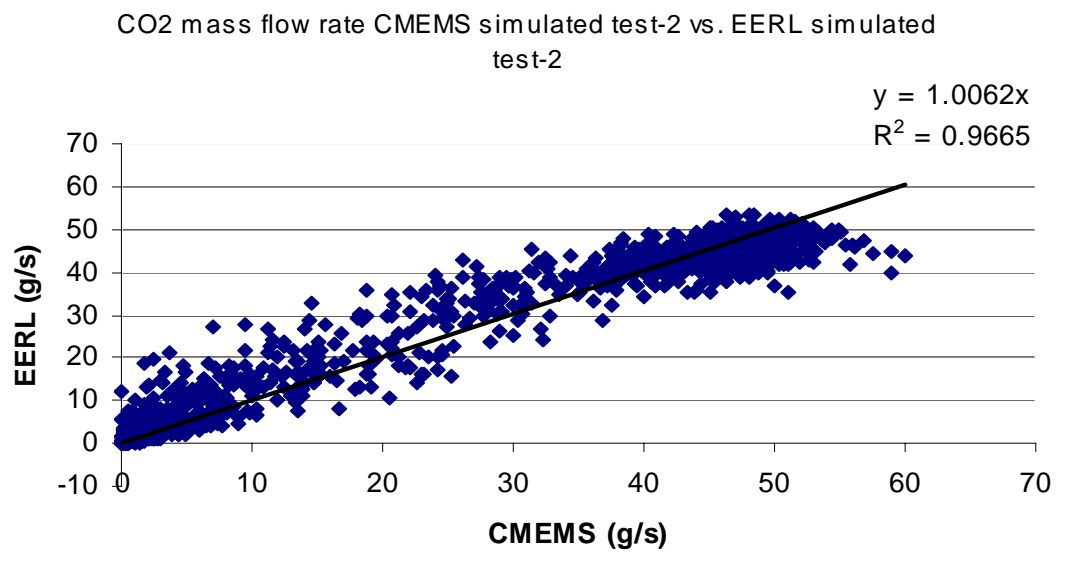

Figure 29: CMEMS vs. EERL $\mathrm{CO}_{2}$ mass flow rate linearity comparison for simulated test-2 


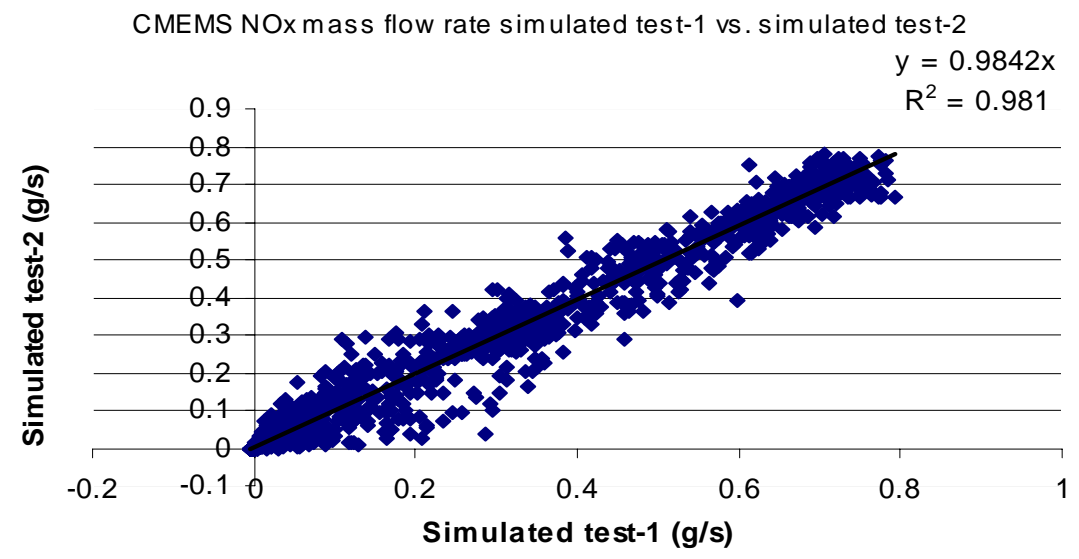

Figure 30: CMEMS NOx mass flow rate linearity comparison for transient test-1 vs. simulated test-2

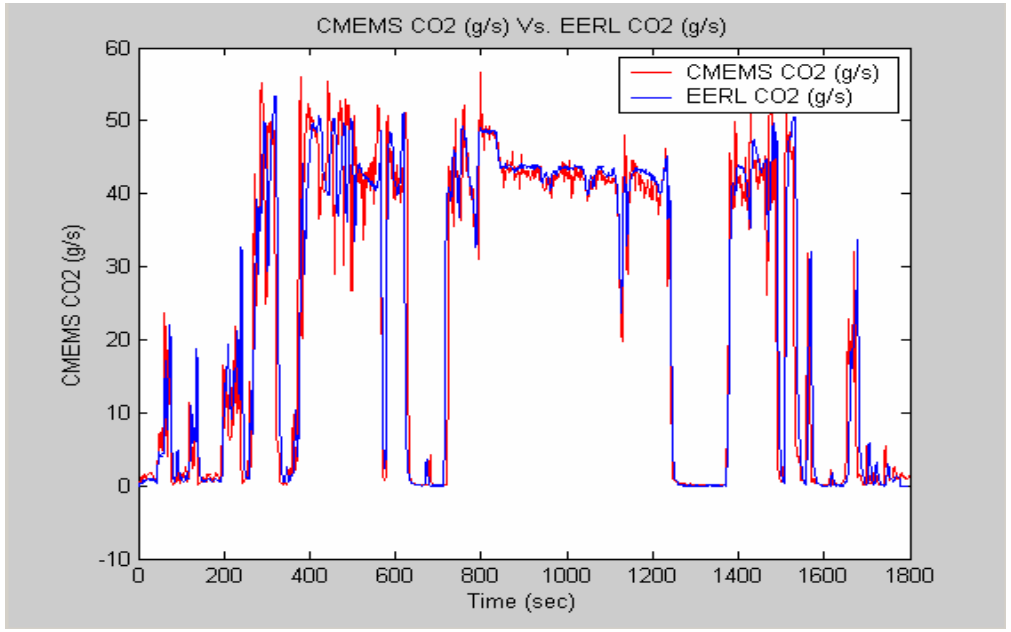

Figure 31: $\mathrm{CO}_{2}$ mass flow rate comparison of CMEMS and EERL results on simulated test-2 


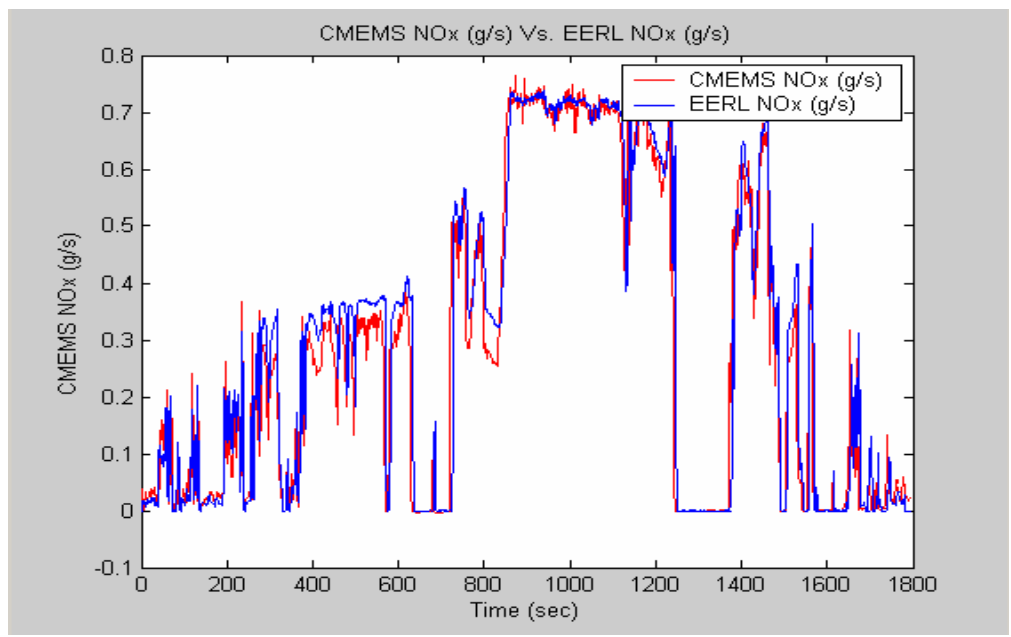

Figure 32: NOx mass flow rate comparison of CMEMS and EERL results on simulated test-2

\subsubsection{On-road Test}

Table 11 shows error percentage of both concentration and mass flow rate of gases between the two systems for on-road tests.

Table 11: Gas comparison of CMEMS vs. MEMS on on-road test

\begin{tabular}{|c|c|c|c|}
\hline $\begin{array}{l}\text { Test } \\
\text { Type }\end{array}$ & $\begin{array}{l}\text { Gas } \\
\text { Type }\end{array}$ & $\begin{array}{c}\text { \% Error } \\
\text { (Concentration) }\end{array}$ & $\begin{array}{c}\text { \% Error } \\
\text { (Mass Flow Rate(g/sec)) }\end{array}$ \\
\hline \multirow{2}{*}{$\begin{array}{l}\text { On-Road } \\
\text { Test A }\end{array}$} & $\mathrm{CO}_{2}$ & -9.1 & -0.1 \\
\hline & $\mathrm{NOx}$ & 5.3 & 7.0 \\
\hline \multirow{2}{*}{$\begin{array}{l}\text { On-Road } \\
\text { Test B }\end{array}$} & $\mathrm{CO}_{2}$ & -2.5 & 7.7 \\
\hline & NOx & -5.9 & 8.0 \\
\hline
\end{tabular}


By looking at the comparison of the two systems on a concentration base for NOx and $\mathrm{CO}_{2}$ (Figure 33, Figure 34), a satisfactory agreement can be observed, but if the comparison is done over the mass flow rate $(\mathrm{g} / \mathrm{s})$ the point-to-point error between the two curves increases (Figure 35, Figure 36). One reason for this can be that the system, being mounted on a truck, is exposed to a high level of vibrations, especially due to its proximity to the exhaust stack. Noise due to vibrations can affect the Annubar absolute and differential pressure signals that are the source signals with which the CMEMS flow is calculated. During the CMEMS testing against the EERL this problem was not critical because proper measures of vibration reduction were adopted. Another problem that might have given higher $\mathrm{CO}_{2}$ reading was the malfunctioning of the chiller; due to mounting issues the AC unit could not be used, thus the chiller was working with lower efficiency.

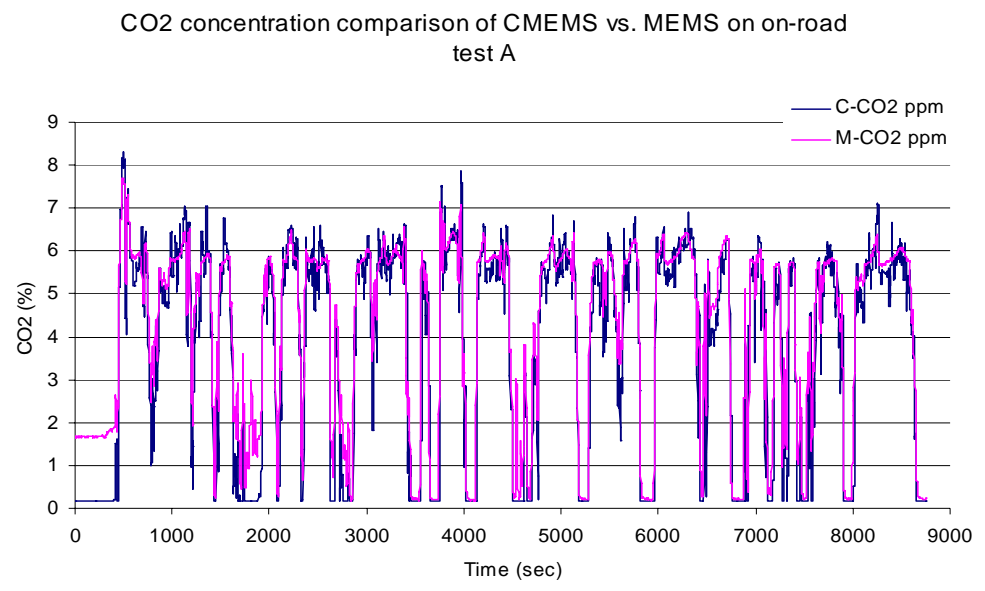

Figure 33: $\mathrm{CO}_{2}$ concentration comparison of CMEMS vs. MEMS on on-road test A 


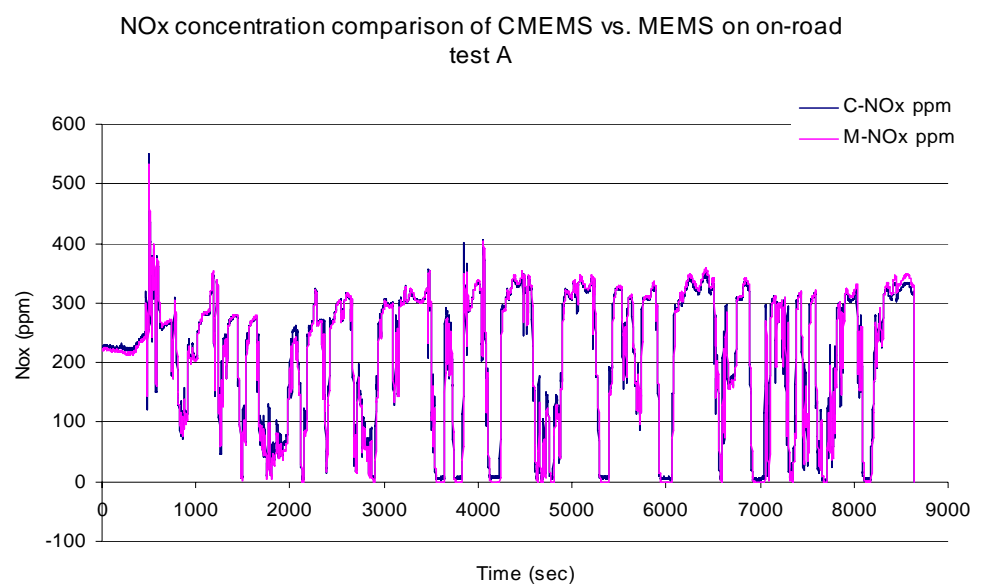

Figure 34: NOx concentration comparison of CMEMS vs. MEMS on on-road test A

CO2 mass flow rate comparison of CMEMS vs. MEMS on on-road test A

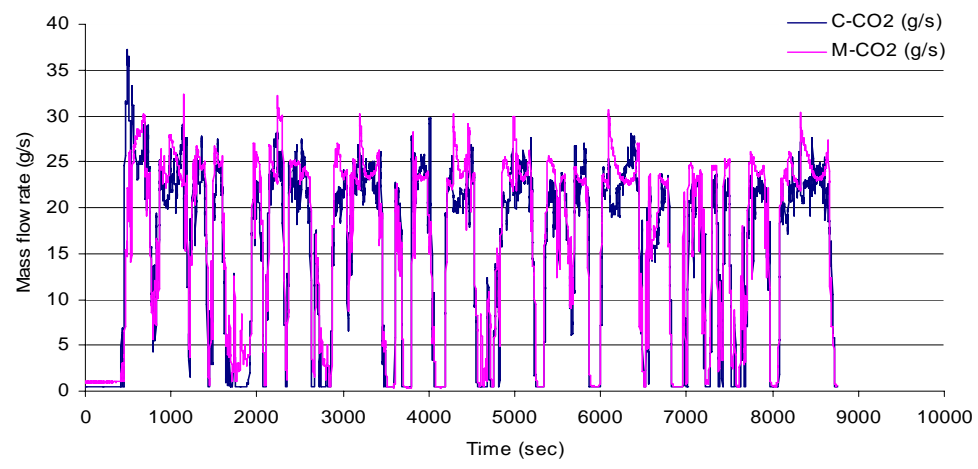

Figure 35: $\mathrm{CO}_{2}$ mass flow rate comparison of CMEMS vs. MEMS on on-road test A 
NOx mass flow rate comparison of CMEMS vs. MEMS on on-road test $\mathrm{A}$

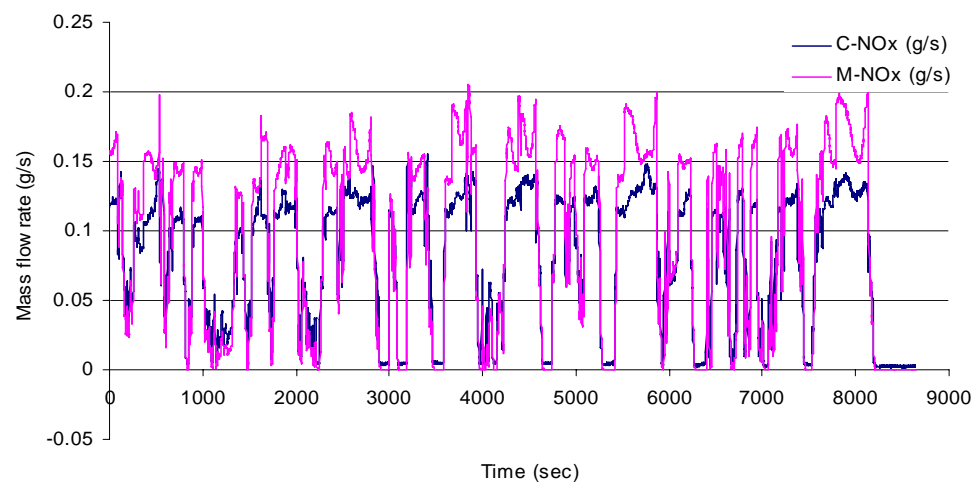

Figure 36: NOx mass flow rate comparison of CMEMS vs. MEMS on on-road test A 


\section{Conclusions and Recommendations}

\subsection{Conclusions}

The goal of this study was to evaluate the performance of CMEMS against laboratory graded analyzers and MEMS. To accomplish the objective, CMEMS was tested with a 1992 Detroit Diesel Corporation (DDC) Series 60 heavy duty diesel engine, which was exercised over the FTP and simulated on-road cycle in an engine laboratory and also on the tailpipe of a truck, instrumented with MEMS, under real-world conditions.

Laboratory testing showed that errors in brake specific $\mathrm{CO}_{2}$ emissions were in the range of $0.02 \%$ to $8.3 \%$, and errors in brake-specific NOx emissions were between $1.3 \%$ and 11.1\%. On-road testing results for $\mathrm{CO}_{2}$ mass emission rates had an error of $0.1 \%$ to $7.7 \%$ compared to the MEMS, and NOx between $7 \%$ to $8 \%$. Measurements of $\mathrm{CO}_{2}$ and $\mathrm{NOx}$ under laboratory conditions were more accurate than on-road predictions.

One of the major challenges during on-road testing was to maintain the chiller at $35^{\circ} \mathrm{F}$ such that the exhaust sample is dry prior to entering the NDIR. Lack of ventilation and poor heat dissipation contributed to the chiller inefficiencies, making the sample temperature high and ultimately affecting the BE-150 readings. Another challenge was the sensitivity of the two analyzers MEXA-720 and BE-150 to vibrations which were present during on-road testing. Under laboratory conditions vibration was minimized, and an external air-conditioning unit was used as a backup cooling system to improve the chiller efficiency. 
Additionally, compactness, and the congested layout of CMEMS made it more time consuming to troubleshoot hardware problems. An organized layout and suitable cables, such as ribbon cables would offer up more free space in a redesigned CMEMS.

It should be noted that this was the first attempt to develop a system that could be installed on the tail pipe of a heavy duty truck to measure engine emissions. Further considerations and work will be needed when redesigning the system in order to get better engine emissions data.

\subsection{Recommendations}

\subsubsection{Overheating Chiller}

The overheating of the chiller in the sampling stream for the NDIR was the major drawback of the CMEMS. For an accurate $\mathrm{CO}_{2}$ reading, the BE-150 requires a dry exhaust gas sample. However, the heat transfer from the exhaust pipe in the CMEMS unit resulted in significantly higher temperature around the chiller. This resulted a higher temperature in the cold chamber; hence, raising the temperature around the chiller. Even though the Peltier element worked well under manufacture specified ambient temperature, its performance was not equally satisfying under real-world operating conditions. Accurate measurement of $\mathrm{CO}_{2}$ with an NDIR requires that the sample temperature be dropped to $35^{\circ} \mathrm{F}$ before the NDIR. However, when the CMEMS was mounted on the exhaust pipe, the temperature of the chiller-out sample hovered around $60^{\circ} \mathrm{F}$ under highway driving conditions.

In the laboratory setting, conditioned air was used to reduce the temperature around the chiller in the CMEMS. The chiller temperature could be maintained below $40^{\circ} \mathrm{F}$ 
throughout the engine testing campaign. However, mounting an air conditioning unit on the CMEMS during on-road testing was impractical.

Under these circumstances, the need for a strong chiller is obvious in order to tackle this problem. As stated earlier, the chiller was based on the Peltier principle. The CMEMS has one Peltier module element attached to the aluminum chamber as was described in Section 3.2.5. A cascade connection of Peltier modules will give a greater temperature difference. This phenomenon will reduce the temperature of the cold side of the Peltier module significantly. The more Peltier modules used the more power it consumes. For this type of connection, the capacity of the power supply unit should not be less than 250W. Therefore, the number of modules that can be used has to be taken into account. While the temperature of the cold side goes down, the temperature of the hot side will rise. Strong fans and heat sinks are required to effect efficient heat dissipation. Again, this would require additional power. Therefore, a robust power supply is a significant factor in building a CMEMS.

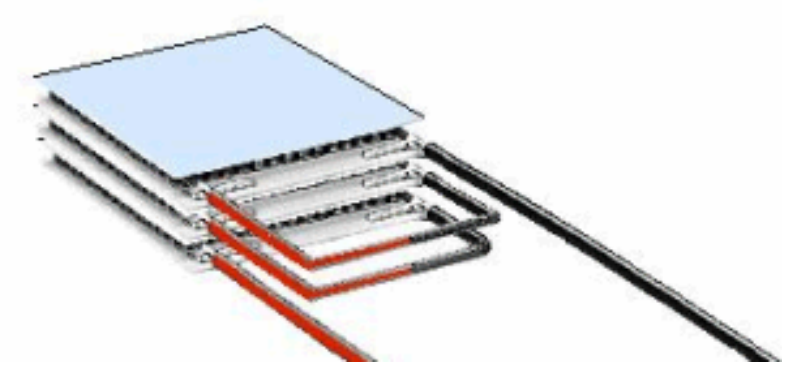

Figure 37: An example of cascade Peltier modules [3] 


\subsubsection{Inadequate Ventilation of the Cold Chamber}

Inadequate ventilation in the cold chamber is another reason for a CMEMS to get very hot. Heat dissipation from instruments in the cold chamber (for example, the power supply unit, FP 2020, pump, MEXA 720 control unit, pressure sensors, etc.) from stainless steel tubes, which carry hot exhaust gas from hot chamber to cold chamber are stagnated in the chamber. If the cold chamber maintains a low temperature, it will be easy for the chiller to maintain its required low temperature.

The door of the CMEMS was opened during laboratory testing to eliminate hot air stagnation inside the cold chamber. However, simply opening the door was not very effective because there was no forced airflow through the chamber. Natural correction is not as effective as forced correction. Moreover, the door cannot be opened during onroad testing.

If there was a way to circulate high volume of fresh air through the CMEMS, then it would be easy to maintain a low temperature inside the system, especially in the cold chamber. Mounting two fans on each side of the CMEMS would solve the problem. Fans should be mounted in a "push-pull" configuration.

\subsubsection{Vibration of the Truck Exhaust Pipe}

Vibration during on-road testing was another obstacle, which CMEMS had to overcome. The $\mathrm{CO}_{2}$ analyzer (BE-150), the NOx analyzer (MEXA-720) were adversely affected by vibrations. Analyzers were designed to handle small vibrations, which are typical of inlaboratory applications. Vibrations due to rugged on-road conditions adversely affected their communication with the data acquisition system. 
Both analyzers were taken out of the CMEMS and placed on a table to avoid the vibration effect during laboratory testing. This approach is impractical in on-road testing. Instead of using a Horiba BE-150 $\mathrm{CO}_{2}$ analyzer, a Horiba BE-140 $\mathrm{CO}_{2}$ analyzer may offer a solution. A BE-140 is less sensitive to vibration and can be used in rugged conditions. The disadvantage of using a BE-140 is its larger size. On the other hand, mounting the BE-150 and the MEXA-720 control units on a vibration proof material will be a solution to reduce the vibration impact.

\subsubsection{Size of CMEMS}

CMEMS was designed to be a compact unit, hence, it has less free space to easily allow hardware troubleshooting problems.

Using ribbon cables instead of using different wires for most of the wiring of the system will help make the system less complex and save some space. Currently a CMEMS uses two different pressure circuit boards as in Figure 5. One is in the hot chamber and the other in the cold chamber. Instead of using two circuit boards, all the pressure and humidity sensors can be mounted on one circuit board in the cold chamber. This will reduce the complexity of wiring two circuit boards as well as free up some space in the system. Making the system slightly wider will allow for more room to troubleshoot the hardware problems. But the overall size of CMEMS should be of paramount concern, since the system has to be fixed on the exhaust pipe. 


\subsubsection{Positioning of Chiller Outlet Probe}

The CMEMS was designed to be vertically aligned on a truck exhaust pipe because the chiller was positioned so as to remove the condensed water vapor using gravity. Since there are trucks with horizontal exhaust pipes, assembling a CMEMS on such an exhaust configuration will be difficult. During on-road testing and laboratory testing, the system was angled at $45^{\circ}$ and rotated upwards to get the gravitational flow for the condensed water vapor to come out of the chiller.

Instead of angling and rotating the entire system, a better solution would have been to angle the outlet probes of the chiller at $45^{\circ}$, so whether the system was installed horizontally or vertically, the gravitational effect will drain the condensed water vapor out of the system.

\subsection{Future Work}

CMEMS can use a programmed Controller Area Network (CAN) interfaced microprocessor to record data from sensors and control the necessary devices in the system. Hence, the National Instruments FP 2020, the current Data Acquisition System, can be replaced by a small microprocessor, which will free up a large amount of space in the system. The CAN protocol is a two-wire, half duplex, high-speed network system and is well suited for high-speed applications using short messages. The CAN interfaced microprocessor can be programmed to read Engine Control Module (ECM) data directly plugging into the socket on the dashboard of the vehicle. Currently MEMS uses a CAN to serial adaptor to read ECM data, which has an internal clock and time delay issues. This 
problem can be eliminated from the CMEMS if it uses a CAN protocol microprocessor to read engine speed, torque and other engine data directly from the ECM. 


\section{References}

1. p://www.digit-life.com/articles/peltiercoolers/, By Rudometov V., Eugene Rudometov, Aug 10, 2006.

2. Tiwari, A., "Design, Development and Qualification of Compact Mobile Emissions Measuring System (CMEMS) for Real Time On-Board Emissions Measurement," M.S. Thesis, Department of Mechanical and Aerospace Engineering, West Virginia University, Morgantown, WV, 2006.

3. http://www.ecnmag.com/article/CA387822.html?ref=nbra by Titus J., Senior Technical Editor ECN, 3/1/2004 (Aug 19 2006).

4. Gautam, M., Clark, N. N., Thompson, G. J., Lyons, D. W., "Assessment of Mobile Monitoring Technologies for Heavy-Duty Vehicle Emissions,” Department of Mechanical and Aerospace Engineering, West Virginia University, Morgantown, WV, 1999.

5. Branstetter, R., Burrahm, R., Dietzmann, H., "Relationship of Underground Diesel Engine Maintenance to Emission," Final Report for 1978 to 1983 to the U.S. Bureau of Mines, Department of the Interior Contract H0292009, 1983.

6. Riddle, W.C., Design and Evaluation of the Emissions Measurement Components for a Heavy-Duty Diesel Powered Vehicle Mobile Emissions Measurement System (MEMS)., M.S Thesis, Department of Mechanical and Aerospace Engineering, West Virginia University, Morgantown, WV, 2001.

7. http://en.wikipedia.org/wiki/Emission_standard, Wikipedia, 01/22/2007 (01/24/2007)

8. http://www.dieselnet.com/standards/us/hd.html, Dieselnet, EcoPoint Inc.,2001 $(01 / 25 / 2007)$.

9. Butler, J. W., Kornisk, T. J., Reading, A. R., Kotenko, T. L., "Generating Dynamometer Quality Data On-board Vehicles for Real-World Emission Measurements," Proceedings of the Ninth CRC On-Road Vehicle Workshop, April 19-21, San Diego, CA, 1999.

10. Kihara, N., Tsukamoto, T., Mastumoto, K., Ishida, K., Kon, M., Murase, T., "RealTime On-Board Measurement of Mass Emission of NOx, Fuel Consumption, Road Load, and Engine Output for Diesel Vehicles," SAE Technical Paper No. 2000-011141, 2000.

11. Jetter, J., Maeshiro, S., Hatcho, S., Klebba, R., "Development of an On-Board Analyzer for Use on Advanced Low Emission Vehicles," SAE Technical Paper No.2000-01-1140, 2000.

12. Fulper, C., Spears, M., "Portable Emission Measurement System (PEMS)," Proceedings of the 11th CRC On-Road Vehicle Emissions Workshop, 2001. NO is measured with a divided detection cell in a dedicated sample tube, using the same principle.

13. Reading, A., Gideon, E., Ensfield, C., "The Design and Implementation of a Portable Analytical System (SEMTECH) for the Measurement of In-Use Diesel Engine Emissions," Proceedings of the 11th CRC On-Road Vehicle Emissions Workshop, 2001.

14. Czachura, B., Brandon, L., May, A., "Demonstration of the 'Simple, Portable OnVehicle Testing' (SPOT) System on a Class 8 Vehicle," Proceedings of the 11th CRC On-Road Vehicle Emissions Workshop, 2001. 
15. Lambert, D., Vojtsisek-Lom, M, “OEM 2100” April 2, 2001 $<\mathrm{http}: / /$ www.cleanairt.com/>.

16. Shade, B. C., "A Performance Evaluation of the MEMS- An On-Road Emissions Measurement System Study," M.S. Thesis, Department of Mechanical and Aerospace Engineering, West Virginia University, Morgantown, WV, 2000.

17. Jayasinghe, D., "Effects of Duty Cycles on Diesel Engine Component Life Estimation,” M.S. Thesis, Department of Mechanical and Aerospace Engineering, West Virginia University, Morgantown, WV, 2006.

18. Carder, D. K., "Performance Evaluation of Exhaust After treatment Devices Used for Emissions Control on Diesel Engines Employed in Underground Coal Mines,” M.S. Thesis, Department of Mechanical and Aerospace Engineering, West Virginia University, Morgantown, WV, 1999.

19. Kistler.com, 10 January 2006, http://www.kistler.com/mediaaccess/ml/000-020m09.95.pdf

20. Rosemount Analytical Model 955 NO/ NOx Analyzer Product Data Sheet, 1992, Rosemount Analytical Inc., La Habra, California.

21. Rosemount Analytical Model 402 Hydrocarbon Analyzer Product Data Sheet, 1992, Rosemount Analytical Inc., La Habra, California.

22. Rosemount Analytical Model 868/880 NDIR Analyzer Product Data Sheet, 1992, Rosemount Analytical Inc., La Habra, California.

23. CODE OF FEDERAL REGULATIONS, Title 40 Part 86, U.S. Government Printing Office, Washington DC, 2000.

24. 02/13/2007 http://www.dieselnet.com/news/2002/07sensors.php

25. Branstetter, R., Burrahm, R., Dietzmann, H., "Relationship of Underground Diesel, Engine Maintenance to Emissions," Final Report for 1978 to 1983 to the U.S. Bureau of Mines, Department of the Interior Contract H0292009, 1983.

26. Chan, L., Carlson, D. H., Johnson, J. H., "Evaluation and Application of a Portable Tailpipe Emissions Measurement Apparatus for Field Use," SAE Technical Paper No. 921647, 1992.

27. Spears, M. W., "An Emissions-Assisted Maintenance Procedure for Diesel-Powered Equipment," University of Minnesota, Center for Diesel Research, Minneapolis, MN, 1997.

28. Englund, M. S., "Field Compatible NOx Emission Measurement Technique," SAE Technical Paper No. 820647, 1982.

29. Human, D. M., Ullman, T. L., "Development of an I/M Short Emissions Test for Buses," SAE Technical Paper No. 920727, 1992.

30. Kelly, N. A., Groblicki, P. J., "Real-world emissions from a modern production vehicle driven in Los Angeles," Journal of the Air \& Waste Management Association, Vol. 43, No. 10, 1993.

31. Mackay, G. I., Nadler, S. D., Karecki, D. R., Schiff, H. I., Butler, J. W., Gierczak, C. A., Jesion, G., "Dynamometer Intercomparison of Automobile Exhaust Gas CO/CO2 Ratios and Temperature Between On-Board Measurements and a Remote Sensing Near Infrared Diode Laser System," Phase 1b Report to the Coordinating Research Council and National Renewable Energy Laboratory, 1994.

32. Mackay, G. I., Nadler, S. D., Karecki, D. R., Schiff, H. I., Butler, J. W., Gierczak, C. A., Jesion, G., "Test Track Intercomparison of Automobile Exhaust Gas $\mathrm{CO} / \mathrm{CO}_{2}$ 
Ratios and Temperature Between On-Board Measurements and a Remote Sensing Near Infrared Diode Laser System," Phase 1c Report to the Coordinating Research Council and National Renewable Energy Laboratory, 1994.

33. Butler, J. W., Gierczak, C. A., Jesion, G., Stedman, D. H., Lesko, J. M., "On-Road NOx Emissions Intercomparison of On-Board Measurements and Remote Sensing," Final Report, Coordinating Research Council, Inc., Atlanta, GA, CRC Report No. VE-11-6, 1994.

34. Gierczak, C. A., Jesion, G., Piatak, J. W., Butler, J. W., "On-Board Vehicle Emissions Measurement Program," Final Report, Coordinating Research Council, Inc., Atlanta, GA, CRC Report No. VE-11-1, 1994.

35. Bentz, A. P., Weaver, E., "Marine Diesel Exhaust Emissions Measured by Portable Instruments," SAE Technical Paper No. 941784, 1994.

36. Bentz, A. P., "Final Summary Report on Project 3310, Marine Diesel Exhaust Emissions (Alternative Fuels)," United States Department of Transportation United States Coast Guard Systems, Report No. CG-D-08-98, 1997.

37. Vojtisek-Lom, M., Cobb, Jr., J. T., "On-Road Light-Duty Vehicle Mass Emission Measurements Using a Novel Inexpensive On-Board Portable System," Proceedings of the Eighth CRC On-Road Vehicle Workshop, San Diego, CA, April 20-22, 1998.

38. "Construction Equipment Retrofit Project," Northeast States for Coordinated Air Use Management, Boston, MA, 1998.

39. Butler, J. W., Kornisk, T. J., Reading, A. R., Kotenko, T. L., "Dynamometer Quality Data On-board Vehicles for Real-World Emission Measurements," Proceedings of the Ninth CRC On-Road Vehicle Workshop, April 19-21, San Diego, CA, 1999.

40. Nagendran V., Characterization of Exhaust Emissions from catalyzed Trap-Equiped Non-Road Heavy-Duty Diesel Engines (MEMS)., M.S Thesis, Department of Mechanical and Aerospace Engineering, West Virginia University, Morgantown, WV, 2003.

41. 02/20/2007, http://www.cotf.edu/ete/modules/carbon/efculprits1c.html

42. 02/20/2007, http://www.dieselnet.com/papers/0501krishnan/

43. 02/20/2007, http://en.wikipedia.org/wiki/Alternative_fuel

44. 02/21/2007, http://www1.eere.energy.gov/vehiclesandfuels/pdfs/deer_2003/session11/2003_deer_ gautam.pdf

45. Ardanese, M., Tiwari, A., Jayasinghe, S., Carder., D. K., Gautam, M., On-Road Measurement of In-Use Emissions from Heavy-Duty Diesel Engines Using the "Micro-MEMS": Modal Analysis, Submitted, SAE Conference , 2007.

46. Dearth, M. A., Butler, J. W., Colvin, A., Gierczak, C., Kaberline, S., Korniski, T., "SemtechD: The Chassis Roll Evaluation of a Commercial Portable Emission Measurement System (PEMS)," SAE Technical Paper No. 2005-01-0673, 2005.

47. 08/05/2007, http://www.cert.ucr.edu/research/project.asp?project=125

48. Krishnamurthy, M., Gautam, M., "Quality Assurance of Exhaust Emissions Test Data Measured using Portable Emissions Measurement System," SAE Technical Paper No. 2005-01-3799, 2005.

49. McConnell, T., Carder, D., Shade, B., Ames, R., Ardanese, M., Ardanese, R., Thompson, G., Gautam, M., Evaluation of Portable Emissions Measurement Systems 
for Heavy-Duty Diesel Engines, $17^{\text {th }}$ CRC On-Road Vehicles Emissions Workshop, San Diego, March 26-28, 2007.

50. Shade, B. C., Ekermo A., Gautam M., Evaluation of Methods to determine In-Use Emissions of a Heavy-Duty Diesel Engine in a Heavy-Duty Vehicle at Varying Test Weights, $17^{\text {th }}$ CRC On-Road Vehicles Emissions Workshop, San Diego, March 2628, 2007.

51. Hu, J., Giannelli, R. A., Booker, D., Spears, M., Fulper, C., McDonald, J., Bies, N., Guerra, Z., Cantrell, B., Portable Particulate Mass Device for In-Use Heavy-Duty Diesel Emissions Measurement, $17^{\text {th }}$ CRC On-Road Vehicles Emissions Workshop, San Diego, March 26-28, 2007.

52. Wei, Q.,_Porter, S., A Partial Flow Sample for On-Board Diesel Particulate Measurement, $17^{\text {th }}$ CRC On-Road Vehicles Emissions Workshop, San Diego, March 26-28, 2007.

53. Gierczak, C. A.,_Korniski, T. J., Butler, J. W., Colvin, A. D., Wallington, T. J., A Compact, Inexpensive, Portable System for Measuring Exhaust Gas Flow From a Vehicle Under Real-World Conditions, $17^{\text {th }}$ CRC On-Road Vehicles Emissions Workshop, San Diego, March 26-28, 2007.

54. Advance Agenda, Research Screening Committee Meeting Cal/EPA Headquarters Building, State of California Air Resources Board, March 24, 2006.

55. Spears, M., US EPA PEMS Measurement Allowance Program, 08/08/2007, http://transportenv07.jrc.it/pdf/C/C_2_20_Spears_M_US\%20Measurement\%20Allow ance\%20Program.pdf. 


\section{Appendix A}

CMEMS data reduction program for the EERL

clc;

clear all;

disp(' ');

disp('CMEMS Data Reduction Program');

disp(' ');

\%Read CMEMS data file

[F1,P1] = uigetfile('*.xls', 'Open CMEMS Data File');

DataLoaded= xlsread([P1 F1]);

$[\mathrm{M}, \mathrm{N}]=\operatorname{size}($ DataLoaded);

\% CMEMSdatapoints=[1:1:M]';

$\%$ Mobiledatapoints=[1:1:P]';

$\% \mathrm{j}=1$; for $\mathrm{i}=1: 2: \mathrm{N} \mathrm{b}(\mathrm{j})=\mathrm{a}(\mathrm{i}) ; \mathrm{j}=\mathrm{j}+1$; end

\%Extract data from the data file

$\% \mathrm{i}=1 ; \mathrm{j}=1$;

$\%$ while $\mathrm{i}<\mathrm{M}$

$\% \operatorname{NOx}(\mathrm{j}, 1)=$ DataLoaded(i,21);

\% co2percent(j,1)=DataLoaded(i,28);

$\%$ aap $(\mathrm{j}, 1)=$ DataLoaded $(\mathrm{i}, 41)$;

$\% \operatorname{adp}(\mathrm{j}, 1)=$ DataLoaded(i,42);

$\%$ flow1(j,1)=DataLoaded(i,8);

$\%$ rhumid(j,1)=DataLoaded(i,25);

$\% \mathrm{i}=\mathrm{i}+50$;

$\% \mathrm{j}=\mathrm{j}+1$;

$\%$ end

$\mathrm{i}=1 ; \mathrm{j}=1$;

while $\mathrm{i}<\mathrm{M}+1$

$\mathrm{k}=1$;

while $\mathrm{k}<6 \& \mathrm{i}<\mathrm{M}+1$

temp1(k,1)=DataLoaded(i,21);

temp2(k,1)=DataLoaded(i,28);

temp3(k,1)=DataLoaded(i,41);

temp4(k,1)=DataLoaded(i,42);

temp5(k,1)=DataLoaded(i,8);

temp6(k,1)=DataLoaded(i,25);

$\mathrm{k}=\mathrm{k}+1$;

$\mathrm{i}=\mathrm{i}+1$;

end

$\%$ Data alignment for MAC's file

$\% \operatorname{NOx}(\mathrm{j}, 1)=$ mean $($ temp 1$)+0.2$; 


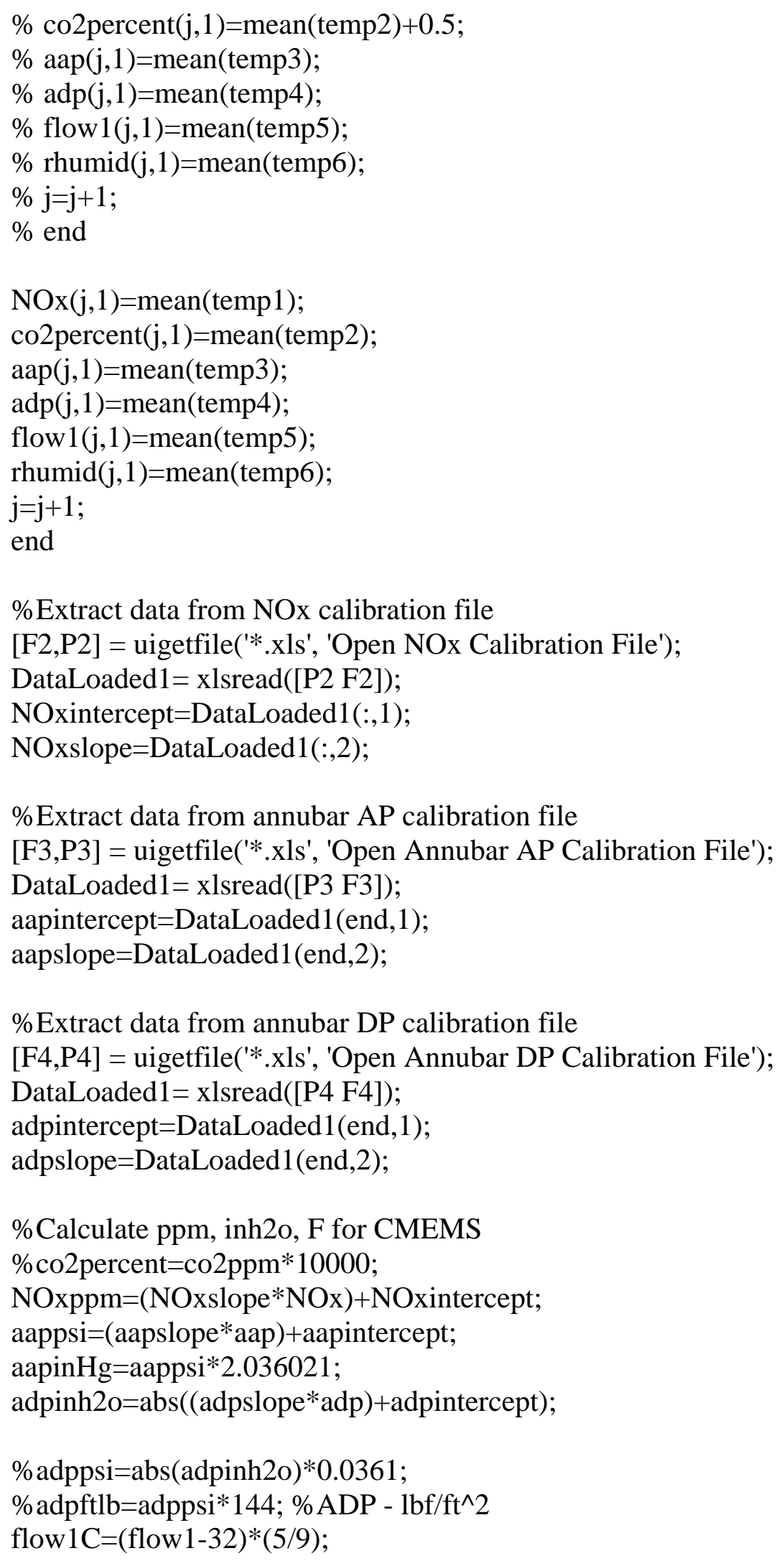


\%Read ERC Lab data file

[F6,P6] = uigetfile('*.xls', 'Open ERC Lab Data File');

DataLoadedM= xlsread([P6 F6]);

$[\mathrm{P}, \mathrm{Q}]=\operatorname{size}($ DataLoadedM);

\%Extract data from Mobile Lab data file

\%MNOxppm=DataLoadedM(:,4);

\%Mco2ppm=DataLoadedM(:,2);

Mco2gps=DataLoadedM(:,11);

MNOxgps=DataLoadedM(:,12);

Vmix=DataLoadedM(:,17);

Mscfm=Vmix*2.12;

ECUspeed=DataLoadedM(:,2); \%in rpm

ECUtorqueLab=DataLoadedM(:,3); \%in Nm

ECUtorque=ECUtorqueLab*0.7375; \%in ft-lbs

power=ECUspeed.*ECUtorque/5252;

Sum_Mco2gps=sum(Mco2gps);

Sum_MNOxgps=sum(MNOxgps);

\%Calculate Gamma

Gamma $=-3.34642 * 10^{\wedge}$ -

16*(flow1C+273).^5+0.000000000000926157*(flow1C+273).^4-

$0.000000000764644 *($ flow1C+273). $\wedge 3+0.0000000648889 *($ flow1C +273$) . \wedge 2+0.0000514$

$974 *($ flow1C+273)+1.3927;

\%Expansion Factor for gases, Yaa

$\% \mathrm{~W}=0.365 i n, \mathrm{D}=4.83$ in, $\mathrm{P}=14.696 \mathrm{psi}, \mathrm{P}=29.92 \mathrm{inHg}$

$\%$ yaa $=1-(((1-0.07869) \wedge 2 * 0.011332-0.00342) *($ adpinh2o./(aappsi*1.4)));

yaa $=1-(((1-(4 * 0.365 /(3.14 * 4.83))) \wedge 2) *(0.011332-$

0.00342)*(adpinh2o./(aapinHg*(14.696/29.92). *Gamma)));

\%Thermal Expansion Factor, Faa

$\%$ Standard Temperature 68F

faa $=1+2 *(0.00000921) *($ flow1-68);

$\%$ faa $=1+2 *(0.000006) *($ flow $1-68)$;

\%Annubar flow ACFM

\%acfm=0.58*pi*((0.3211^2)/4)*sqrt(2*adpftlb*32.14/0.077402)*60.*faa.*yaa;

\%Annubar flow SCFM

$\%$ Standared temp-528R

$\% \mathrm{~K}=0.6264, \mathrm{~T}=68 \mathrm{~F}$

\%scfm=acfm*528.*aappsi./((flow1+460)*14.695); 
$\operatorname{scfm}=5.6362 * 0.6264 *(4.83 \wedge 2) * 1 *$ yaа*(14.73/14.696)*((68+460)/520).*(520./(flow1+46

$0)) . \wedge 0.5 * 1 * 1 * 1 . *$ faa*1.*(adpinh2o.*aapinHg*14.696/29.92).^0.5;

\% Density of CO2@68 F and 29.92 "Hg g/ft^3 - 51.82

\% Density of NOx@68 F and 29.92 "Hg g/ft^3 - 54.16

$\%$ Dry to wet correction factor for CO2, \%vol - 0.98

co2gps $=$ co2percent $* 0.98 . *(\mathrm{scfm} / 60) * 51.81 / 100$;

NOxgps=NOxppm. $*(\mathrm{scfm} / 60) * 54.16 / 10^{\wedge} 6$;

$\%$ co2gps $=$ co2gps +0.5 ;

NOxgps $=$ NOxgps +0.01 ;

Sum_co2gps=sum(co2gps);

Sum_NOxgps=sum(NOxgps);

ErrorCO2=(((Sum_Mco2gps)-Sum_co2gps)/Sum_Mco2gps)*100

ErrorNOx=(((Sum_MNOxgps)-Sum_NOxgps)/Sum_MNOxgps)*100

\%CO2 g/bhp-hr

co2bhp=mean(co2gps)*3600/mean(power)

\%NOx g/bhp-hr

NOxbhp=mean(NOxgps)*3600/mean(power)

timeCMEMS=zeros $(\mathrm{j}-1,1)$;

for $i=2: j-1$

timeCMEMS(i,1)=timeCMEMS $(\mathrm{i}-1,1)+200 /(\mathrm{j}-1)$;

end

timeL=zeros $(\mathrm{P}, 1)$;

for $\mathrm{i}=2: \mathrm{P}$

timeL(i,1)=timeL(i-1,1)+200/P;

end

figure(1)

plot(timeCMEMS,co2gps,'r',timeL,Mco2gps,'b')

Title('CMEMS CO2 (g/s) Vs. ERC Lab CO2 (g/s)');

xlabel('Time (s)');

ylabel('CMEMS CO2 (g/s)');

legend('CMEMS CO2 (g/s)', 'ERC Lab CO2 (g/s)');

figure(2)

plot(timeCMEMS,NOxgps,'r',timeL,MNOxgps,'b')

Title('CMEMS NOx (g/s) Vs. ERC Lab NOx (g/s)');

xlabel('Time (s)');

ylabel('CMEMS NOx (g/s)'); 
legend('CMEMS NOx (g/s)', 'ERC Lab NOx (g/s)');

$\%$ figure(3)

$\%$ plot(timeCMEMS,scfm,'r',timeL,Mscfm,'b');

$\%$ Title('CMEMS SCFM Vs. ERC Lab SCFM');

$\%$ xlabel('Time (s)');

$\%$ ylabel('CMEMS SCFM');

$\%$ legend('CMEMS SCFM', 'ERC SCFM'); 


\section{CMEMS data reduction program for MEMS}

clc;

disp(' ');

disp('CMEMS Data Reduction Program');

$\operatorname{disp}(')$;

\%Read CMEMS data file

[F1,P1] = uigetfile('*.xls', 'Open CMEMS Data File');

DataLoaded= xlsread([P1 F1]);

$[\mathrm{M}, \mathrm{N}]=\operatorname{size}($ DataLoaded);

$\% \mathrm{j}=1$; for $\mathrm{i}=1: 2: \mathrm{N} \mathrm{b}(\mathrm{j})=\mathrm{a}(\mathrm{i}) ; \mathrm{j}=\mathrm{j}+1$; end

$\%$ Extract data from the data file

NOx=DataLoaded(:,21);

co2percent=DataLoaded(:,28);

aap=DataLoaded $(:, 41)$;

adp=DataLoaded(:,42);

flow1=DataLoaded(:,8);

\%flow2=DataLoaded(:,9);

\%rhumid=DataLoaded(:,25);

\%Extract data from NOx calibration file

[F2,P2] = uigetfile('*.xls', 'Open NOx Calibration File');

DataLoaded= xlsread([P2 F2]);

NOxintercept=DataLoaded(:,1);

NOxslope=DataLoaded(:,2);

\%Extract data from annubar AP calibration file

[F3,P3] = uigetfile('*.xls', 'Open Annubar AP Calibration File');

DataLoaded= xlsread([P3 F3]);

aapintercept=DataLoaded(end,1);

aapslope=DataLoaded(end,2);

\%Extract data from annubar DP calibration file

[F4,P4] = uigetfile('*.xls', 'Open Annubar DP Calibration File');

DataLoaded= xlsread([P4 F4]);

adpintercept=DataLoaded(end,1);

adpslope=DataLoaded(end,2);

\%Calculate ppm, inh2o, F for CMEMS

\%co2percent $=$ co2ppm*10000;

NOxppm $=($ NOxslope $* \mathrm{NO})+\mathrm{NOxintercept;}$

aappsi $=$ (aapslope*aap)+aapintercept;

aapinHg=aappsi*2.036021;

adpinh2o=abs((adpslope*adp)-adpintercept);

\%adppsi=abs(adpinh2o)*0.0361; 


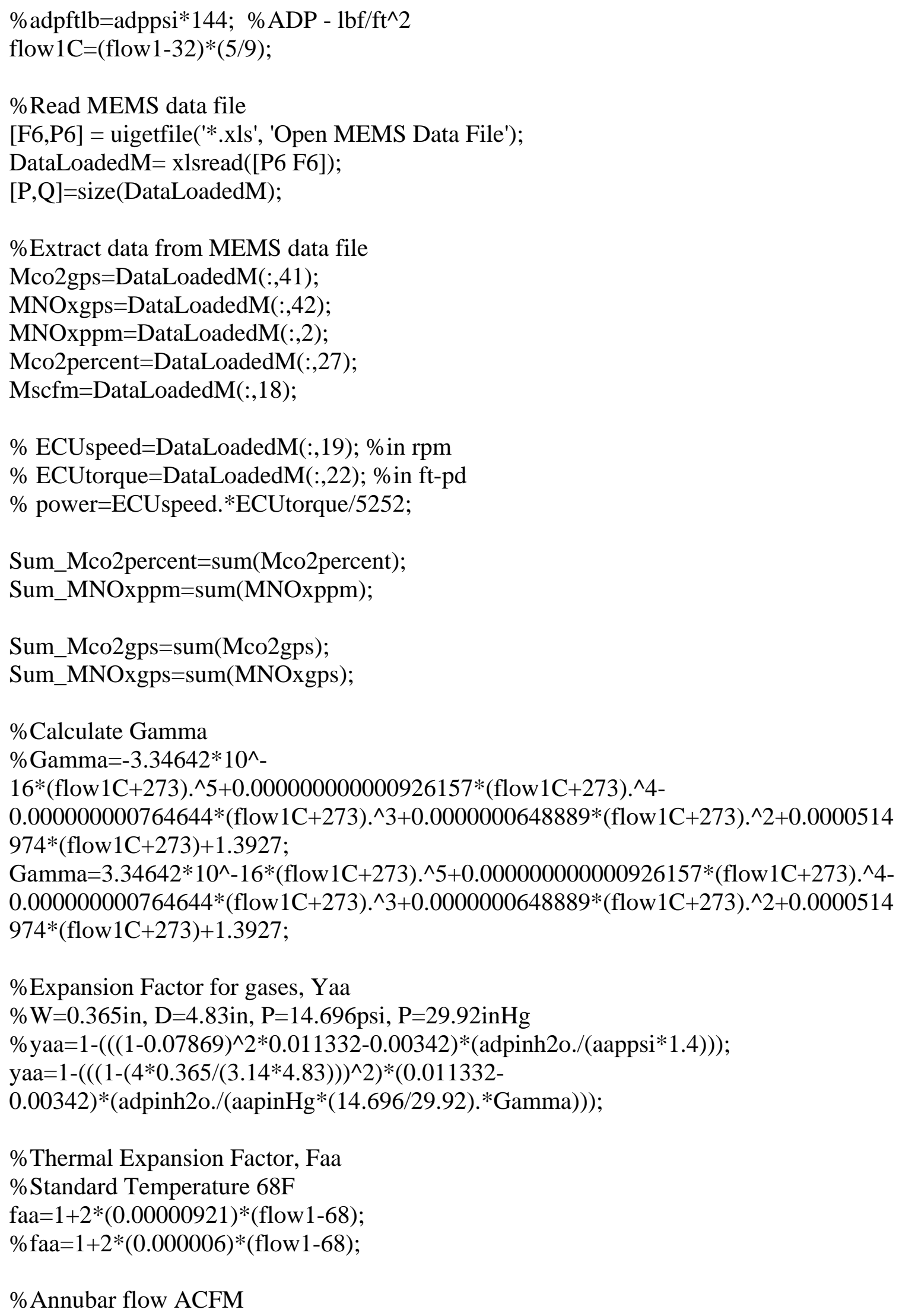




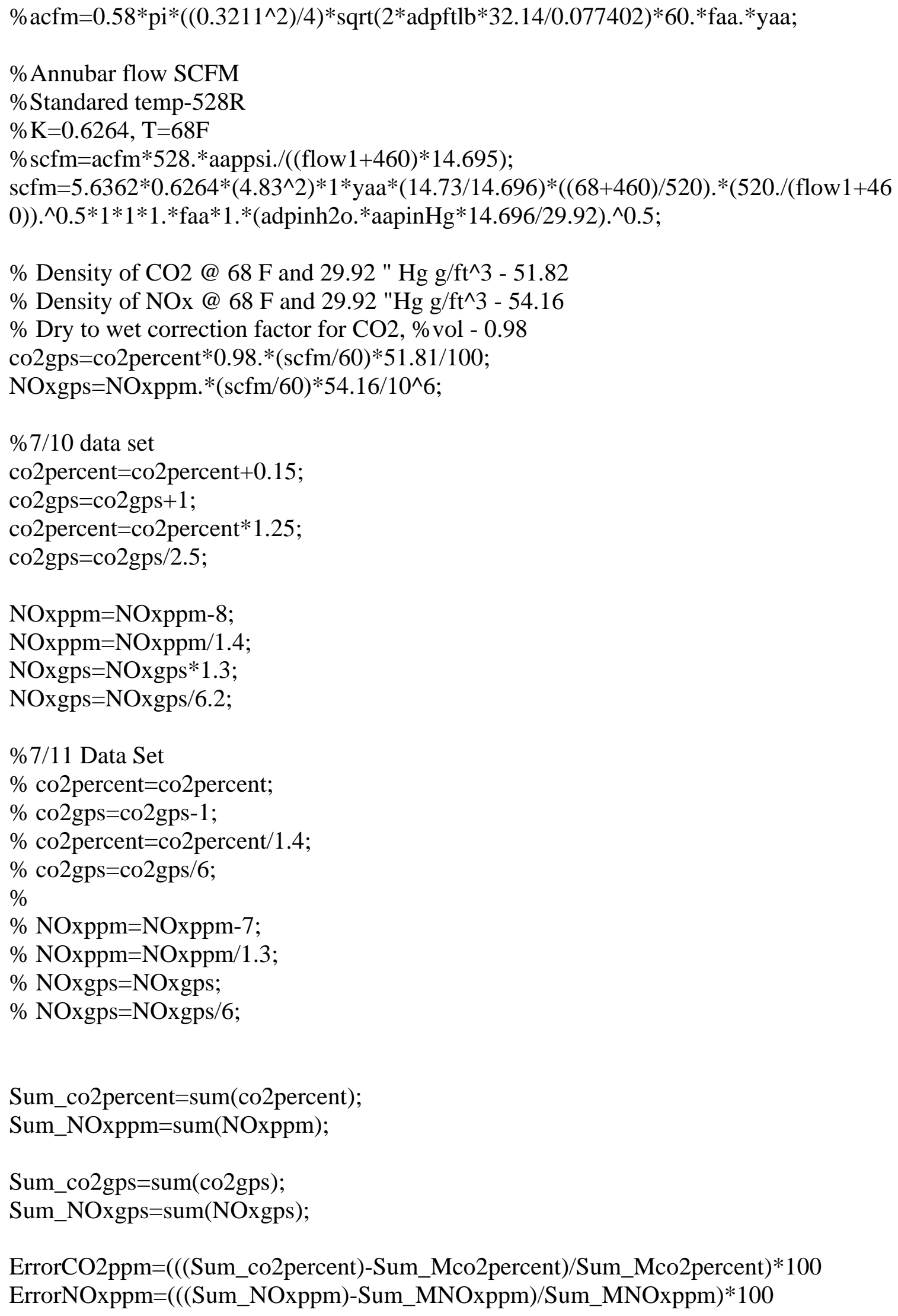




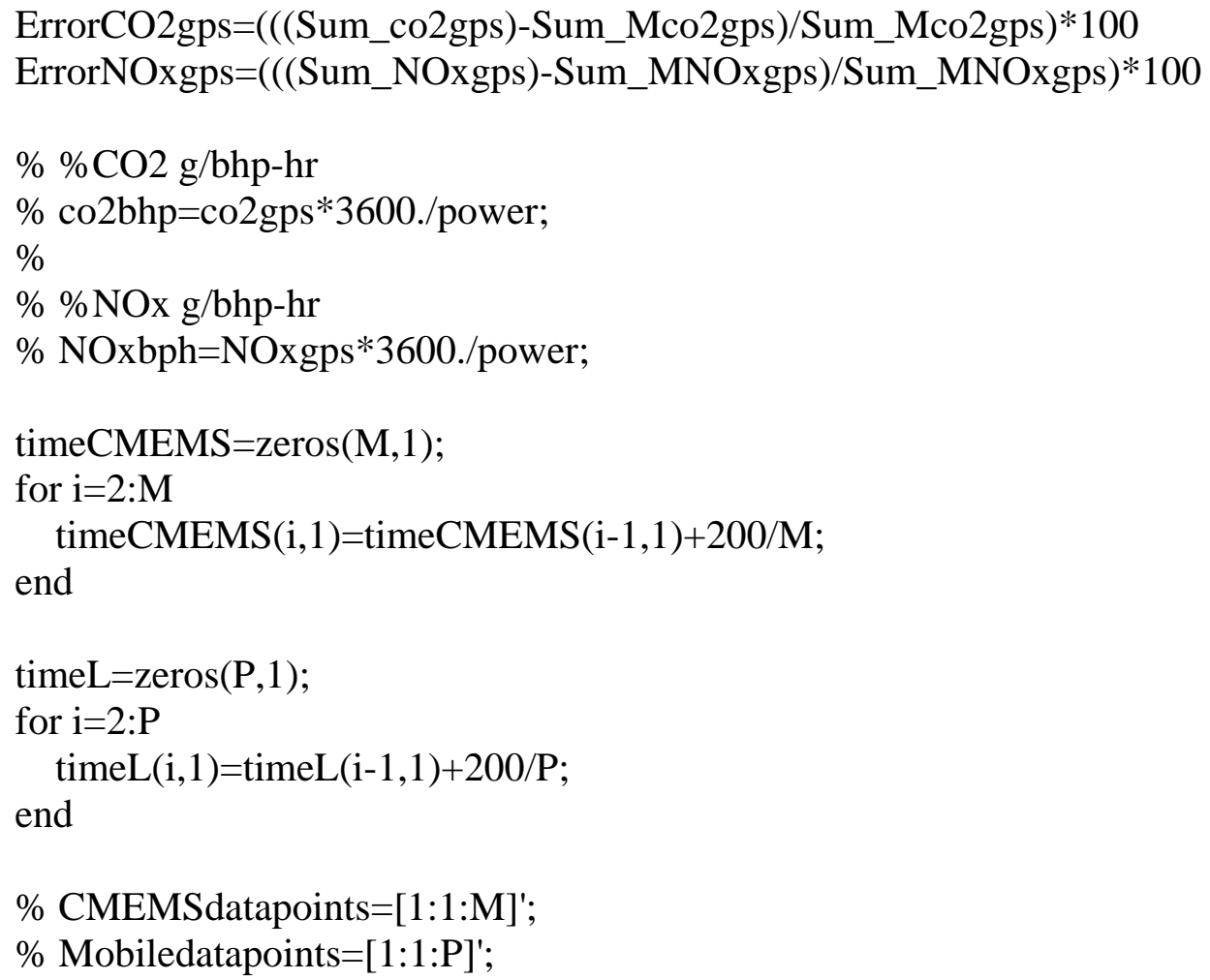




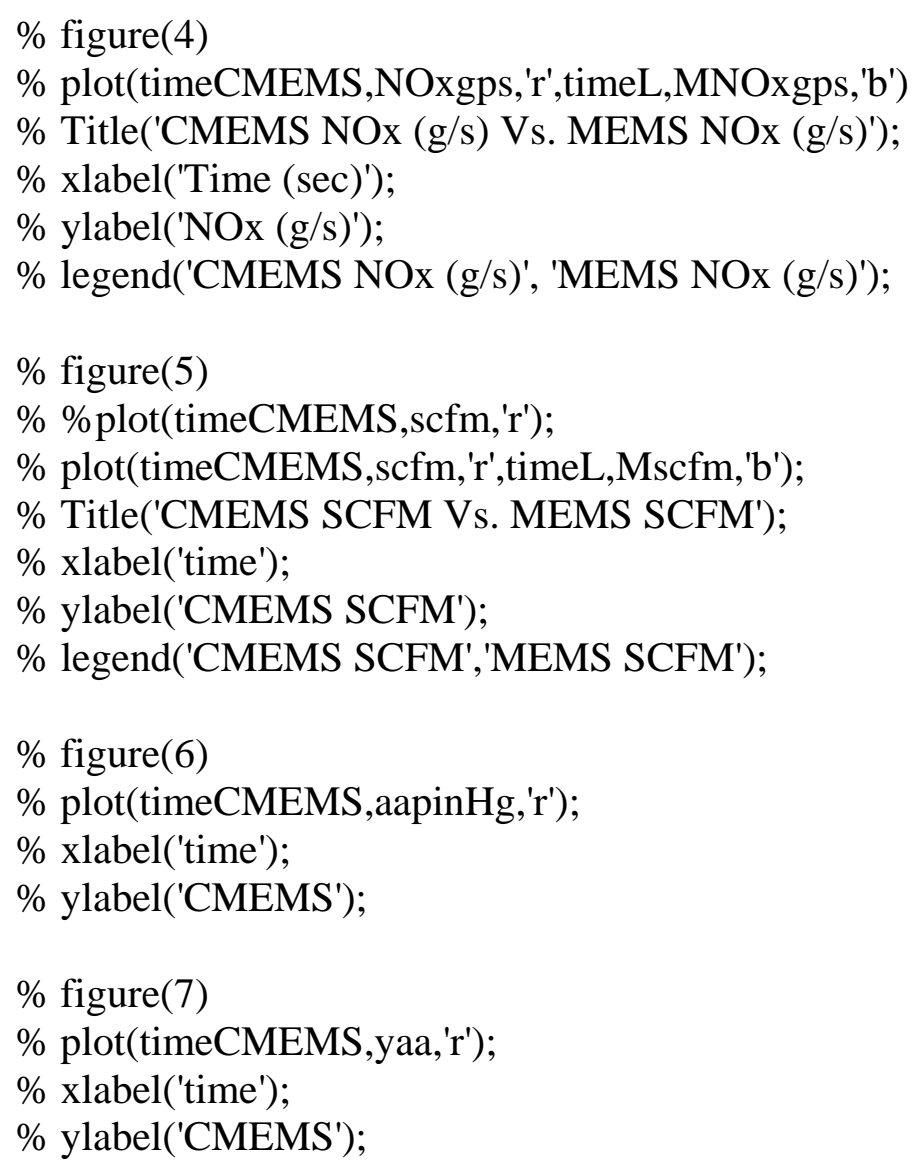




\section{Appendix B}

Steady state test-B NOx mass flow rate for CMEMS vs. EERL

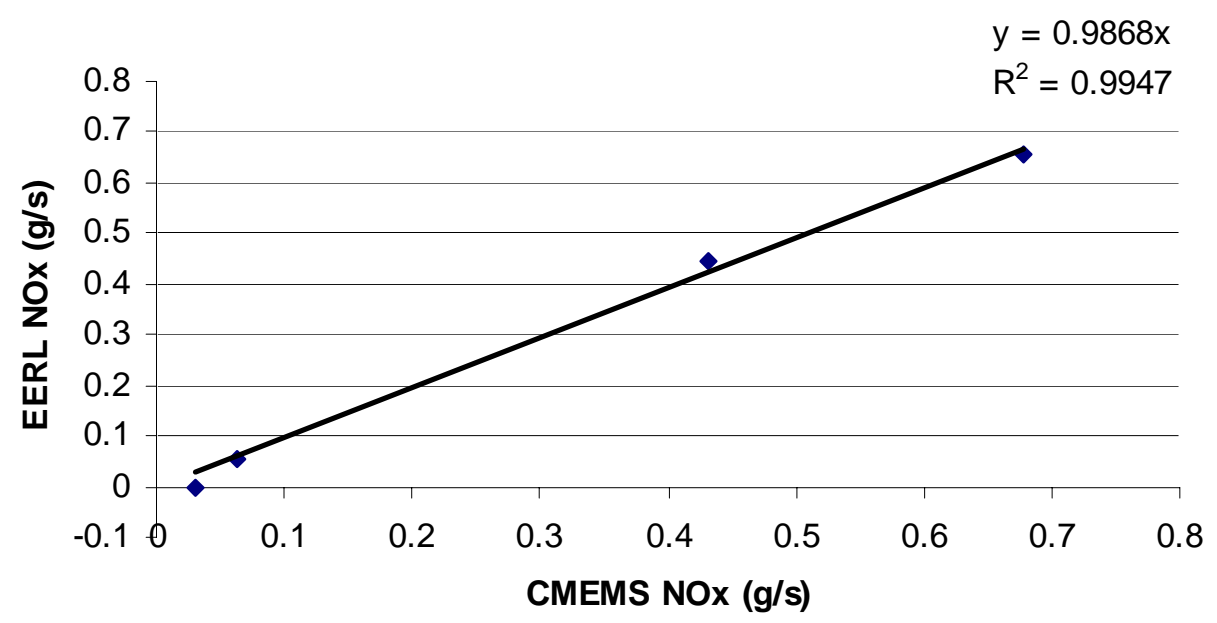

Figure 38: CMEMS vs. EERL NOx mass flow rate linearity comparison for steady state test-B

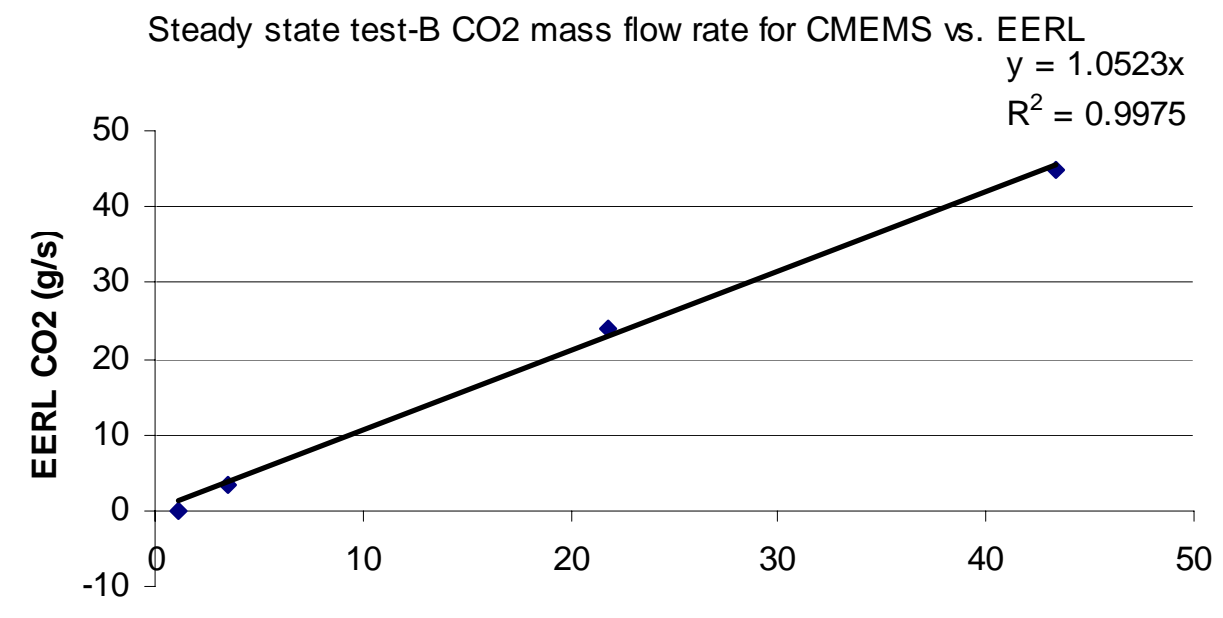

CMEMS CO2 (g/s)

Figure 39: CMEMS vs. EERL $\mathrm{CO}_{2}$ mass flow rate linearity comparison for steady state test-B 


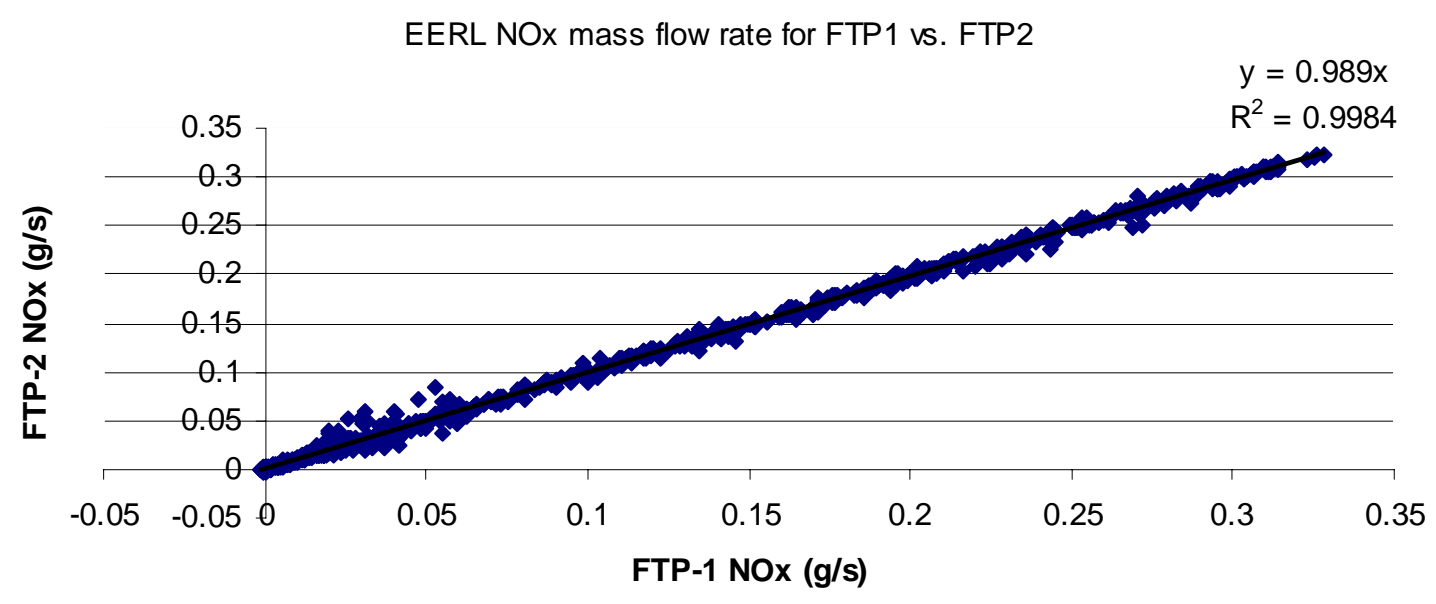

Figure 40: EERL NOx mass flow rate linearity comparison of FTP1 vs. FTP2

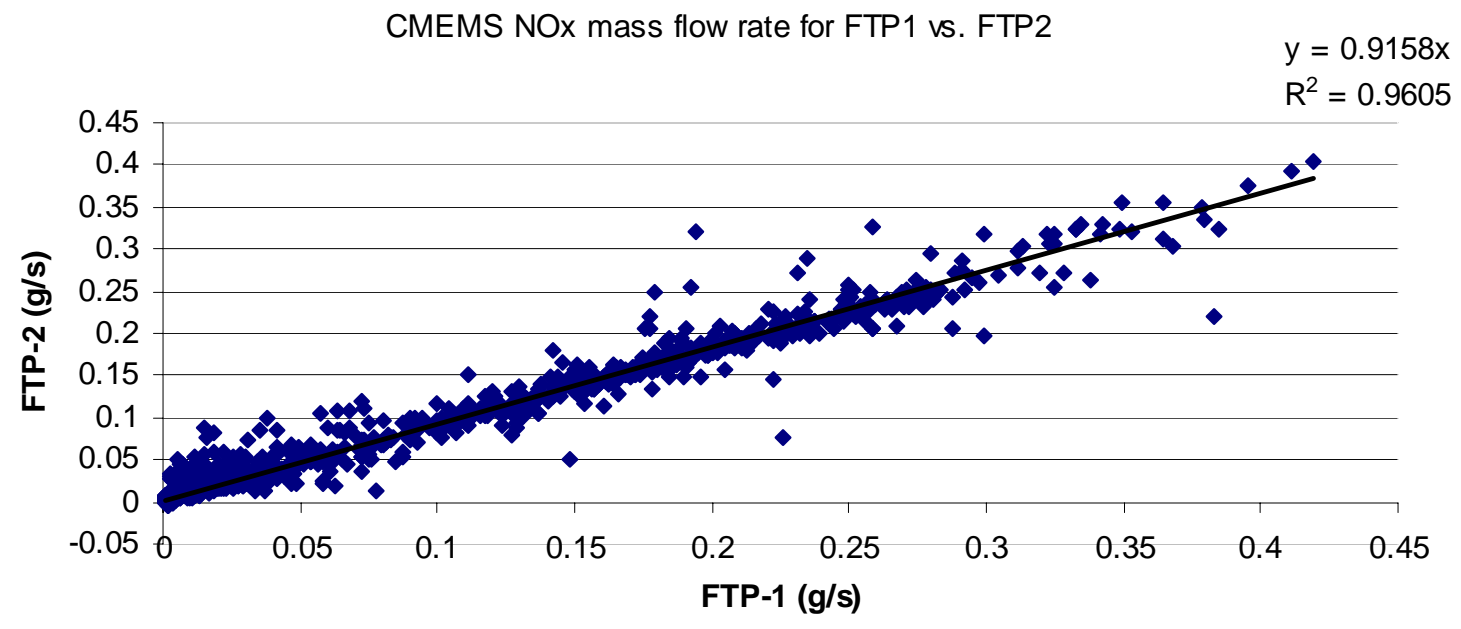

Figure 41: CMEMS NOx mass flow rate linearity comparison of FTP1 vs. FTP2 


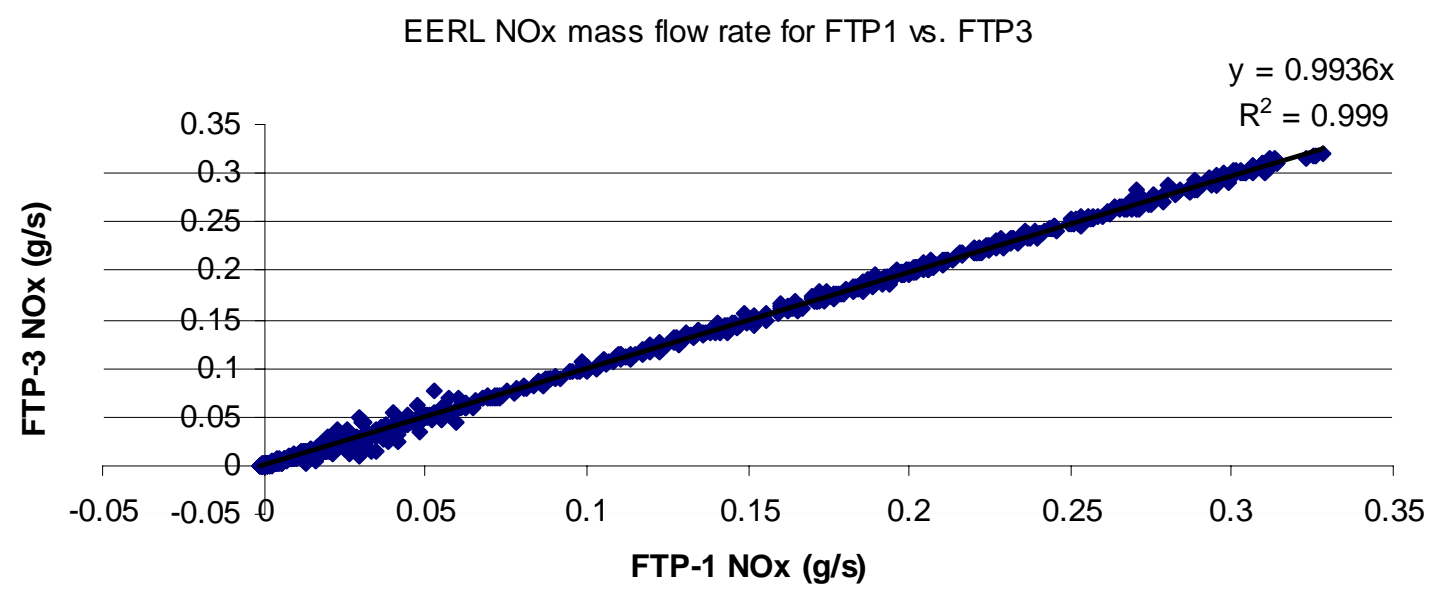

Figure 42: EERL NOx mass flow rate linearity comparison of FTP1 vs. FTP3

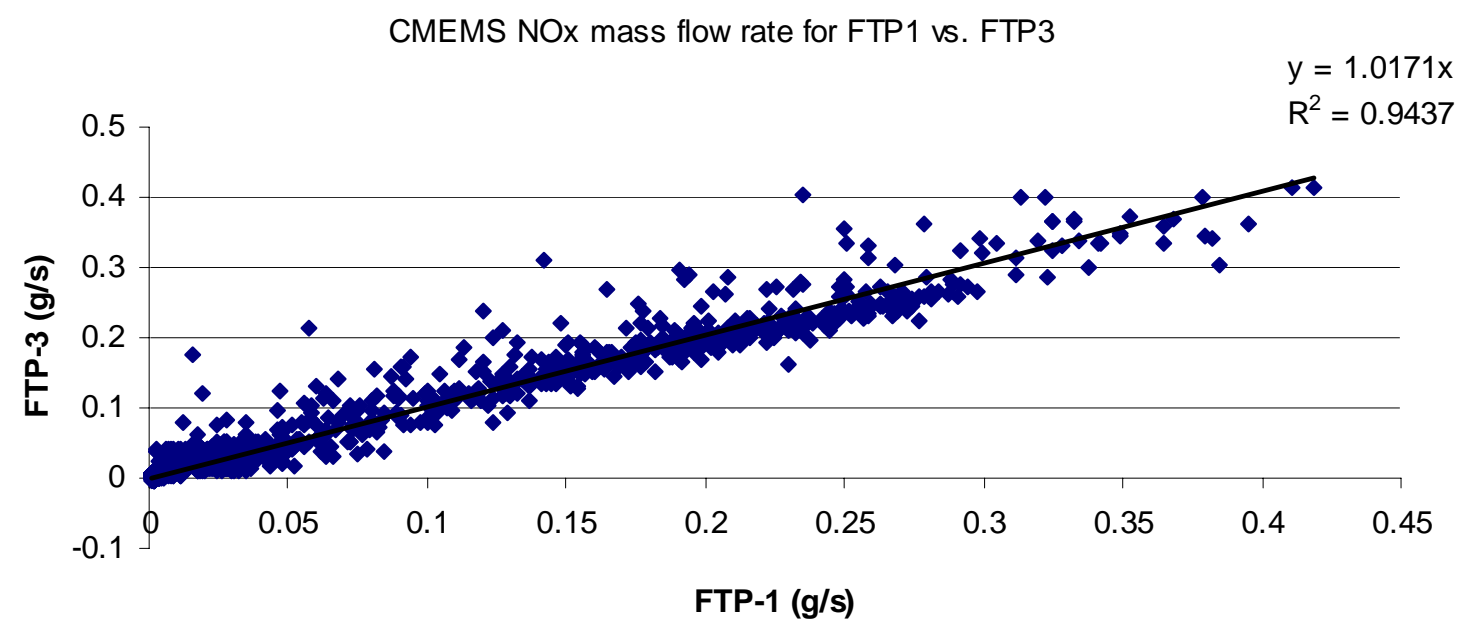

Figure 43: CMEMS NOx mass flow rate linearity comparison of FTP1 vs. FTP3 


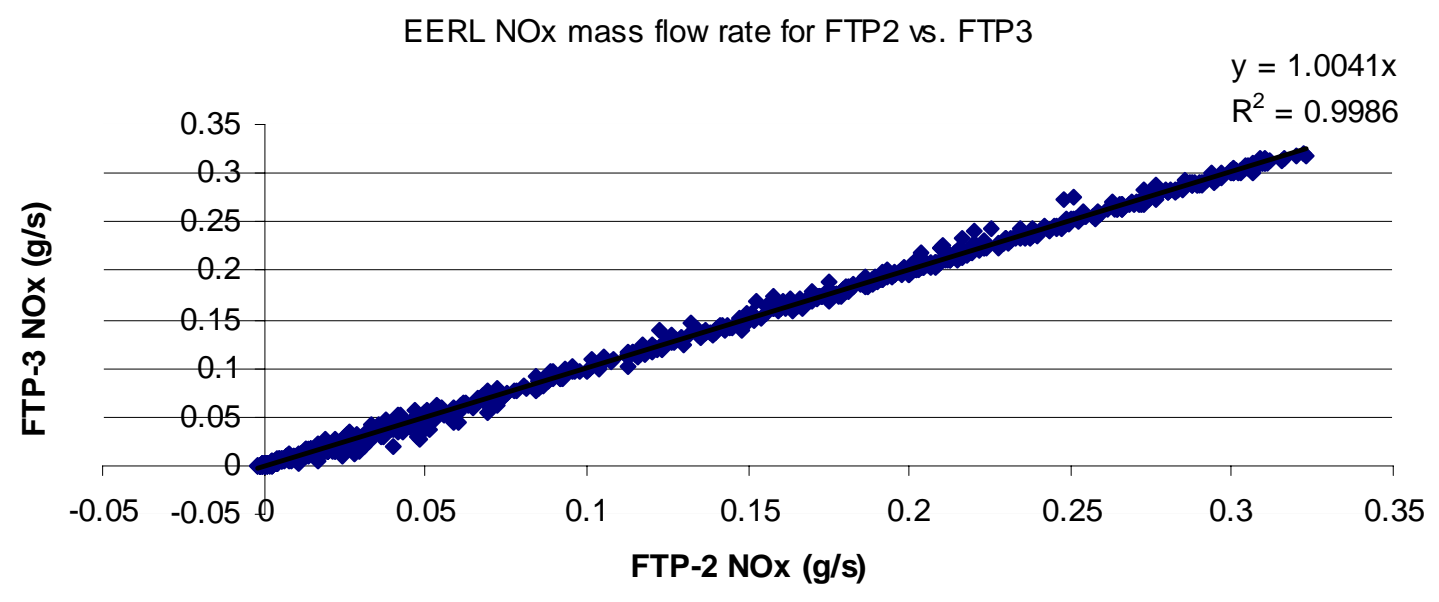

Figure 44: EERL NOx mass flow rate linearity comparison of FTP2 vs. FTP3

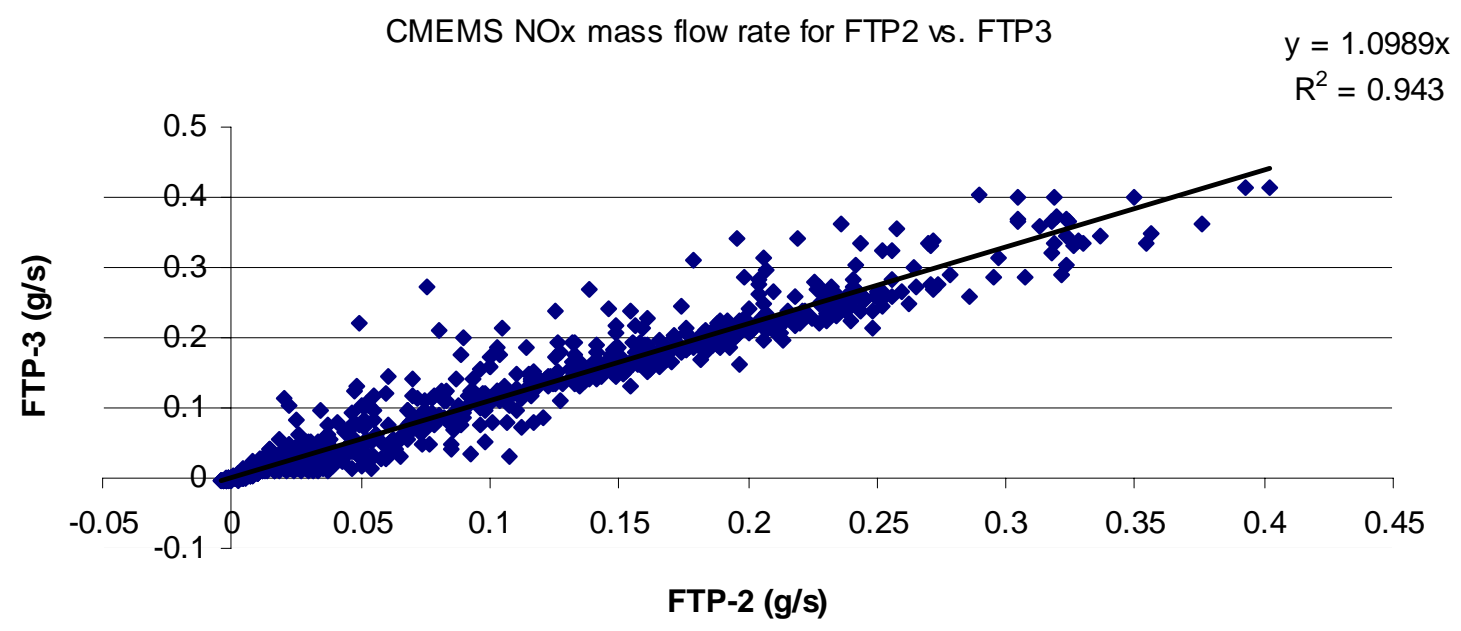

Figure 45: CMEMS NOx mass flow rate linearity comparison of FTP2 vs. FTP3 


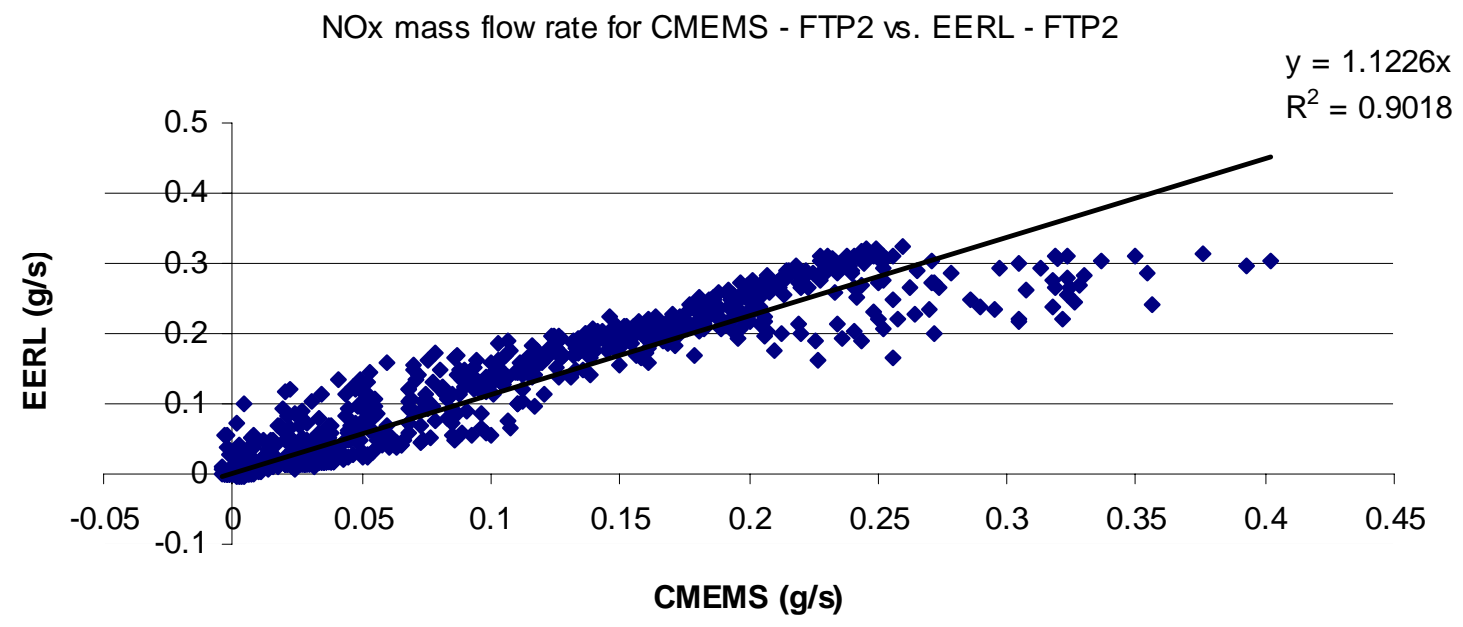

Figure 46: CMEMS vs. EERL NOx mass flow rate linearity comparison for FTP2

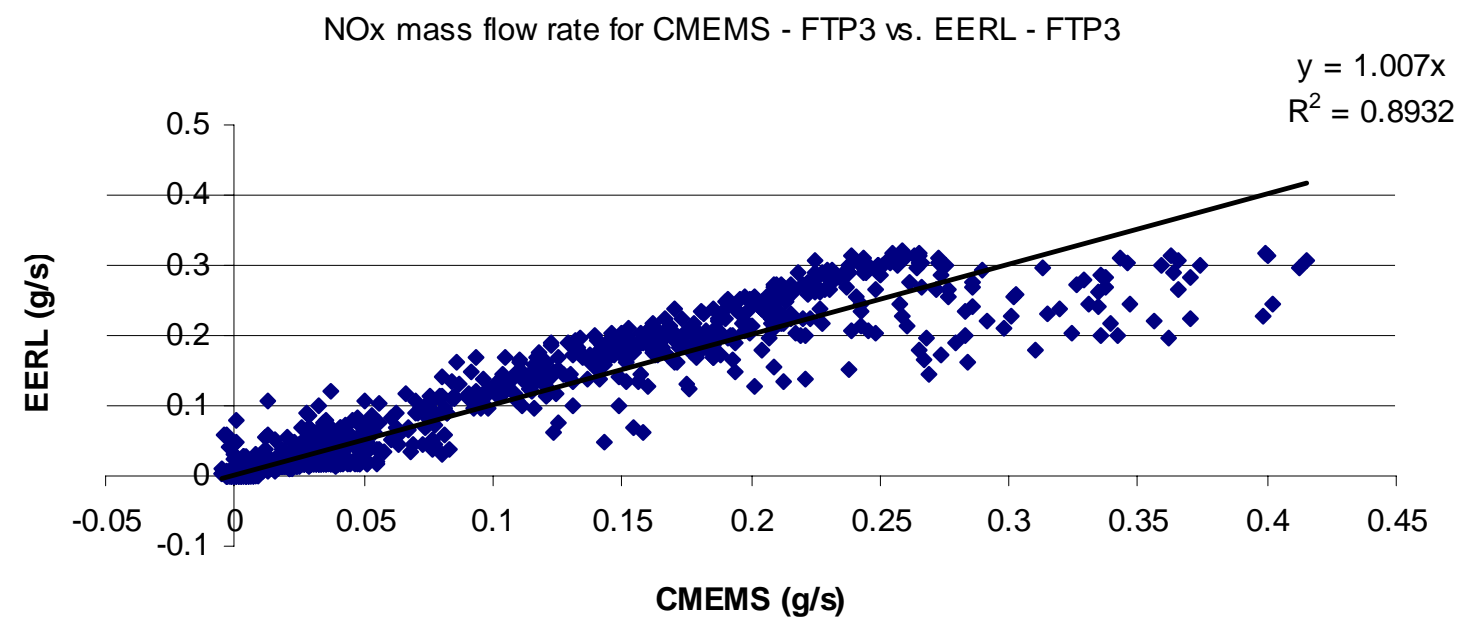

Figure 47: CMEMS vs. EERL NOx mass flow rate linearity comparison for FTP3 


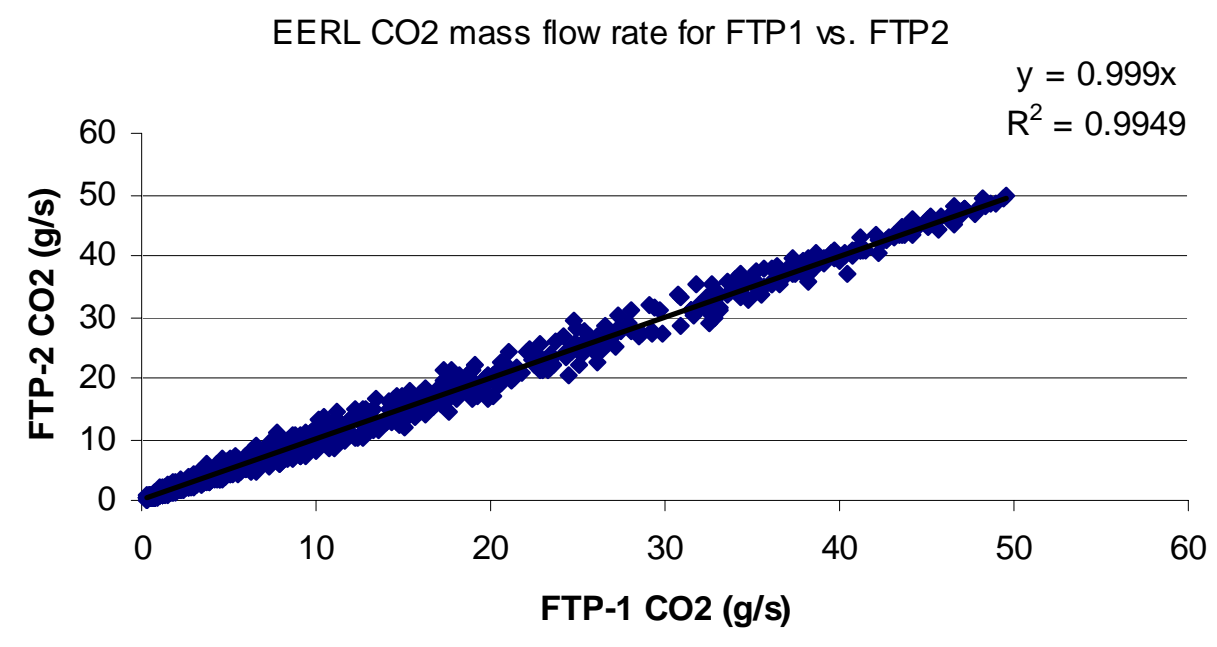

Figure 48: EERL $\mathrm{CO}_{2}$ mass flow rate linearity comparison of FTP1 vs. FTP2

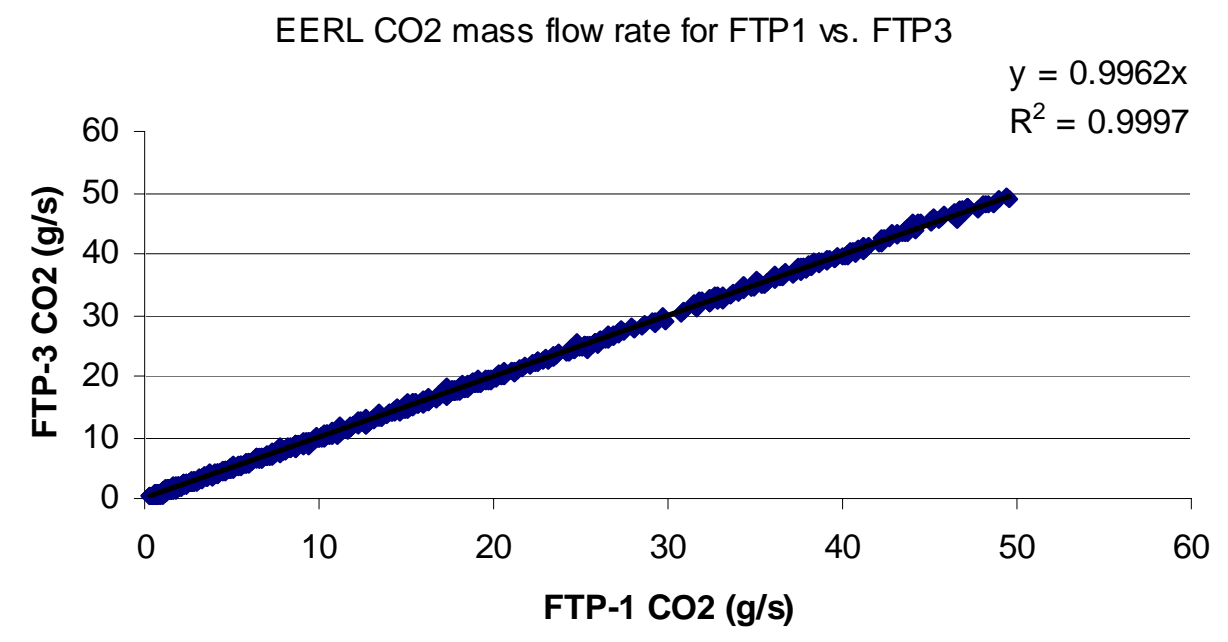

Figure 49: EERL $\mathrm{CO}_{2}$ mass flow rate linearity comparison of FTP1 vs. FTP3 


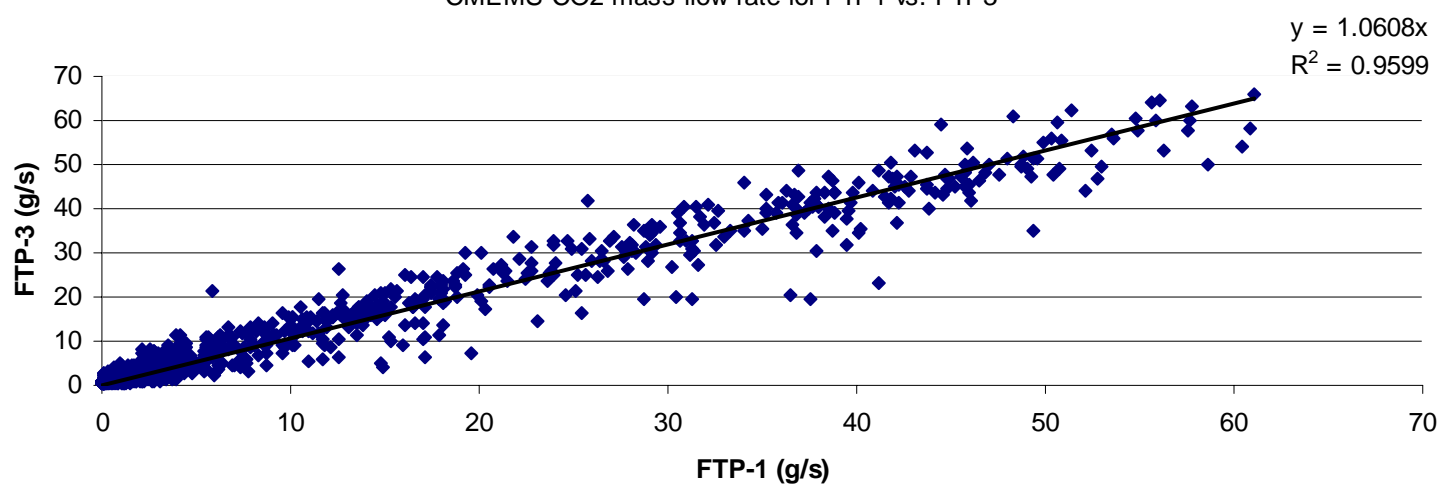

Figure 50: $\mathrm{CMEMS} \mathrm{CO}_{2}$ mass flow rate linearity comparison of FTP1 vs. FTP3

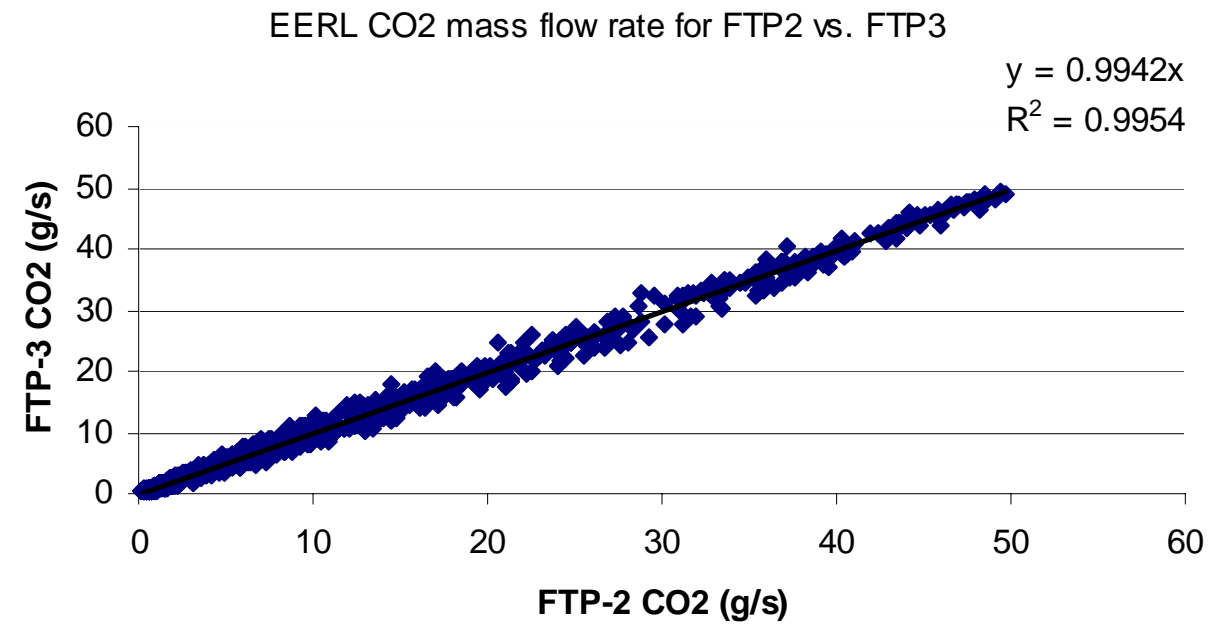

Figure 51: EERL $\mathrm{CO}_{2}$ mass flow rate linearity comparison of FTP2 vs. FTP3 


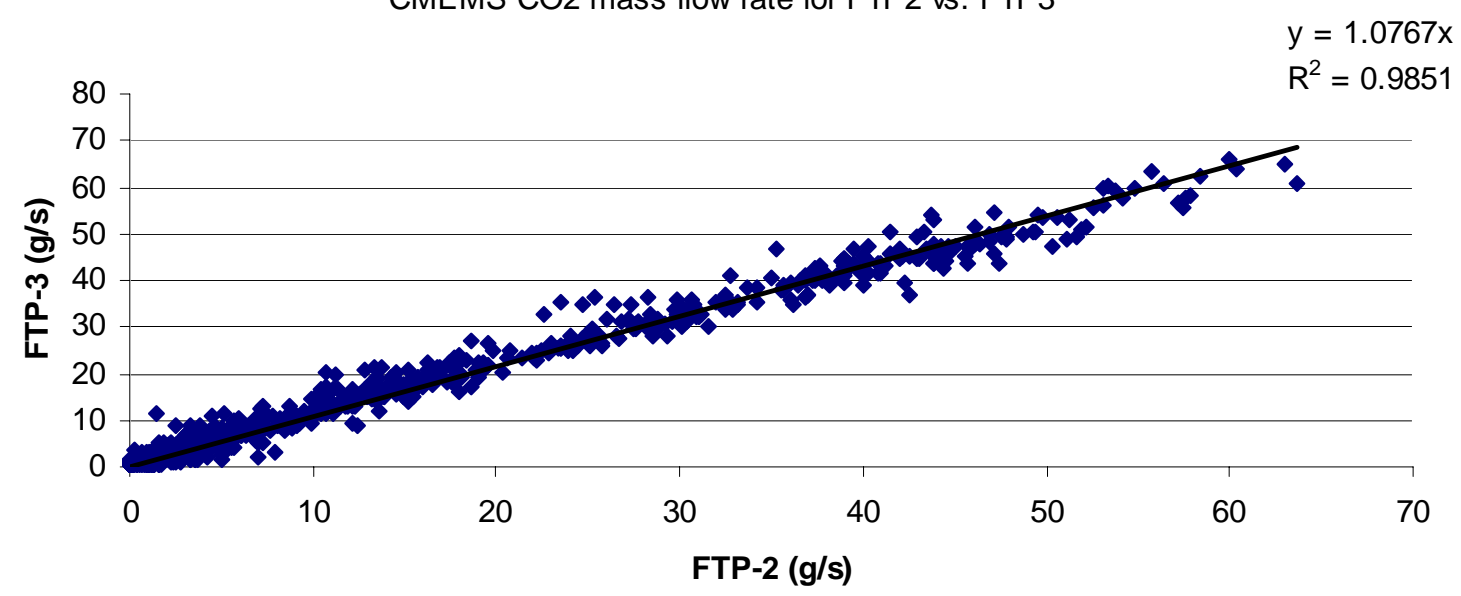

Figure 52: CMEMS $\mathrm{CO}_{2}$ mass flow rate linearity comparison of FTP2 vs. FTP3

CO2 mass flow rate for CMEMS - FTP1 vs. EERL - FTP1

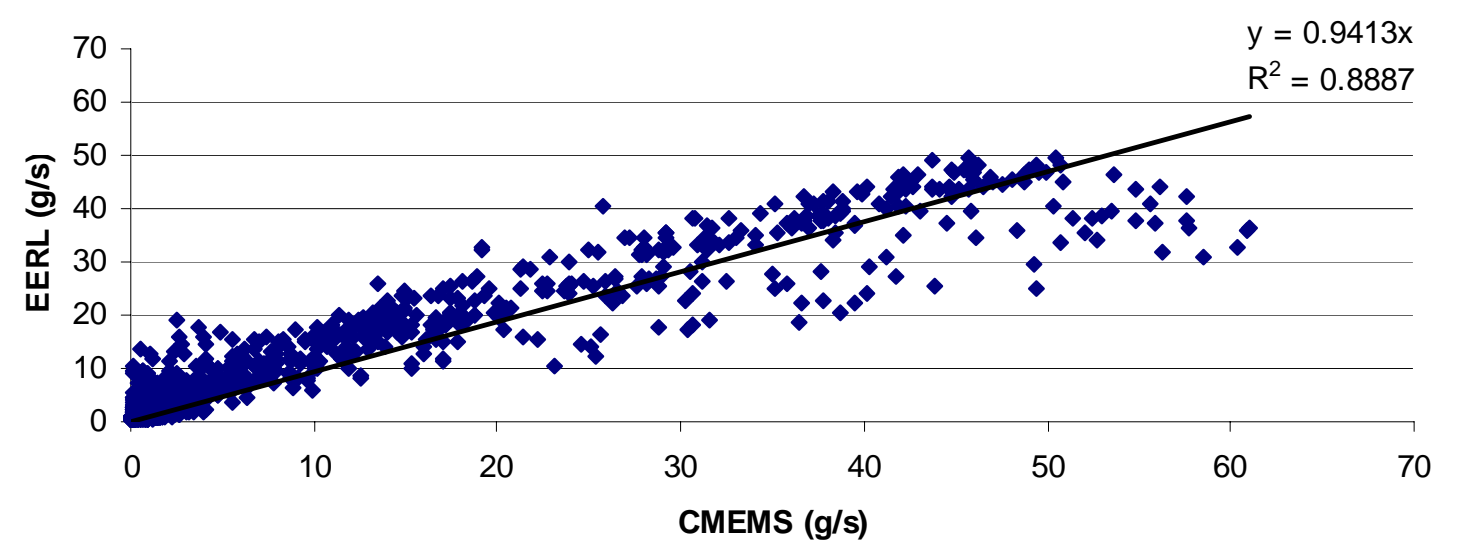

Figure 53: CMEMS vs. EERL $\mathrm{CO}_{2}$ rate linearity comparison for FTP1 


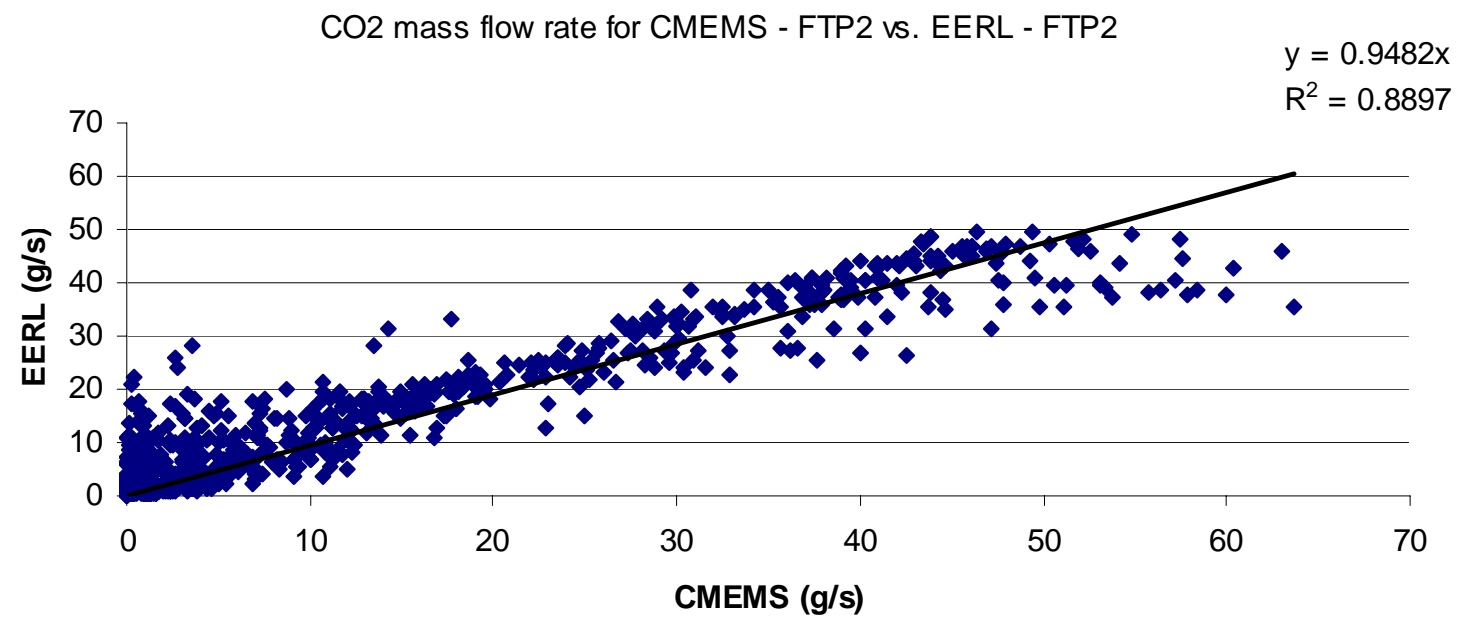

Figure 54: CMEMS vs. EERL $\mathrm{CO}_{2}$ mass flow rate linearity comparison for FTP2

CO2 mass flow rate for CMEMS - FTP3 vs. EERL - FTP3

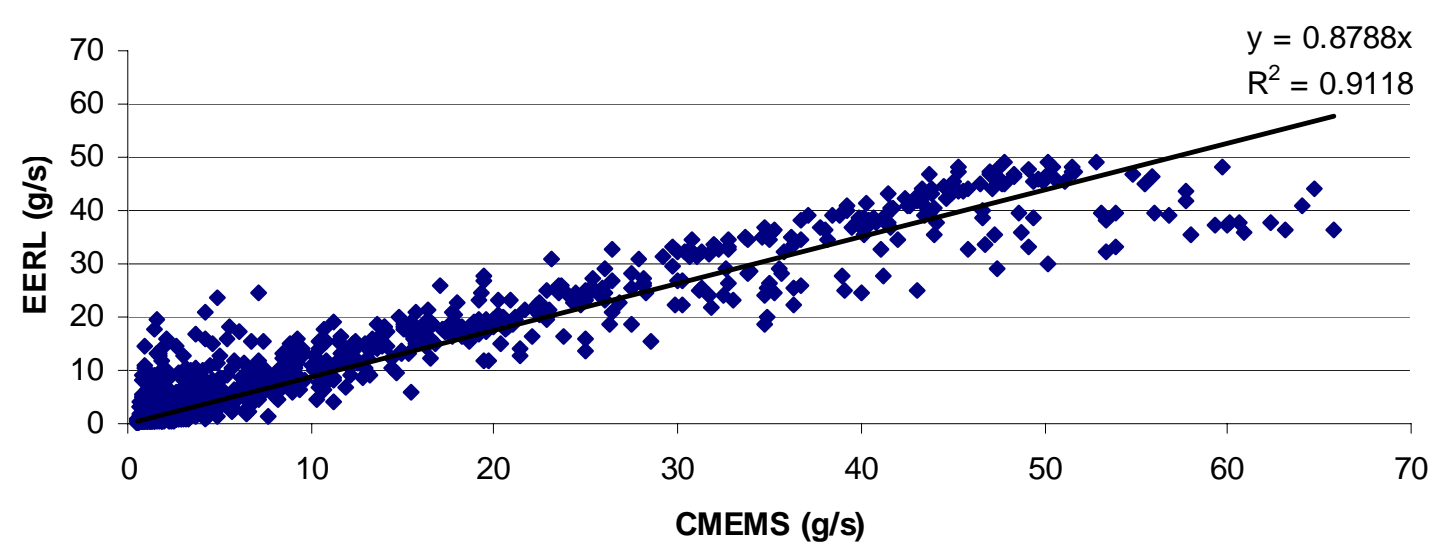

Figure 55: CMEMS vs. EERL $\mathrm{CO}_{2}$ mass flow rate linearity comparison for FTP3 
Average BSNOx values for FTP tests

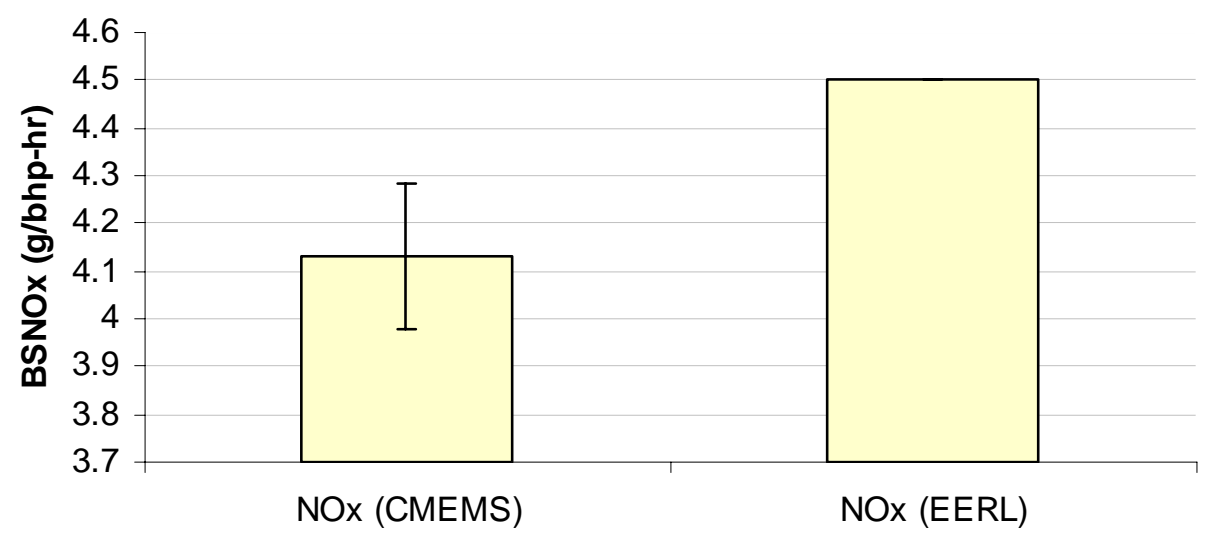

Figure 56: Average BSNOx emissions for FTP tests. (Error bars represent the standard deviation of the considered FTP runs)

Average BSCO2 values for FTP tests

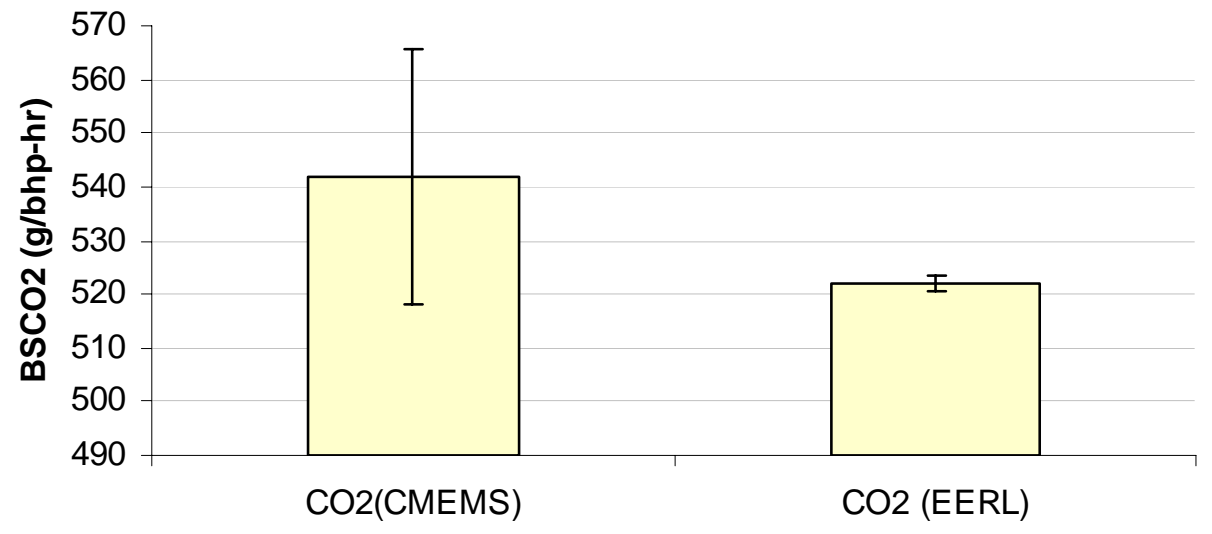

Figure 57: Average $\mathrm{BSCO}_{2}$ emissions for FTP tests. (Error bars represent the standard deviation of the considered FTP runs) 
CMEMS NOx mass flow rate simulated test-1 vs. simulated test-2

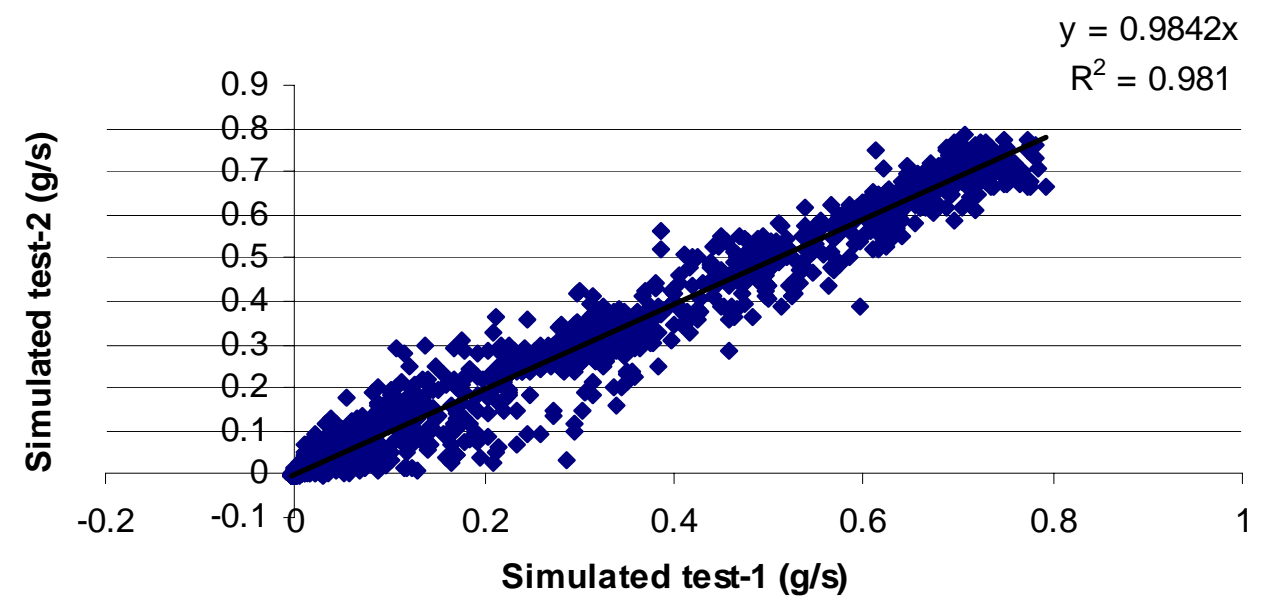

Figure 58: EERL NOx mass flow rate linearity comparison for simulated test-1 vs. simulated test- 2

EERL CO2 mass flow rate simulated test-1 vs. simulated test-2

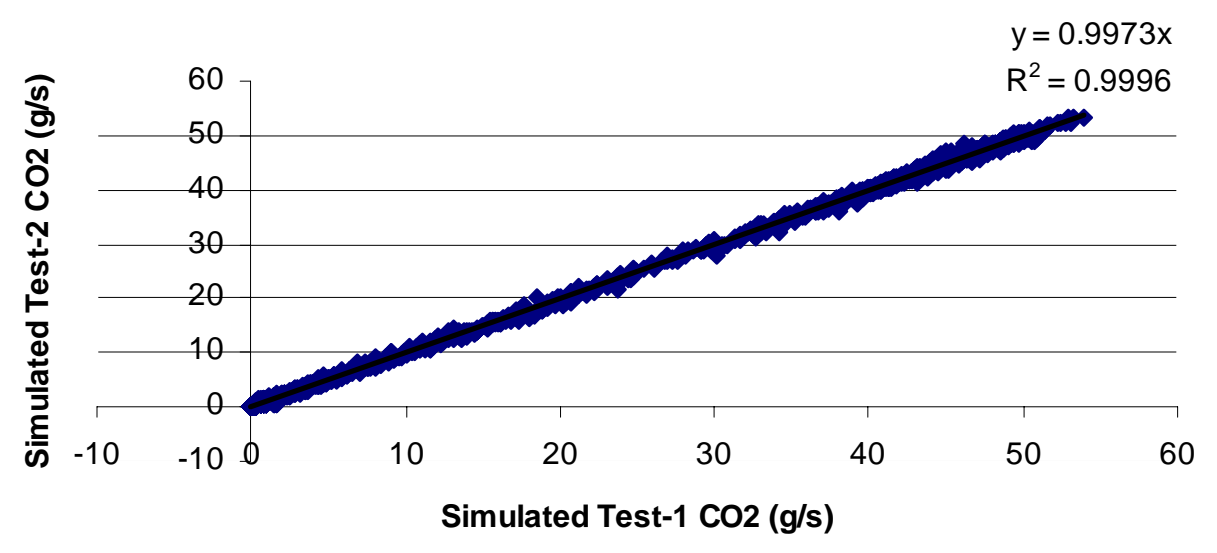

Figure 59: EERL $\mathrm{CO}_{2}$ mass flow rate linearity comparison for simulated test-1 vs. simulated test-2 
CMEMS CO2 mass flow rate simulated test- 1 vs. simulated test-2

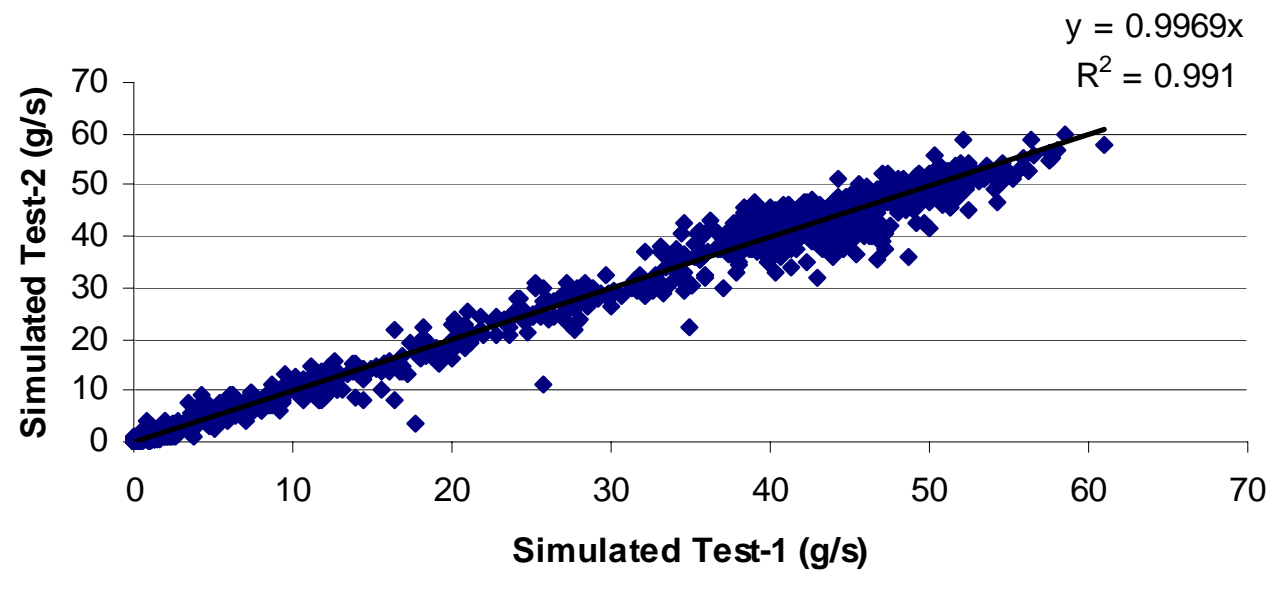

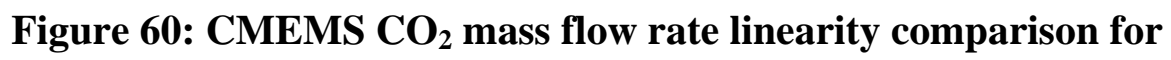
simulated test-1 vs. simulated test-2

NOx mass flow rate CMEMS simulated test-1 vs. EERL simulated test-1

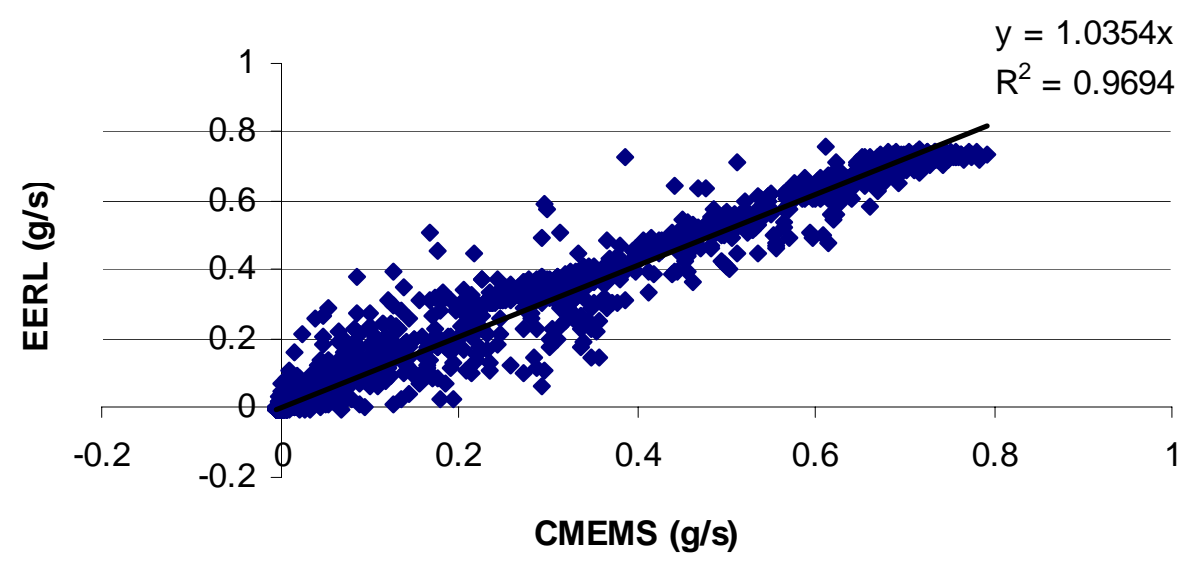

Figure 61: CMEMS vs. EERL NOx mass flow rate linearity comparison for simulated test-1 
NOx mass flow rate CMEMS simulated test-2 vs. EERL simulated test-2

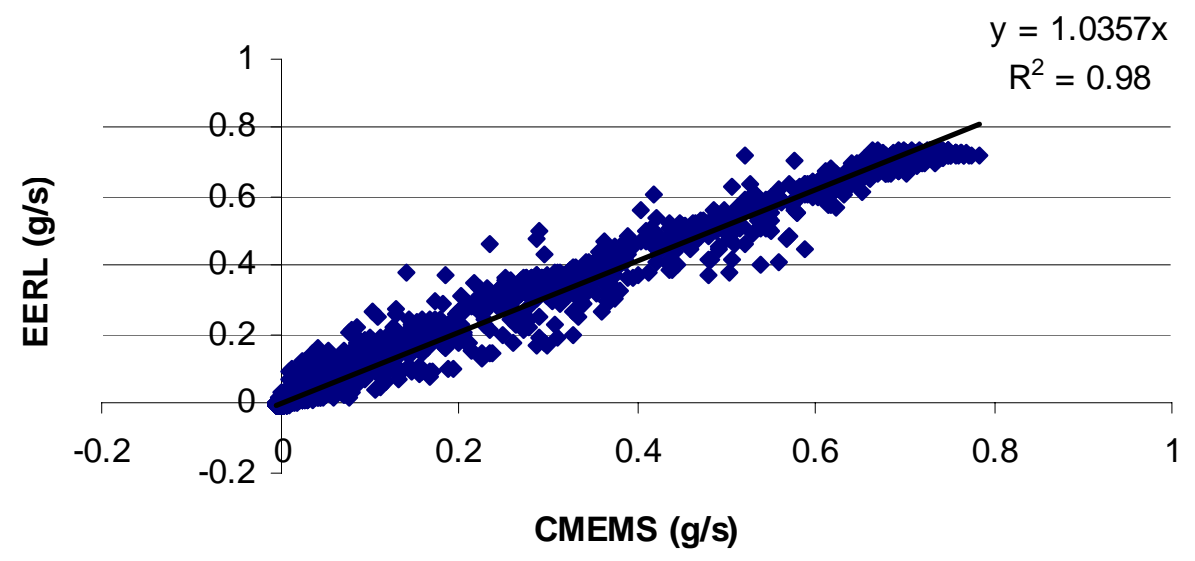

Figure 62: CMEMS vs. EERL NOx mass flow rate linearity comparison for simulated test-2

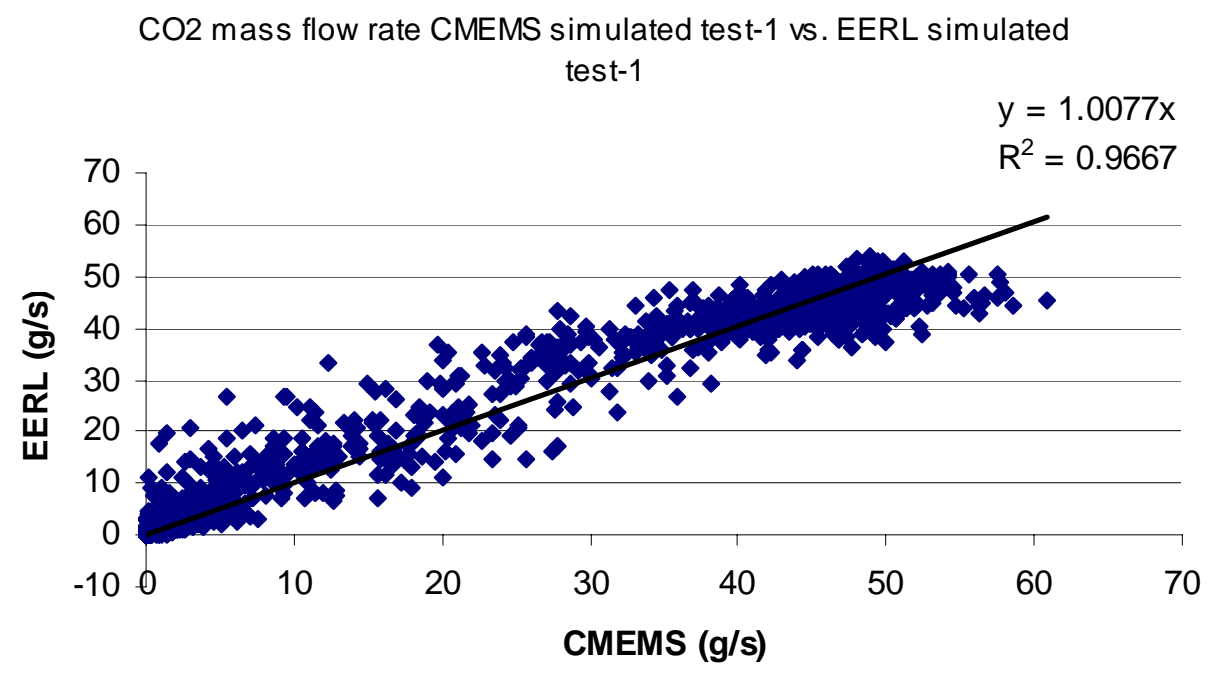

Figure 63: $\mathrm{CMEMS} \mathrm{vs.} \mathrm{EERL} \mathrm{CO}_{2}$ mass flow rate linearity comparison for simulated test-1 
Average BSNOx values for simulated tests

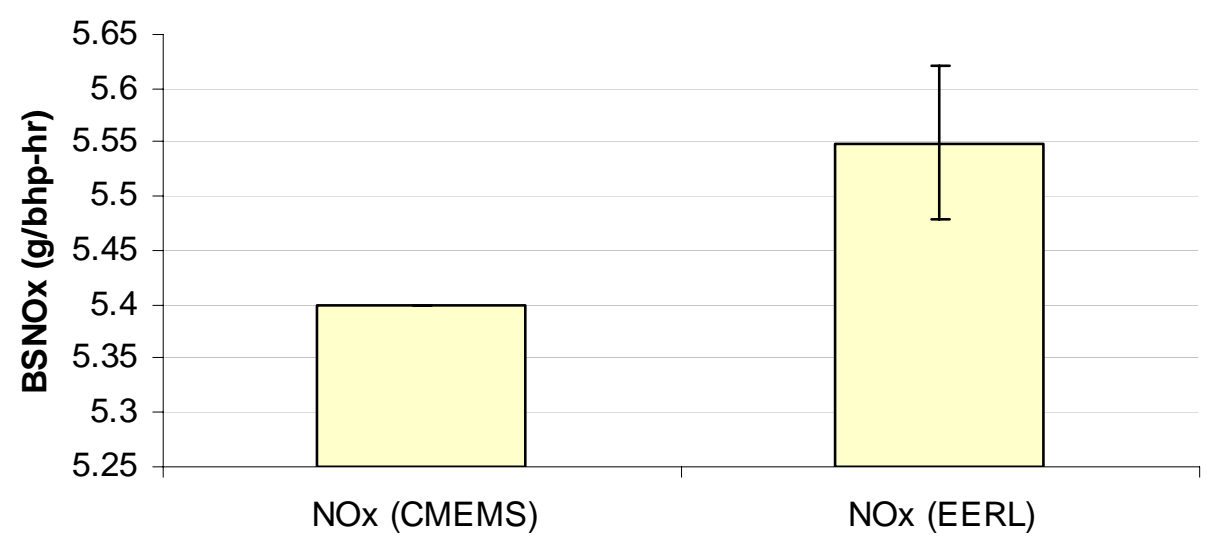

Figure 64: Average BSNOx emissions for simulated tests. (Error bars represent the standard deviation of the considered transient runs)

Average $\mathrm{BSCO} 2$ values for simulated tests

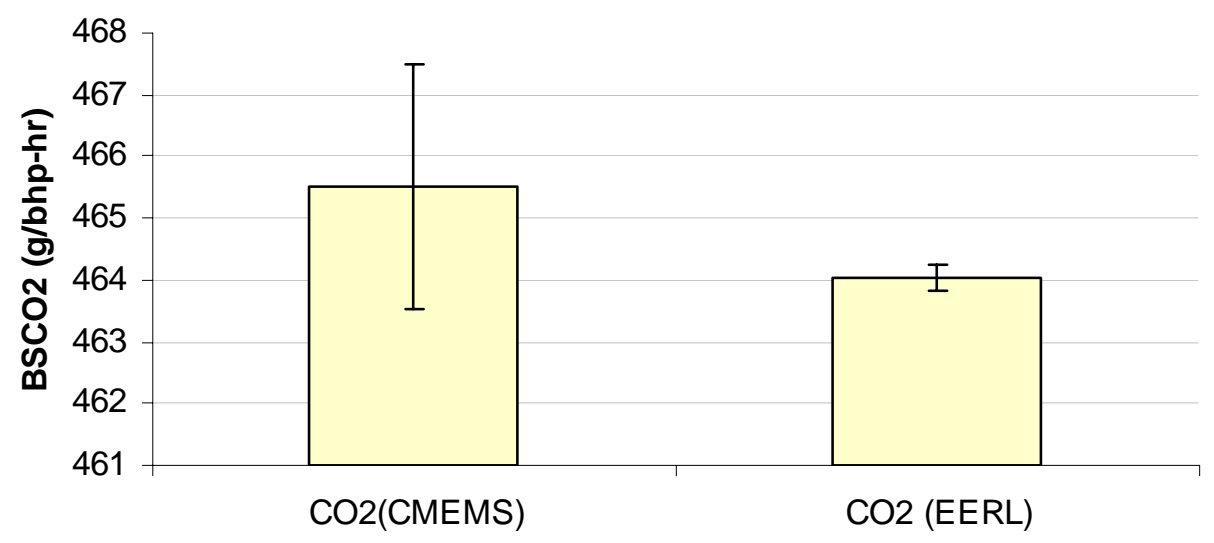

Figure 65: Average $\mathrm{BSCO}_{2}$ emissions for simulated tests. (Error bars represent the standard deviation of the considered transient runs) 


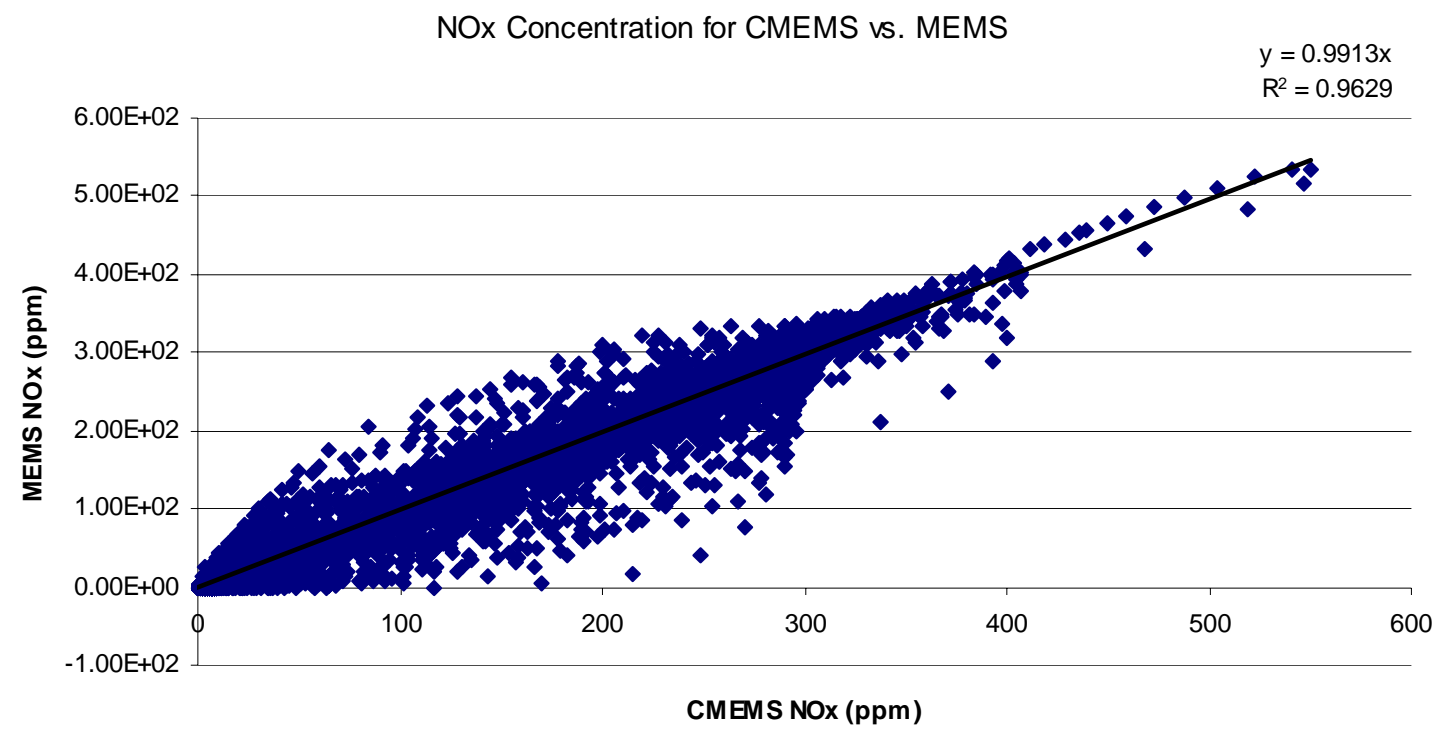

Figure 66: CMEMS vs. MEMS NOx concentration linearity comparison for on-road test $A$

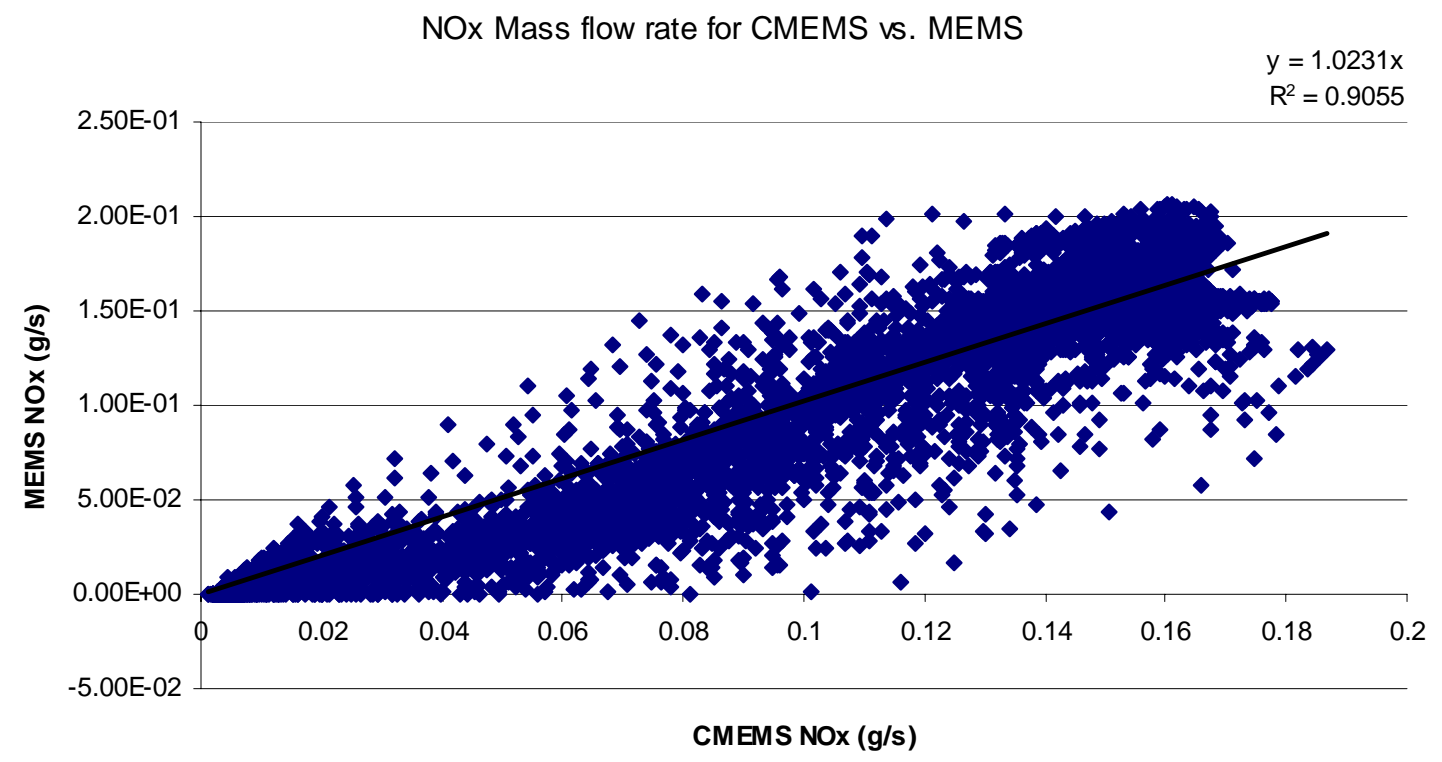

Figure 67: CMEMS vs. MEMS NOx mass flow rate linearity comparison for on-road test A 


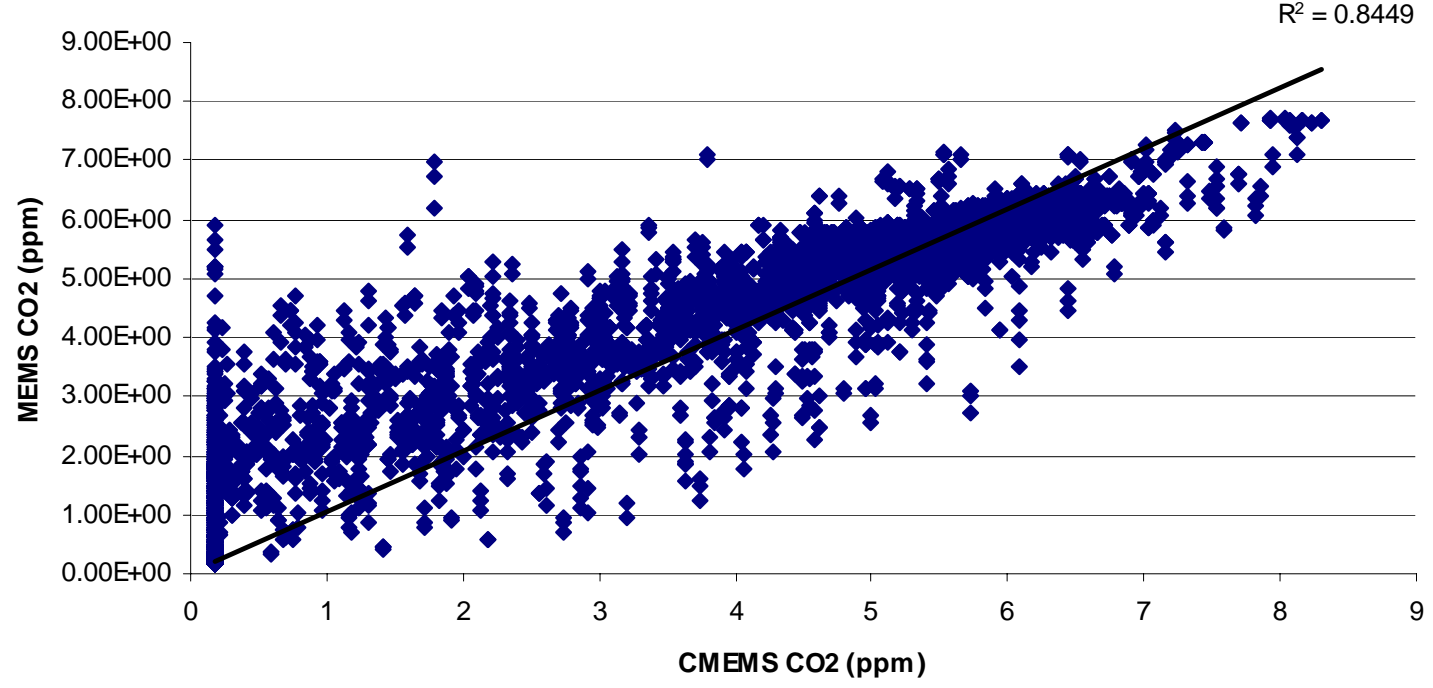

Figure 68: CMEMS vs. MEMS $\mathrm{CO}_{2}$ concentration linearity comparison for on-road test B

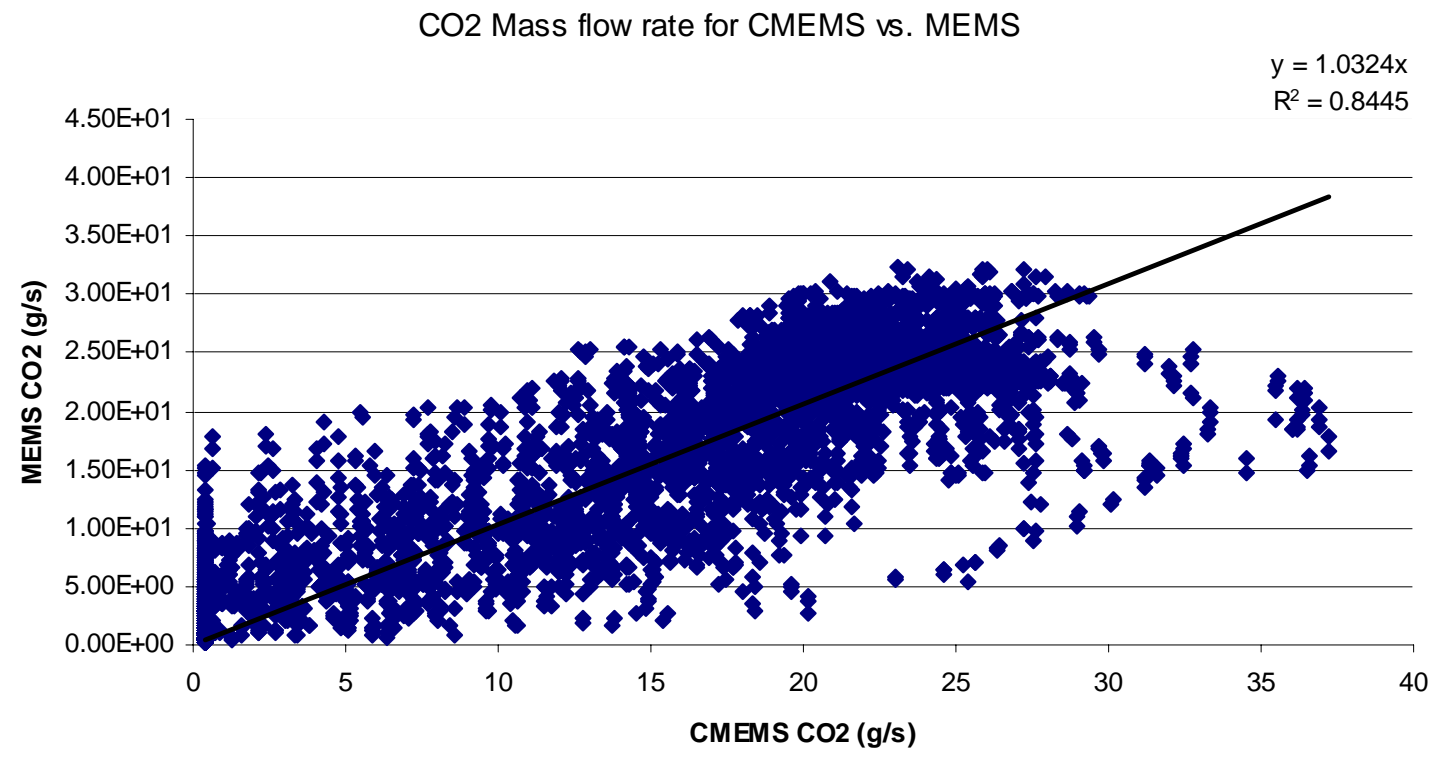

Figure 69: CMEMS vs. MEMS $\mathrm{CO}_{2}$ mass flow rate linearity comparison for on-road test $B$ 


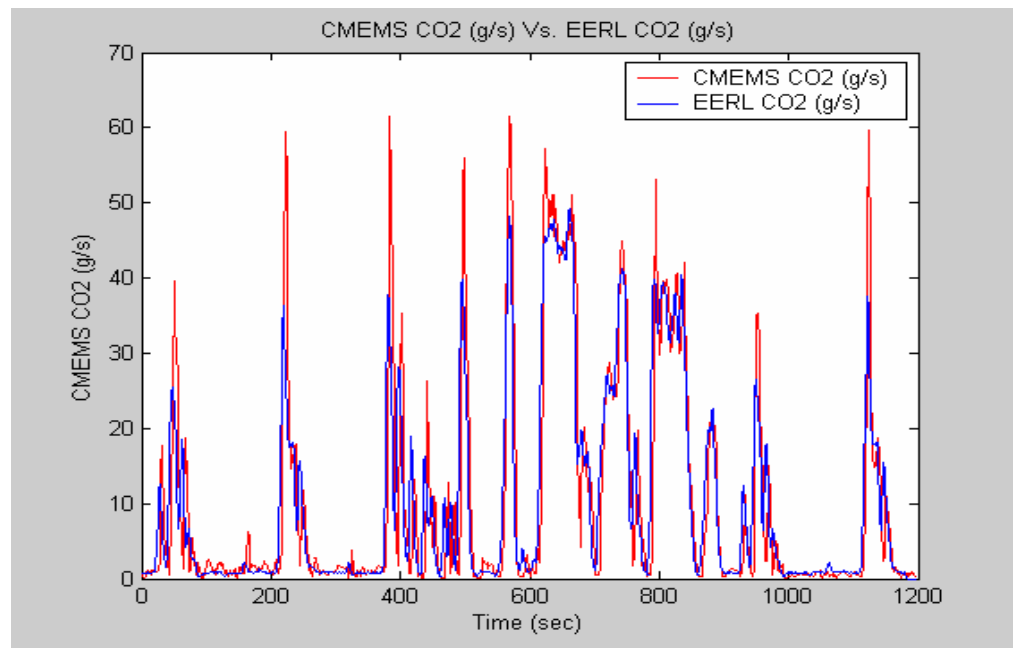

Figure 70: $\mathrm{CO}_{2}$ mass flow rate comparison of CMEMS and EERL results on FTP2

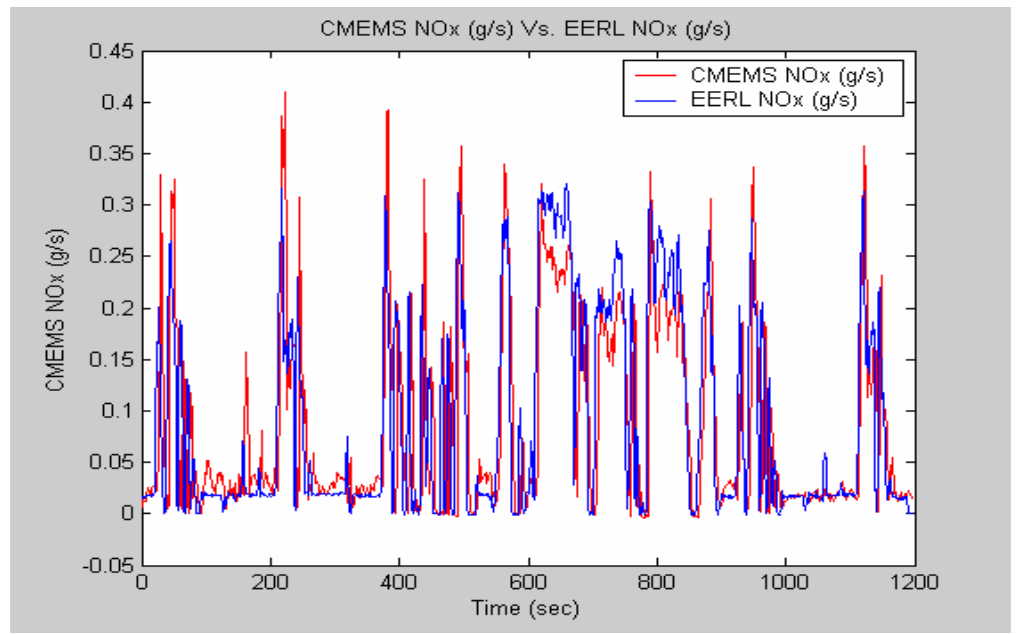

Figure 71: NOx mass flow rate comparison of CMEMS and EERL results on FTP2 


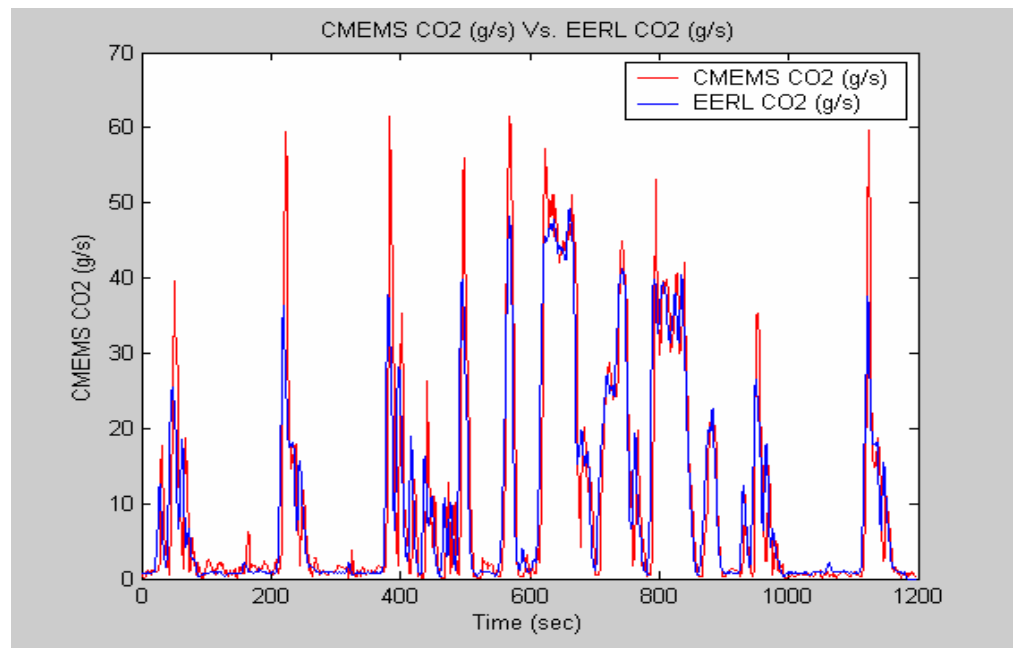

Figure 72: $\mathrm{CO}_{2}$ mass flow rate comparison of CMEMS and EERL results on FTP3

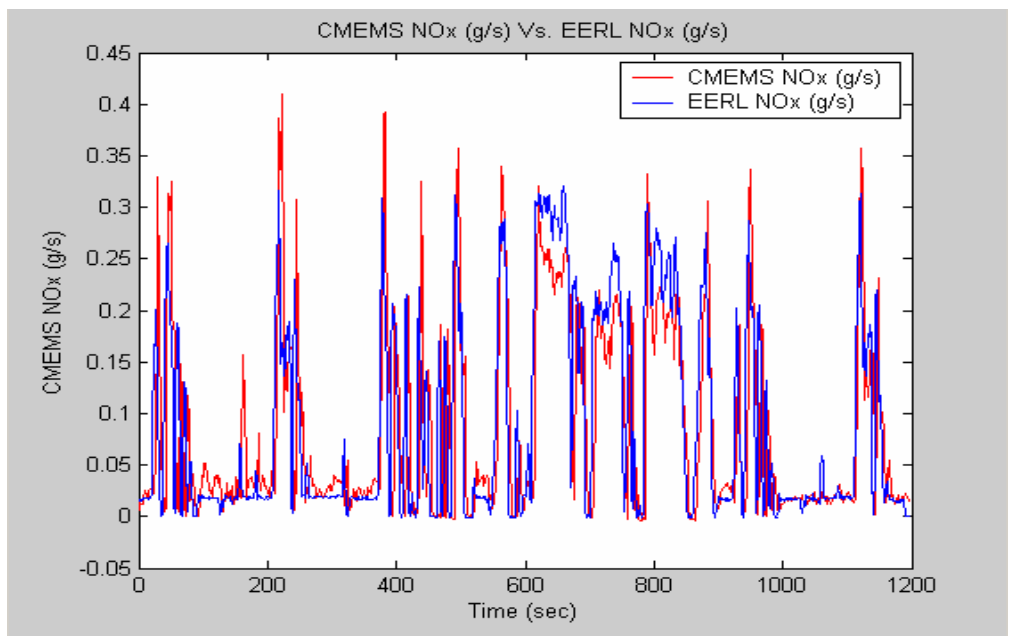

Figure 73: NOx mass flow rate comparison of CMEMS and EERL results on FTP3 


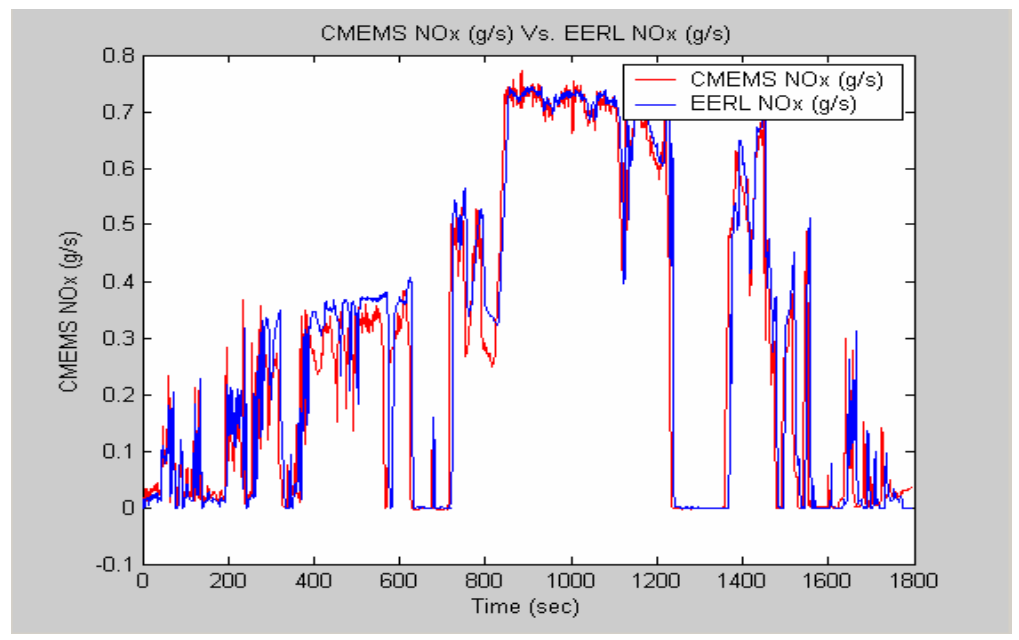

Figure 74: NOx mass flow rate comparison of CMEMS and EERL results on simulated test-1

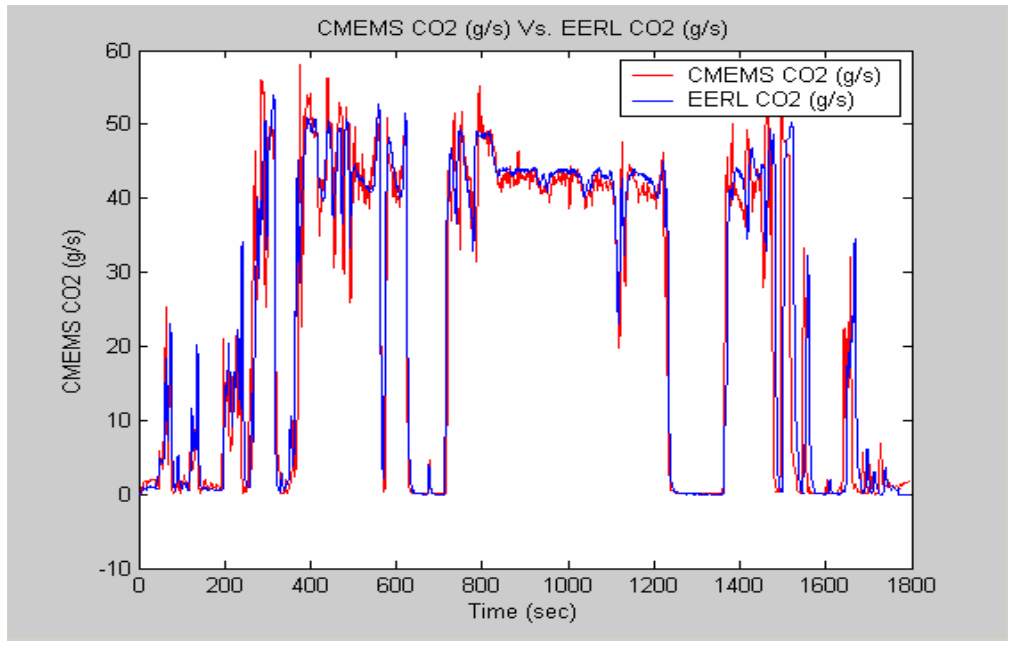

Figure 75: CO2 mass flow rate comparison of CMEMS and EERL results on simulated test-1 


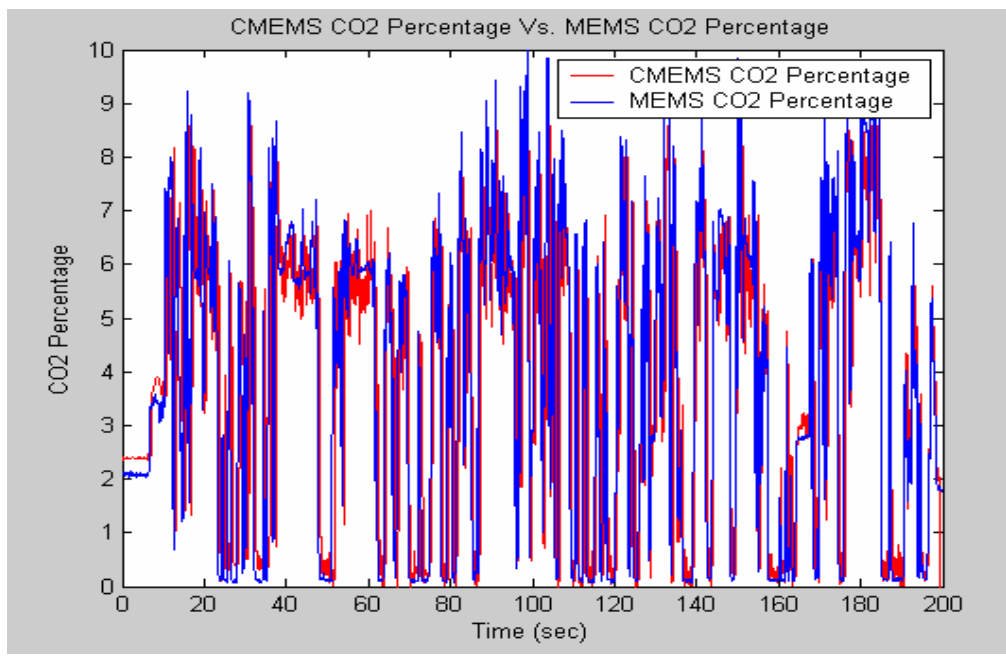

Figure 76: $\mathrm{CO}_{2}$ concentration comparison of CMEMS vs. MEMS on on-road test B

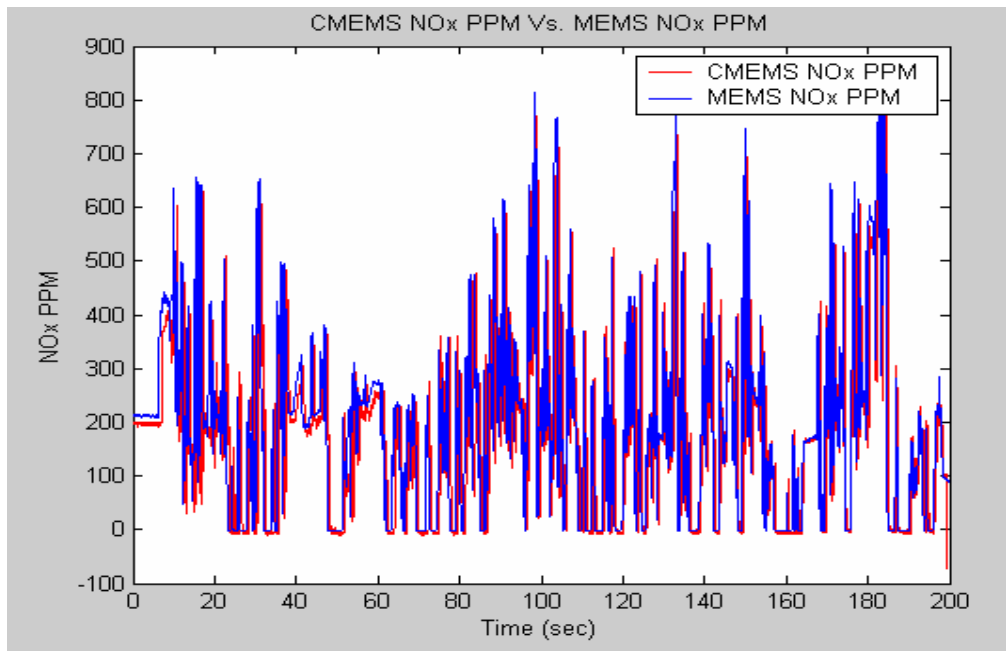

Figure 77: NOx concentration comparison of CMEMS vs. MEMS on on-road test B 


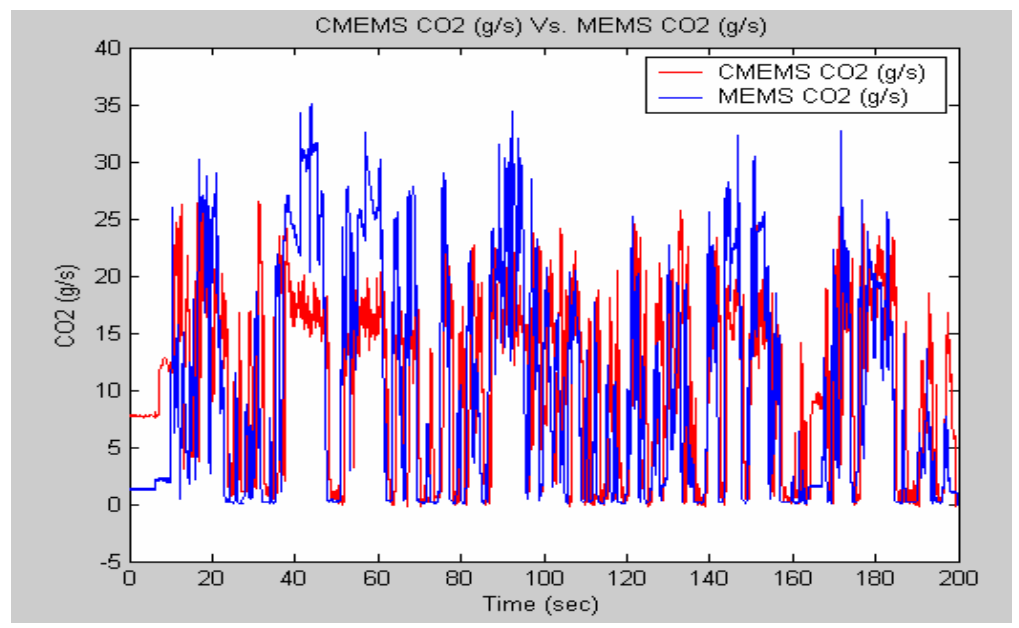

Figure 78: $\mathrm{CO}_{2}$ mass flow rate comparison of CMEMS vs. MEMS on on-road test $\mathrm{B}$

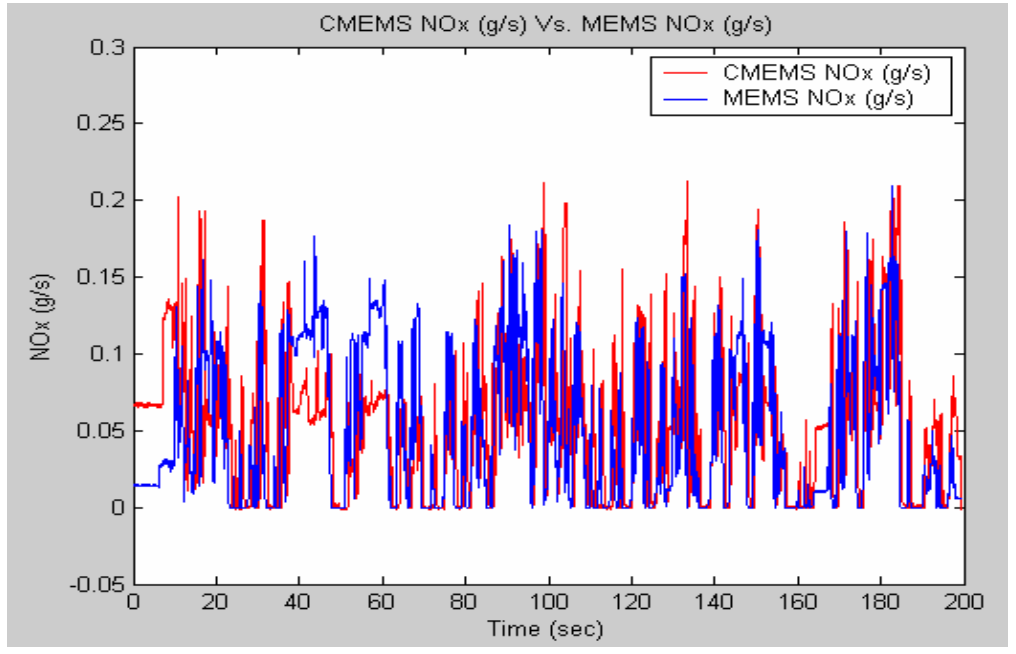

Figure 79: NOx mass flow rate comparison of CMEMS vs. MEMS on on-road test B 